\title{
Espaces de production et histoire des techniques à Délos : fouleries, teintureries, meuneries et boulangeries
}

Rapport sur les campagnes 2018 et 2019

Enora Le Quéré, Nicolas Monteix et Sandra Zanella

\section{OpenEdition}

\section{Journals}

Édition électronique

URL : http://journals.openedition.org/baefe/1313

DOI : 10.4000/baefe.1313

ISSN : 2732-687X

Éditeur

ResEFE

\section{Référence électronique}

Enora Le Quéré, Nicolas Monteix, Sandra Zanella, «Espaces de production et histoire des techniques à Délos : fouleries, teintureries, meuneries et boulangeries » [notice archéologique], Bulletin archéologique des Écoles françaises à l'étranger [En ligne], Grèce, mis en ligne le 26 novembre 2020, consulté le 22 mars 2021. URL : http://journals.openedition.org/baefe/1313 ; DOI : https://doi.org/10.4000/baefe 1313

Ce document a été généré automatiquement le 22 mars 2021.

\section{$\otimes \oplus \Theta \Theta$}

Le Bulletin archéologique des Écoles françaises à l'étranger est mise à disposition selon les termes de la Licence Creative Commons Attribution - Pas d'Utilisation Commerciale - Pas de Modification 4.0 International. 


\section{Espaces de production et histoire des techniques à Délos : fouleries, teintureries, meuneries et boulangeries}

Rapport sur les campagnes 2018 et 2019

Enora Le Quéré, Nicolas Monteix et Sandra Zanella

\section{NOTE DE L'AUTEUR}

Autorité nationale présente : Éphorie des Cyclades

Composition de l'équipe : Caroline Autret (céramologue ; GRHis EA 3831), Sandra

Zanella (archéologue ; BIBRACTE EPCC) ; Grégoire Meazza, Tristan Michel, Ludovic Saint-George (étudiants à l'Université de Rouen), Andromeda-Ludmila Liberiou (étudiante à l'Université de Prague et à l'Université l'Orientale de Naples).

Partenariats institutionnels : École française de Rome, École française d'Athènes, Soprintendenza di Pompei, Éphorie des Cyclades, Institut universitaire de France, GrHis (Université de Rouen).

Établissements porteurs de l'opération : EFA

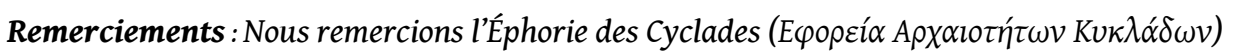
pour nous avoir permis de travailler dans les meilleures conditions, et tout particulièrement $M$. Dimitris Athanasoulis, Éphore des Cyclades, Mme Zozi Papadopoulou, Directrice du Département des Antiquités classiques, et Mme Maria Koustoumpou, archéologue à Délos. Nous remercions également vivement M. Panaghiotis Chatzidakis, ancien Épimélète de Délos et ancien Éphore des Cyclades, pour nous avoir donné l'autorisation de travailler sur des secteurs qu'il a fouillés en 2002-2003, restés depuis largement inédits. 
Données scientifiques produites :

Délos par l'EFA

DELPO par le RESEFE

1 Ces deux campagnes d'étude s'inscrivent dans un projet plus large ( DELPO : Espaces urbains de production et histoire des techniques à Délos et à Pompéi ») faisant partie des programmes de recherche quinquennaux de l'École française d'Athènes et de l'École française de Rome. Elles ont pu se dérouler également grâce au soutien de l'Institut Universitaire de France, du Centre Jean-Bérard (CNRS-EFR, USR3133), du Groupe de Recherche d'Histoire (GRHis - EA 3831) et de l'Université de RouenNormandie. Les campagnes se sont déroulées du 3 au 22 juin 2018 et du 9 au 23 juin 2019. Les photogrammétries ont été réalisées en utilisant une licence Photoscan fournie par la TGIR Huma-Num.

2 Ces deux campagnes de nettoyages de surface et de relevés visaient à analyser plus précisément deux types d'activités présentes sur l'île, à travers l'étude des espaces urbains liés à la production textile d'une part, et de ceux liés à la production alimentaire d'autre part.

\section{Les espaces urbains liés à la production textile}

\section{Les fouleries du Quartier du Théâtre}

\section{La foulerie de la Rue 1 du Théâtre}

3 Dans la «boutique » 1 (pièce $c$ de la Maison II B, dégagée en 1894 par L. Couve) de la Rue 1 du Théâtre (fig. 1), le nettoyage fut relativement aisé car le sol de la pièce a été entièrement cimenté lors de travaux de restauration. Seuls trois bassins maçonnés ont été conservés sans trop de modifications postérieures au dégagement. Situés dans l'angle sud-est de la pièce et de forme quadrangulaire, ils sont alignés et appuyés le long du mur oriental. Au nord et à l'ouest, ils sont délimités par des petits murets en moellons de gneiss, aujourd'hui en grande partie restaurés (fig. 2). La stratigraphie ayant été fortement perturbée par les fouilles et restaurations précédentes, il n'est pas possible de déterminer la relation de ces bassins avec un quelconque niveau de sol antique: ils se trouvent désormais à une cote inférieure à celle du sol restauré (fig. 3-4). 
Fig. 1. Emplacement de la " boutique » 4 de la Rue du Théâtre, des «boutiques » 1 et 2 de la Rue 1 du Théâtre et de la « boutique " 1 de la Rue supérieur du Théâtre.

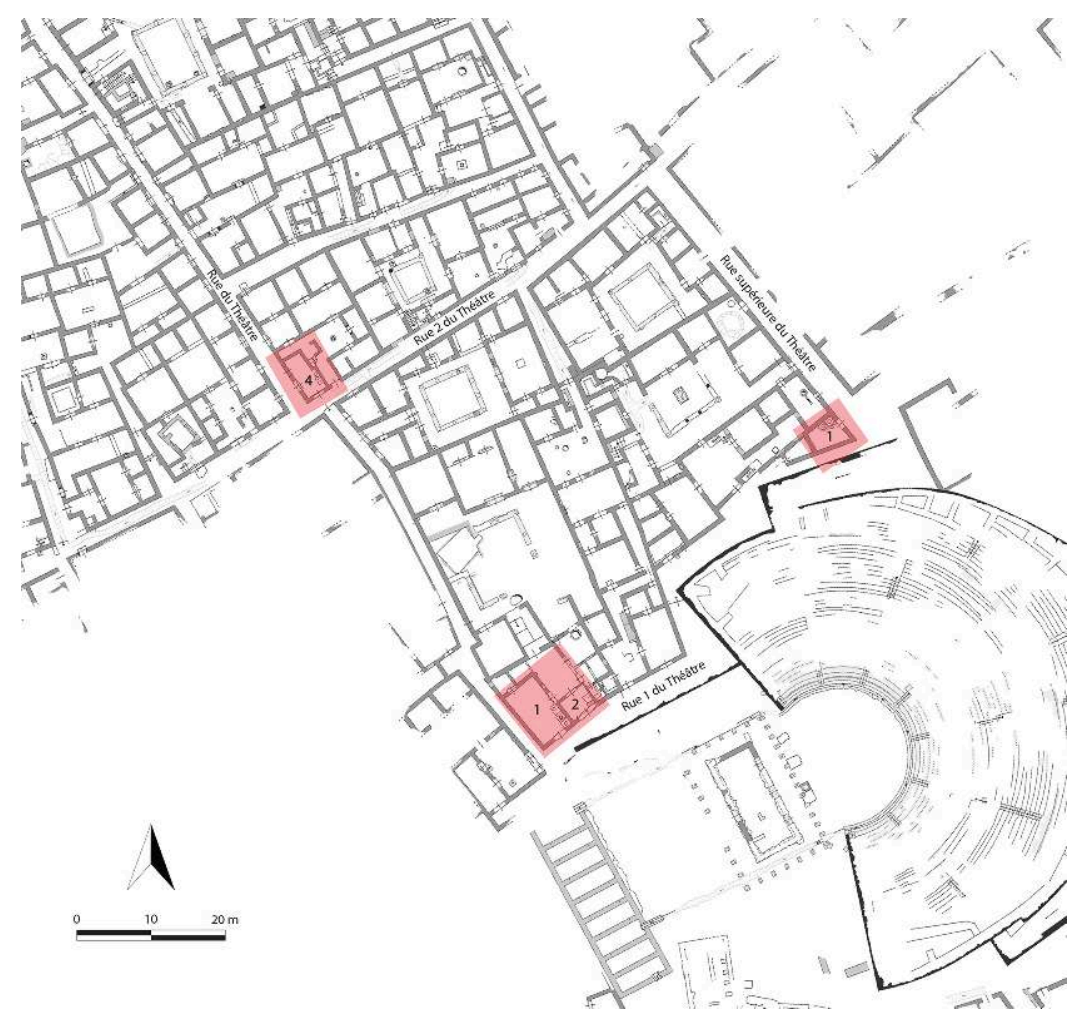

D'après https://sig-delos.efa.gr/

Fig. 2. Plan des trois bassins maçonnés à l'angle sud-est de la « boutique » 1 .

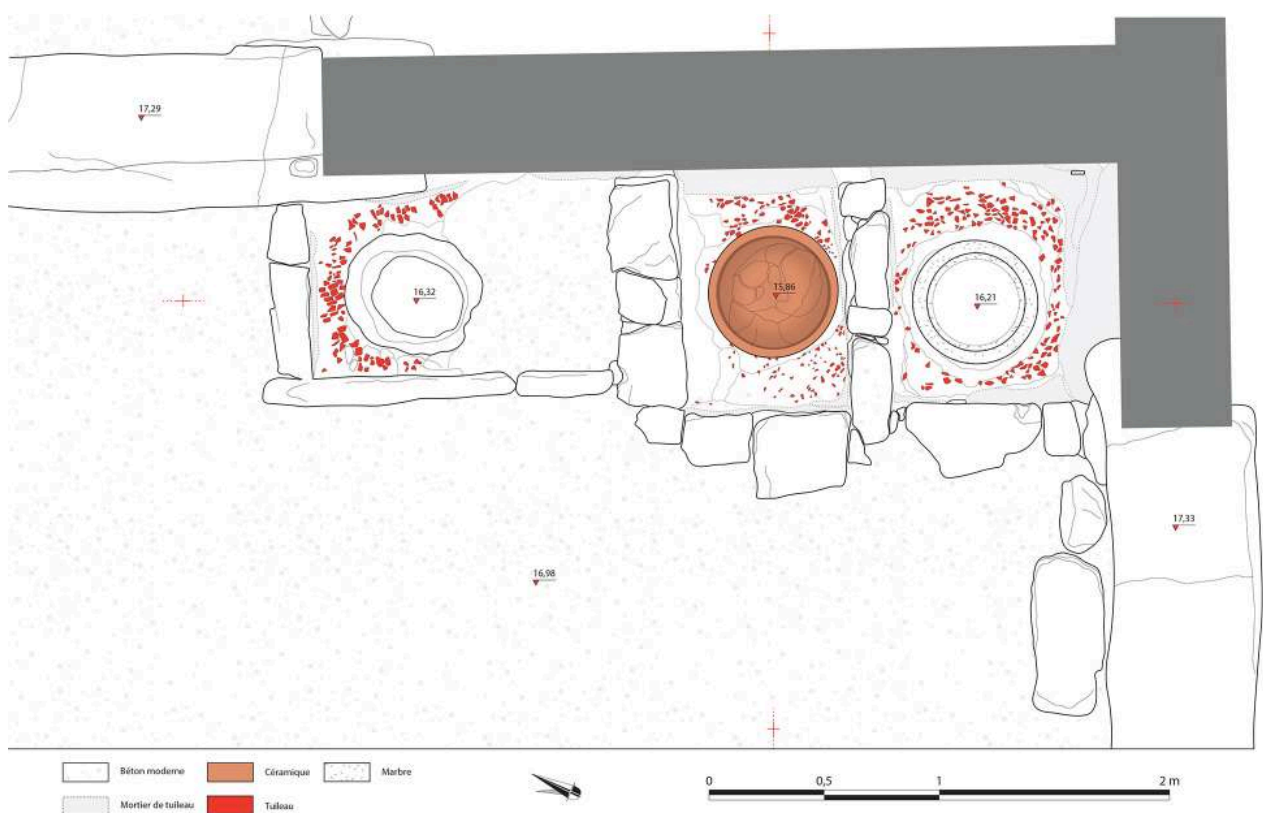

Échelle : $1 / 20$.

Relevé, dessin E. Le Quéré / EFA. 
Fig. 3. Coupe nord-sud sur les stalles de la « boutique » 1.

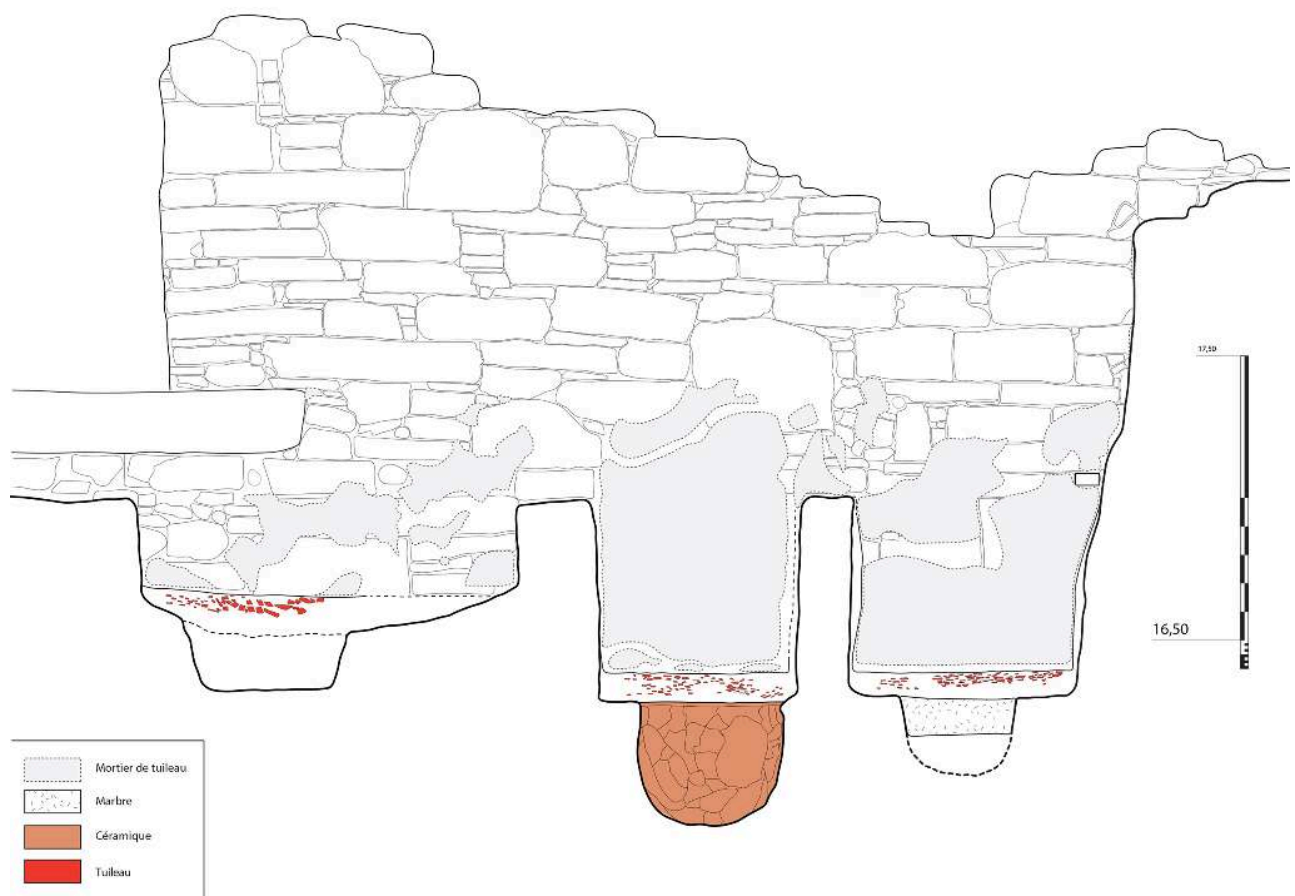

Échelle : 1/20.

Relevé, dessin E. Le Quéré / EFA.

Fig. 4. Coupe est-ouest sur la stalle 2 de la « boutique » 1.

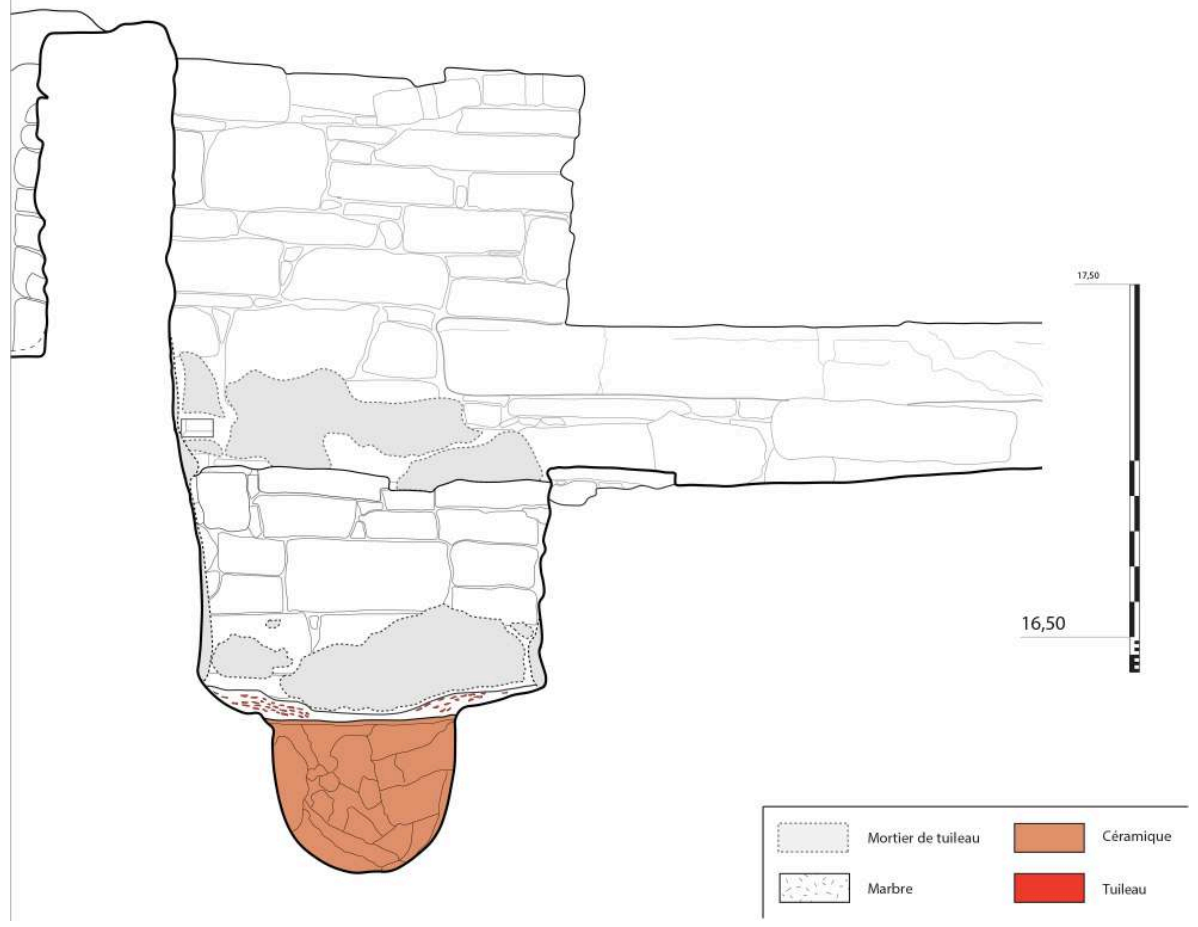

Échelle : 1/20.

Relevé, dessin E. Le Quéré / EFA. 
Ces trois bassins disposent de caractéristiques morphologiques similaires à défaut d'être identiques (tabl. 1). Tous trois sont creusés dans le sol, présentent un plan rectangulaire et disposent de parois verticales. Ils sont séparés par des murets d'épaisseur variable - montés en moellons de gneiss - qui constituent également leurs parois mitoyennes. Toutes les parois sont recouvertes de mortier de tuileau, parfois seulement réduit à l'état de traces. Un mortier de même nature a été appliqué sur les murs est et sud, sur une hauteur totale de $0,22 \mathrm{~m}$, de manière à les protéger de l'humidité.

Tableau 1. Dimensions (en mètres) des trois bassins à l'angle sud-est de la « boutique » 1.

\begin{tabular}{|c|c|c|c|c|c|c|}
\hline & $\begin{array}{l}\text { Largeur } \\
(\mathrm{N}-\mathrm{S})\end{array}$ & $\begin{array}{l}\text { Longueur } \\
(\mathrm{E}-\mathrm{O})\end{array}$ & $\begin{array}{l}\text { Profondeur } \\
\text { conservée } \\
\text { (hors } \\
\text { vasque) }\end{array}$ & $\begin{array}{l}\text { Diamètre } \\
\text { intérieur } \\
\text { de la } \\
\text { vasque }\end{array}$ & $\begin{array}{l}\text { Profondeur } \\
\text { de la vasque }\end{array}$ & $\begin{array}{l}\text { Profondeur } \\
\text { totale } \\
\text { observée }\end{array}$ \\
\hline $\begin{array}{l}\text { Bassin } 1 \\
\text { (septentrional) }\end{array}$ & 1,36 & 0,82 & 0,40 & 0,54 & 0,28 & 0,68 \\
\hline $\begin{array}{ll}\text { Bassin } & 2 \\
\text { (central) } & \end{array}$ & 0,74 & 1,00 & 0,70 & 0,42 & 0,42 & 1,12 \\
\hline $\begin{array}{l}\text { Bassin } \\
\text { (méridional) }\end{array}$ & 0,83 & 1,00 & 0,66 & 0,28 & 0,12 & 0,78 \\
\hline
\end{tabular}

5 Le fond de chacun des bassins est réalisé en béton de tuileau comportant des inclusions de tessons céramiques de dimensions assez importantes - jusqu'à 5-6 cm de longueur. Dans le fond de chacun d'entre eux, une cavité circulaire a été ménagée dans laquelle prend - ou devait prendre - place un récipient. Seules changent la matière et les dimensions de ces récipients: marbre blanc pour le bassin 3, en céramique pour le bassin 2, quant au premier bassin, le récipient a disparu ${ }^{1}$. Le nettoyage a permis de s'assurer qu'il n'y avait aucun système d'adduction ou d'évacuation hydraulique dans ces trois aménagements.

6 Enfin, signalons que, dans l'angle sud-est de la pièce, deux encoches quadrangulaires ont été ménagées dans le béton de tuileau (fig. 5) ${ }^{2}$. Elles servaient très probablement à l'insertion de pièces en bois, pouvant servir d'appui au-dessus des bassins. 
Fig. 5. Détail des deux encoches dans les murs est et sud de la « boutique » 1 .

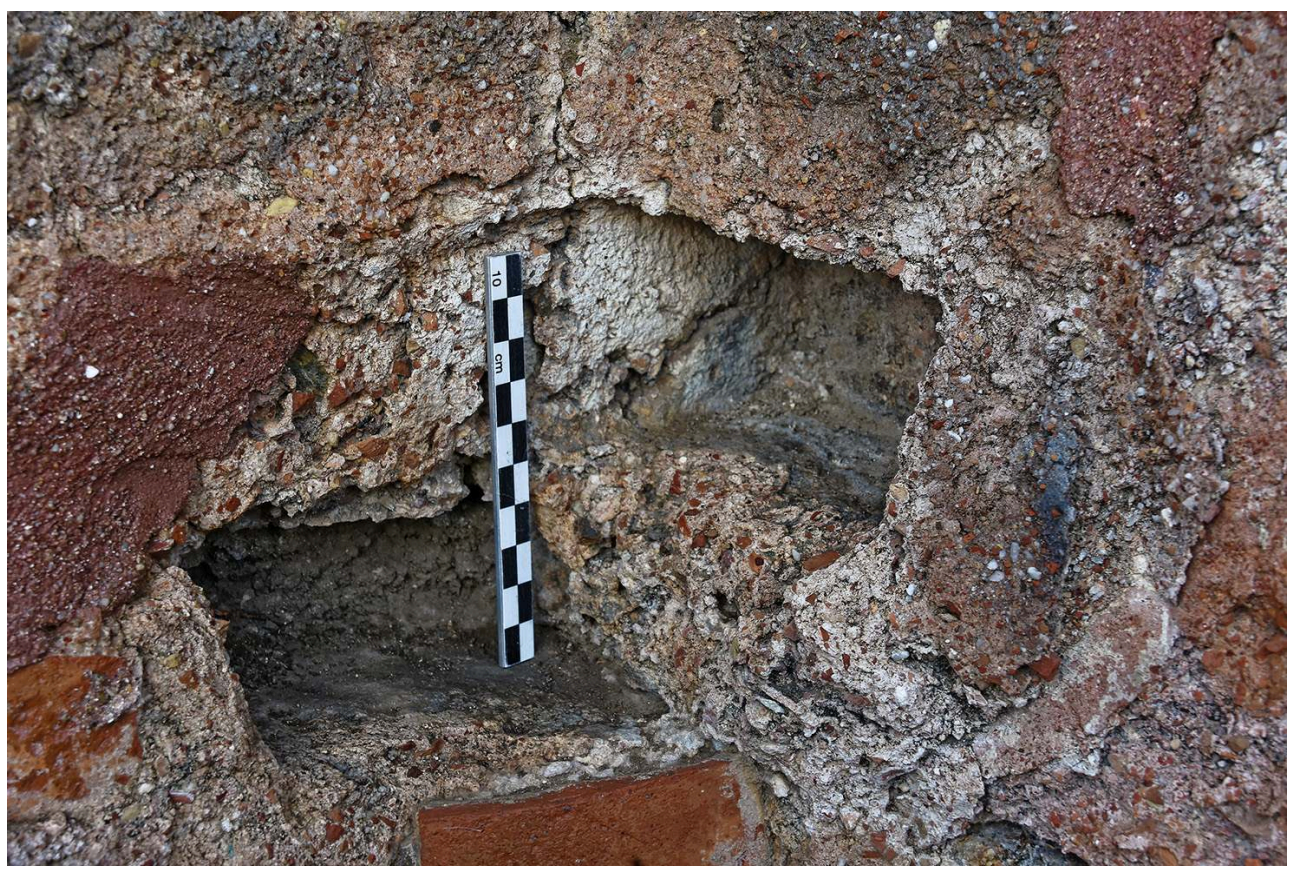

Vue du nord-ouest.

Cliché E. Le Quéré / EFA.

7 J. Chamonard a proposé, sans justifier cette interprétation, que ces éléments étaient des pithoi servant à la conservation et à la vente de denrées et de liquides ${ }^{3}$. L'usage du béton et du mortier de tuileau, ainsi que l'analogie morphologique avec les vestiges des sites de Pompéi ou d'Ostie, incitent cependant à proposer que ces trois aménagements correspondent plutôt à des stalles de foulerie, dans lesquelles les foulons piétinaient le tissu mouillé pour le laver à grand renfort de substances alcalines - urine, terre à foulon ${ }^{4}$. La principale similitude tient à l'existence de deux volumes emboîtés - un parallélépipède rectangle dont le fond est percé d'une demi-sphère ${ }^{5}$ - dans lesquels une isolation hydraulique était réalisée avec du mortier de tuileau. La principale divergence formelle entre les vestiges italiens et ceux de Délos tient à la différence de niveau entre le fond de la stalle et le niveau de circulation. À Délos, si le niveau de sol antique était à peu près le même que le sol restauré, ces stalles se trouvaient alors très fortement en dessous du niveau de circulation (fig. 3-4); à Pompéi et à Ostie, la différence d'altitude est moindre : rarement plus d'une vingtaine de centimètres - hors profondeur de la vasque. Cependant, cette différence morphologique ne saurait véritablement permettre de repousser notre hypothèse. En effet, si dans l'ergonomie générale d'une foulerie la position du fond de la stalle - donc de la vasque - a son importance, le facteur primordial reste celui de la hauteur entre le fond de la vasque et le sommet des murets sur lesquels les foulons appuyaient leurs avant-bras, humérus à l'horizontale 6 . À Délos, l'installation "basse » de la vasque est compensée par une hauteur plus faible des murets. Ainsi, la différence de hauteur reste la même.

8 Il est pour l'instant impossible de proposer une datation pour cet atelier, ne serait-ce que relative. Aussi nous contenterons-nous de rappeler que la Maison II B a connu de nombreux réaménagements internes au cours de son histoire - certains restés inachevés - et qu'on y observe de nombreux matériaux en remploi ${ }^{7}$. Nos observations architecturales concernant l'économie générale de la Maison II B nous ont conduits à 
déduire que l'installation des bassins et des vasques est à replacer dans une des dernières phases de l'aménagement de ce secteur, qui pourrait dès lors être contemporaine des autres réaménagements et réoccupations observés sur le bâtiment de scène du théâtre et dans différentes maisons de l'îlot II, une fois le théâtre abandonné et démantelés.

La «boutique » 2 (pièce $a$ de la Maison II B), située immédiatement à l'est de la pièce 1 et accessible depuis celle-ci à travers une large ouverture, comporte deux niveaux de sols visibles, plus ou moins bien conservés à la suite des travaux de restauration. Le niveau supérieur, recouvert d'une mosaïque en éclats de marbre blanc, est visible le long des murs ouest et nord, ainsi qu'à l'entrée, au nord-est du seuil. Toujours à l'entrée, au nord-ouest du seuil, une petite surface est conservée, recouverte d'une mosaïque en grosses tesselles de marbre blanc et gris, pouvant appartenir au même niveau. Le niveau inférieur quant à lui n'est visible que dans le quart nord-est de la pièce : il s'agit d'un sol constitué de grandes dalles de gneiss.

Cette pièce a attiré notre attention en raison de la présence d'un grand bassin quadrangulaire $(1,10 \times 0,92 \times$ prof. max. cons. $0,92 \mathrm{~m})$ appuyé directement contre son mur oriental (fig. 6-7). Ses parois, construites en moellons de gneiss, sont entièrement enduites d'un épais mortier de tuileau d'environ 4 à $5 \mathrm{~cm}$ d'épaisseur, restauré en de nombreux endroits. Ces restaurations empêchent de comprendre de quoi était composé le fond de ce bassin. Il semble qu'il était également recouvert de mortier ou de béton de tuileau. En son centre, un grand cercle de $0,74 \mathrm{~m}$ de diamètre, aujourd'hui cimenté, reste pour l'instant sans explication faute de description dans les carnets de fouille.

Fig. 6. Le grand bassin quadrangulaire contre le mur est de la « boutique » 2 .

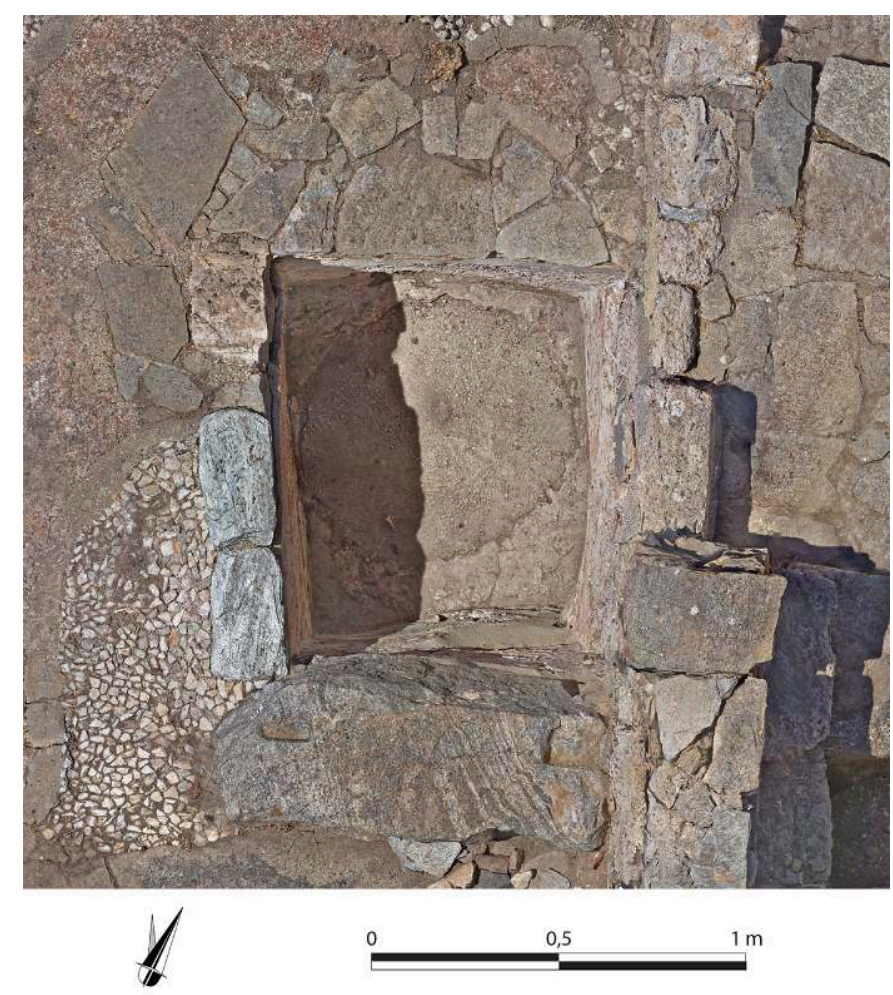

Vue zénithale.

Orthophotogrammétrie N. Monteix / EFA. 
Fig. 7. Coupe est-ouest sur le bassin de la « boutique » 2 .

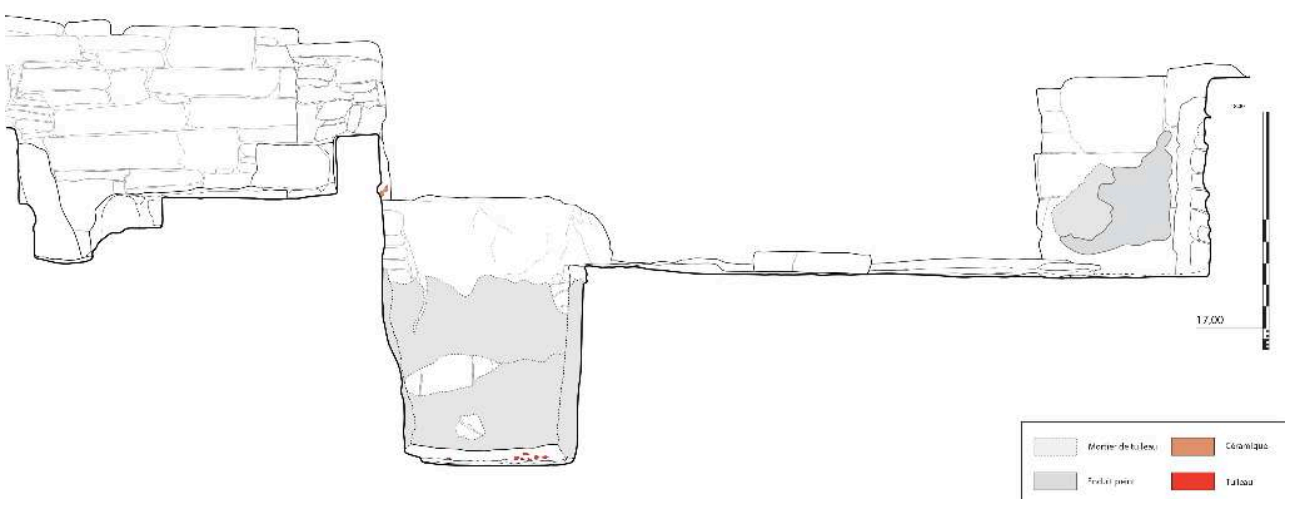

Échelle : 1/20.

Relevé, dessin E. Le Quéré / EFA.

11 La «boutique » 2 était surplombée par un étage, comme le prouve le seuil posé sur le bord sud du bassin, dans lequel sont entaillés les trous d'encastrement des limons d'un escalier en bois. On y accédait depuis la rue par une porte séparée, comme en témoigne le dédoublement du seuil d'entrée, selon un schéma souvent adopté dans les boutiques de Délos, ce qui pointe vers une indépendance de l'étage vis-à-vis du rez-de-chaussée, au moins en termes d'espaces.

Dans le mur oriental, à 1,20 $\mathrm{m}$ au-dessus du fond du bassin, le nettoyage a par ailleurs mis en évidence un orifice (h. $0,13 \mathrm{~m}$ ) servant à l'adduction de liquide, constitué d'un grand fragment de pithos ou d'amphore pris dans la maçonnerie (fig. 8).

Fig. 8. Détail de la conduite d'alimentation dans le mur est de la « boutique » 2 .

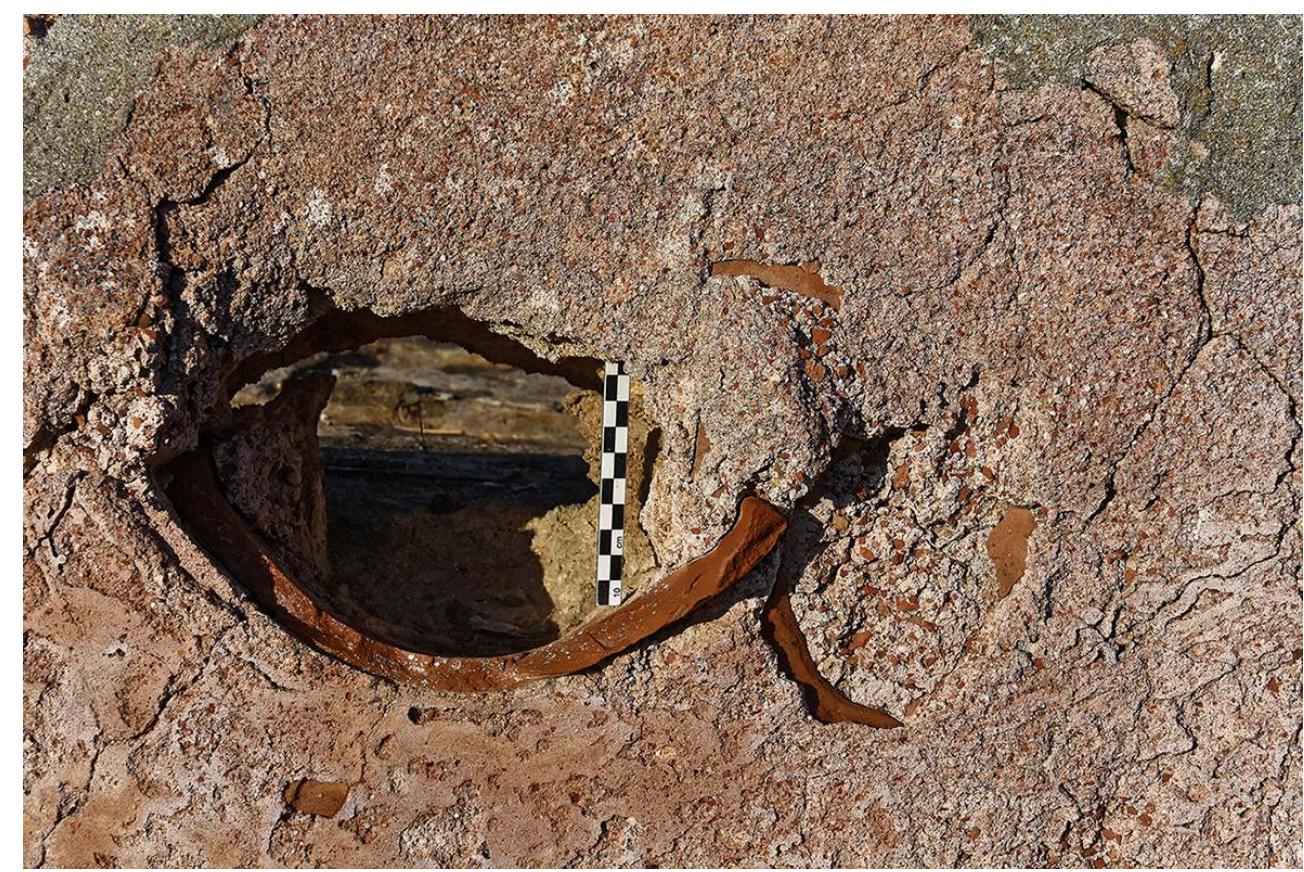

Vue de l'ouest.

Cliché N. Monteix / EFA. 
13 Afin de comprendre le lien entre ce bassin, la conduite d'alimentation et la pièce adjacente, nous avons également effectué un nettoyage de l'autre côté du mur est, le long du mur occidental de la pièce $f$. Cette dernière est en réalité une latrine, dont il ne reste plus que le système d'évacuation des eaux usées délimité par de grands blocs de poros posés de champ, le long des murs est et sud de la pièce, et servant de support aux banquettes percées. Les eaux se déversaient dans l'égout de la Rue 1 par une évacuation située au pied du mur sud de la pièce $f$. Il serait intéressant de pouvoir nettoyer ces latrines afin de comprendre le lien entre ses deux niveaux de sol - pavement de tuileau pour le niveau inférieur, épais dallage de gneiss pour le niveau supérieur - et la conduite d'alimentation du bassin susmentionné. En l'état actuel de la documentation, il reste cependant difficile de comprendre la fonction de ce bassin et son lien avec les pièces adjacentes $f$ et $g$.

\section{La foulerie de la Rue supérieure du Théâtre}

14 La «boutique » 1 de la Rue supérieure du Théâtre (fig. 1) a été dégagée en 1905 par J. Chamonard, et récemment étudiée à frais nouveaux par P. Karvonis et J.-J. Malmary99. Par conséquent, nous ne nous étendrons pas sur les caractéristiques architecturales de la pièce. En revanche, nous présentons ici rapidement les installations que nous y avons nettoyées, car l'interprétation que nous en faisons diverge de celles précédemment proposées. Le nettoyage de cette pièce fut là encore relativement aisé, puisque son sol a été presque sur toute sa surface restauré et cimenté.

15 La «boutique » se situe au croisement de la Rue 1 et de la Rue supérieure du Théâtre; son entrée se fait depuis l'extrémité sud de la Rue supérieure du Théâtre. Dans l'angle nord-est de la pièce, cinq récipients encastrés dans le sol sont conservés : deux en marbre et trois en céramique (fig. 9-11). Là encore, la stratigraphie ayant été fortement perturbée par les fouilles et les restaurations précédentes, il n'est pas possible de déterminer la relation de ces installations avec un quelconque niveau de sol antique. 
Fig. 9. Plan des deux bassins et des cinq récipients à l'angle nord-est de la « boutique » 1 .

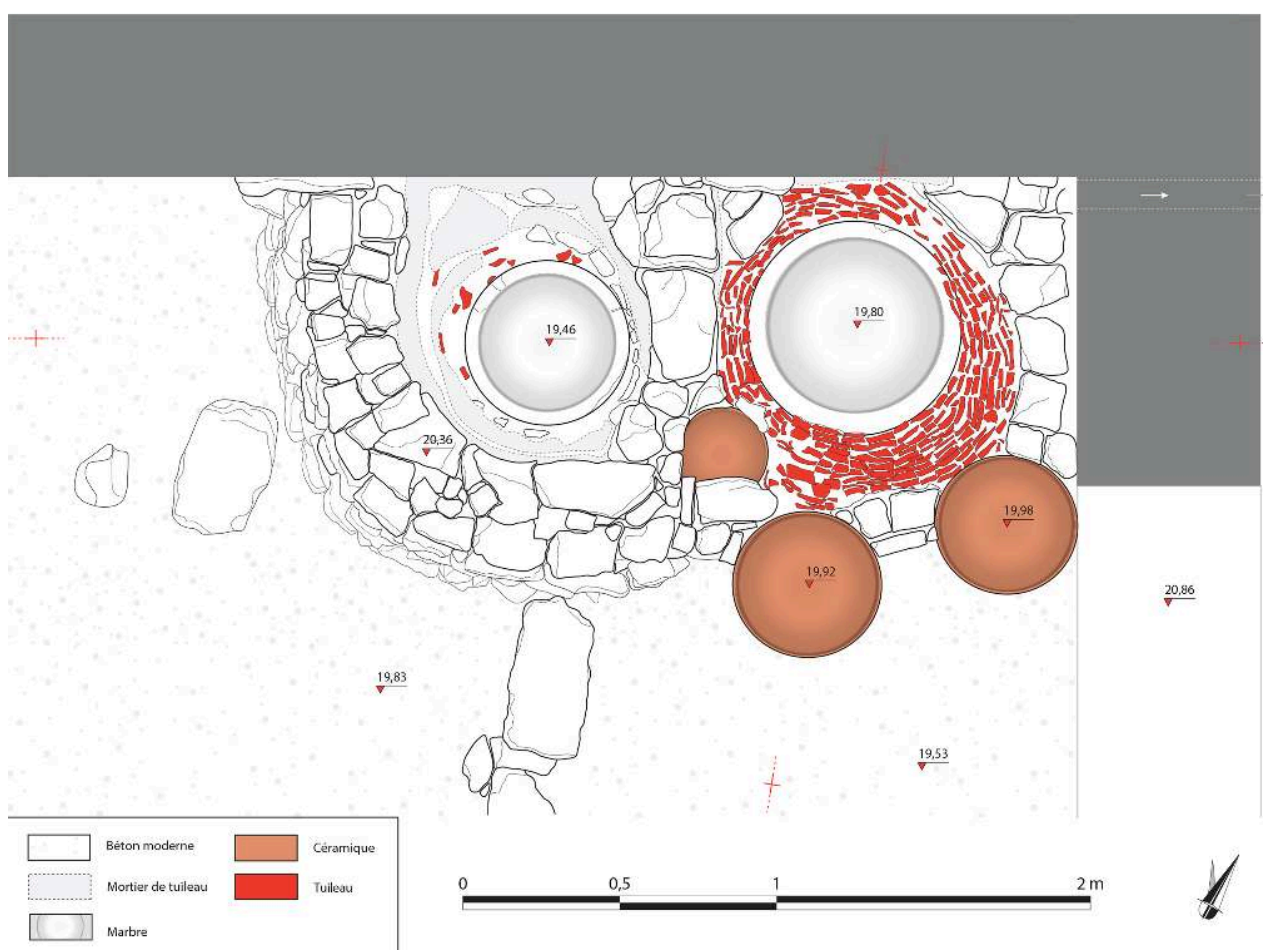

Échelle : 1/20.

Relevé, dessin E. Le Quéré / EFA.

Fig. 10. Coupe est-ouest sur les deux stalles de la « boutique » 1.

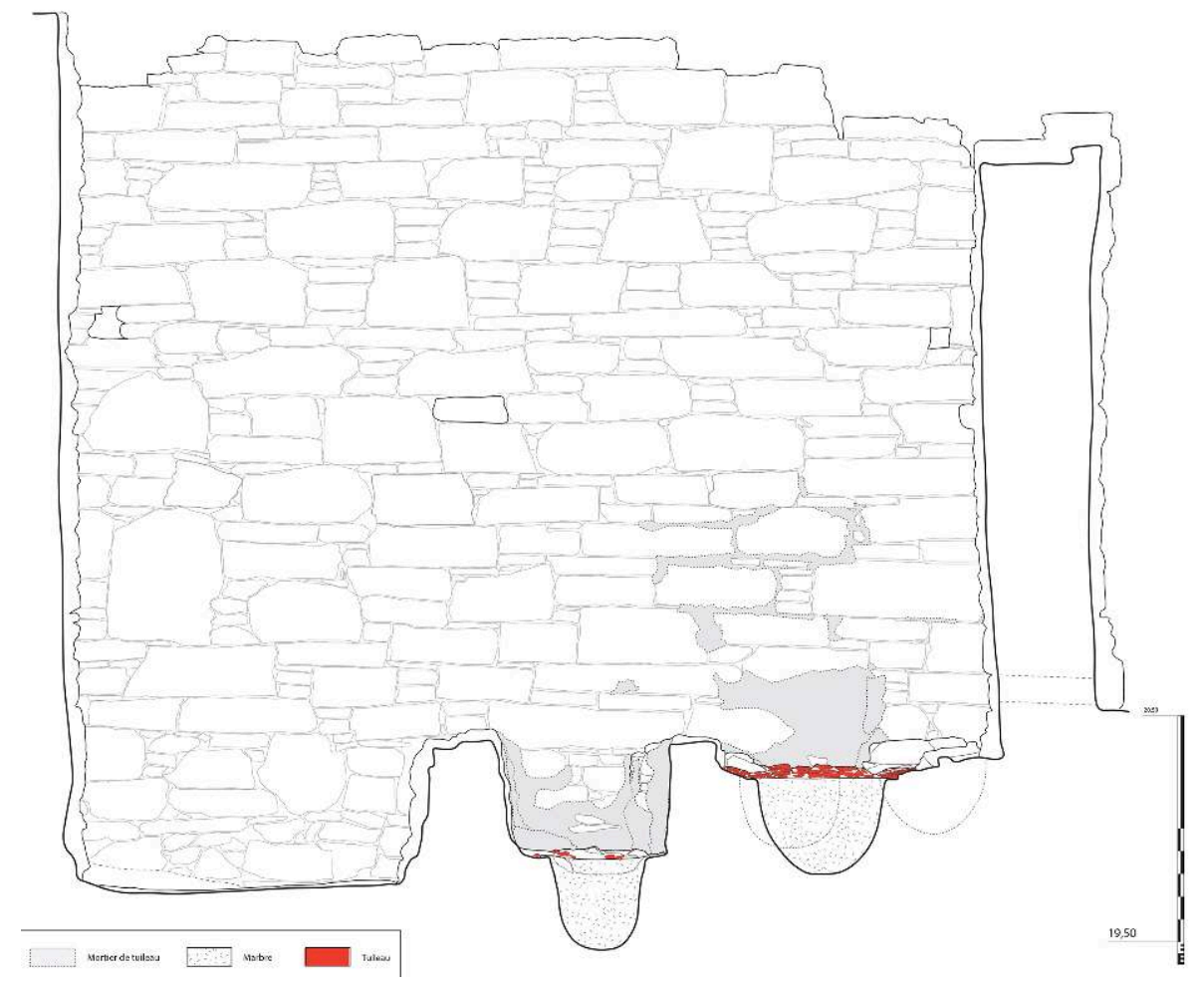

Échelle : 1/20.

Relevé, dessin E. Le Quéré / EFA. 
Fig. 11. Coupe nord-sud sur la stalle orientale de la « boutique » 1.

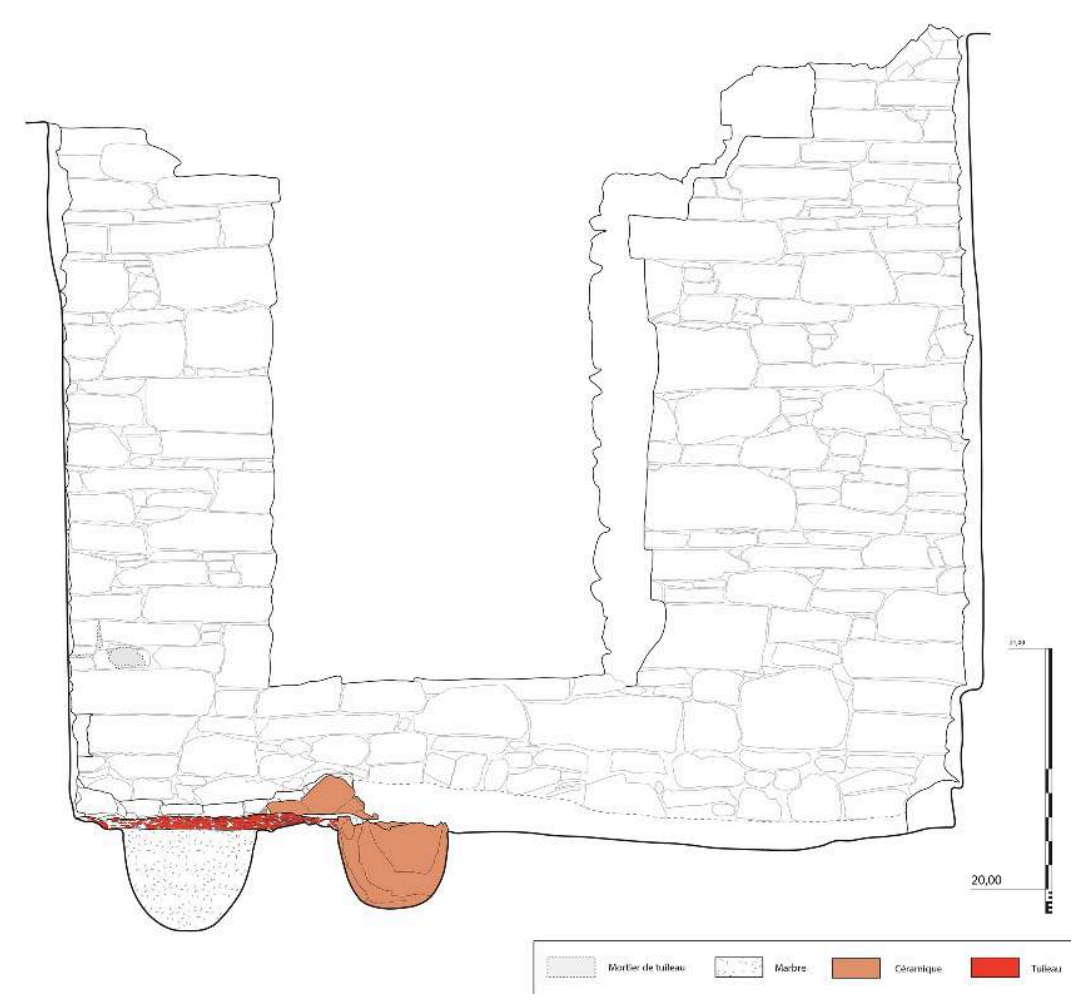

Échelle : 1/20.

Relevé, dessin E. Le Quéré / EFA.

Deux grandes cuves en marbre blanc sont disposées le long du mur nord : celle à l'angle nord-est de la pièce, plus large et à fond moins concave, a une capacité de 77,87 litres, tandis que celle à l'ouest de la précédente, de forme conique, a une capacité de 39,28 litres $^{10}$ (fig. 9-10). Comme dans la foulerie de la Rue 1 précédemment décrite, ces deux vasques sont entourées par des murets bas en moellons de gneiss, désormais largement arasés, mais qui étaient conservés sur une plus grande hauteur au moment de leur découverte, comme le prouve le cliché pris au moment des fouilles par J. Chamonard ${ }^{11}$. Ces murets forment ainsi deux bassins fermés; leurs parois sont entièrement enduites d'un mortier de tuileau d'environ $2 \mathrm{~cm}$ d'épaisseur - bien conservé autour de la cuve ouest-, destiné à les imperméabiliser. Ces deux récipients en marbre sont entourés d'un sol en béton de tuileau, très bien conservé autour de la cuve est. Par ailleurs, une conduite d'évacuation part de l'angle nord-est de la pièce pour se déverser dans l'égout de la Rue supérieure du Théâtre.

Au niveau du bassin oriental, pris dans le muret sud aujourd'hui très arasé, se trouvent deux récipients en céramique, d'une capacité de 48,60 litres pour celui situé à l'est et de 47,52 litres pour celui situé à l'ouest (fig. 11-12) ${ }^{12}$. Ce dernier, dont seule la moitié inférieure est conservée aujourd'hui, était intact au moment de sa découverte ${ }^{13}$. Le cliché pris au moment des fouilles permet de comprendre qu'il ne s'agit pas de restes d'amphores ou de pithoi, mais de sortes de vasques ou de jattes terminées par une lèvre épaisse et plate. Enfin, un dernier récipient, plus petit, est pris dans la maçonnerie des murs, à l'angle sud-ouest de ce même bassin, et enfoncé dans le sol de sorte que son ouverture se trouve au niveau du béton de tuileau (fig. 13). Contrairement à ce qui a 
été avancé précédemment, il ne s'agit sans doute pas d'une amphore. Sa forme globulaire, sa pâte fine et très claire invitent plutôt à y reconnaître un vase à anse de panier, du type de ceux, nombreux, que l'on retrouve à Délos au $\mathrm{I}^{\mathrm{er}} \mathrm{s}$. av. J.-C. ${ }^{14}$. Cette identification est d'autant plus probable qu'un trou avait été percé dans sa partie supérieure (fig. 14), solution couramment utilisée pour ce type de vases, lorsque leur anse, fragile, se cassait sous le poids de l'eau puisée ${ }^{15}$. On perçait alors deux trous de part et d'autre du vase pour y faire passer une corde et continuer tout de même à l'utiliser. Ce vase est donc ici en remploi, sa partie supérieure ayant été cassée accidentellement, ou tronquée à dessein.

Fig. 12. Détail des deux récipients céramiques pris dans le muret de gneiss à l'angle sud-est de la pièce.

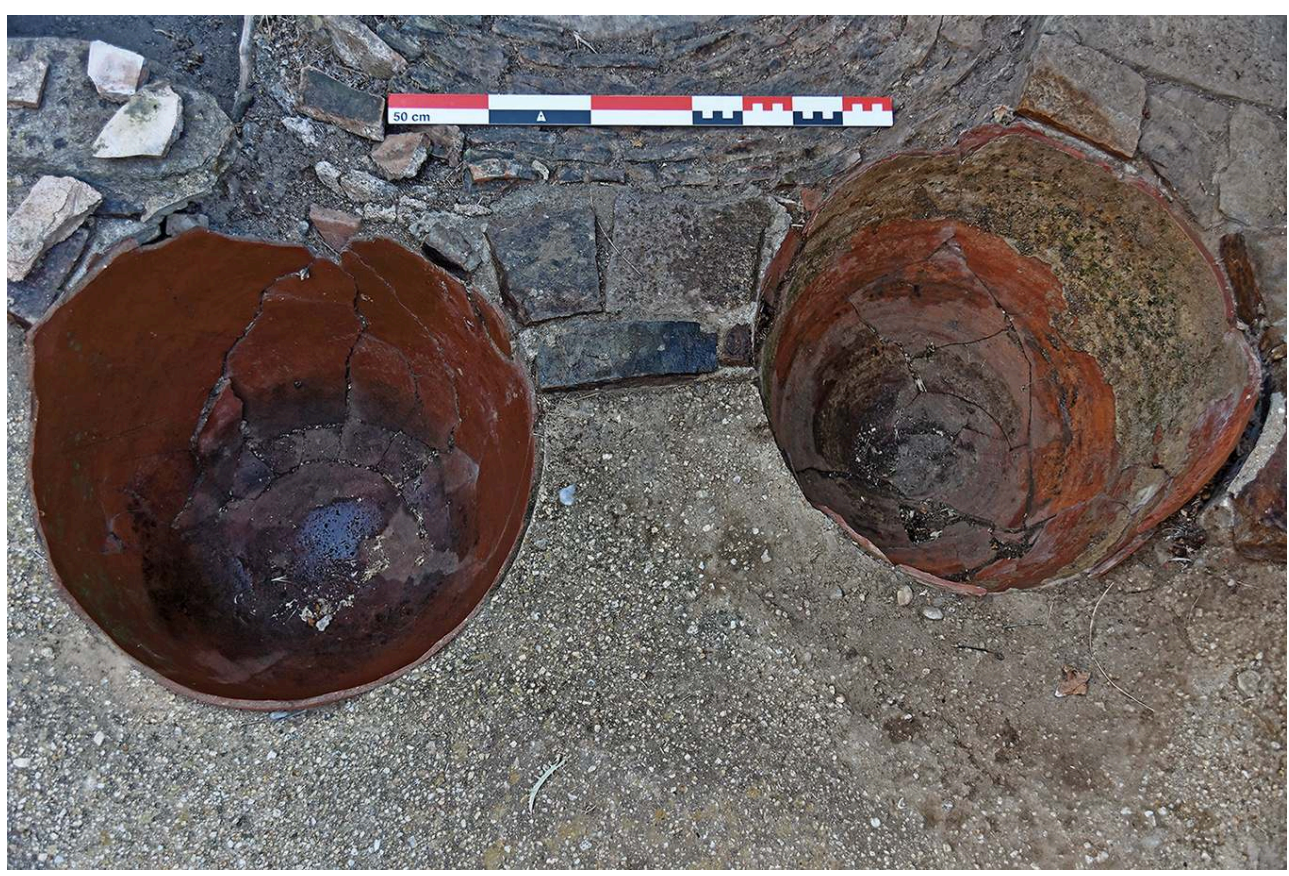

Vue du dessus et du sud.

Cliché N. Monteix / EFA. 
Fig. 13. La cuve en marbre du bassin oriental et le petit récipient en terre cuite dans son angle sudouest.

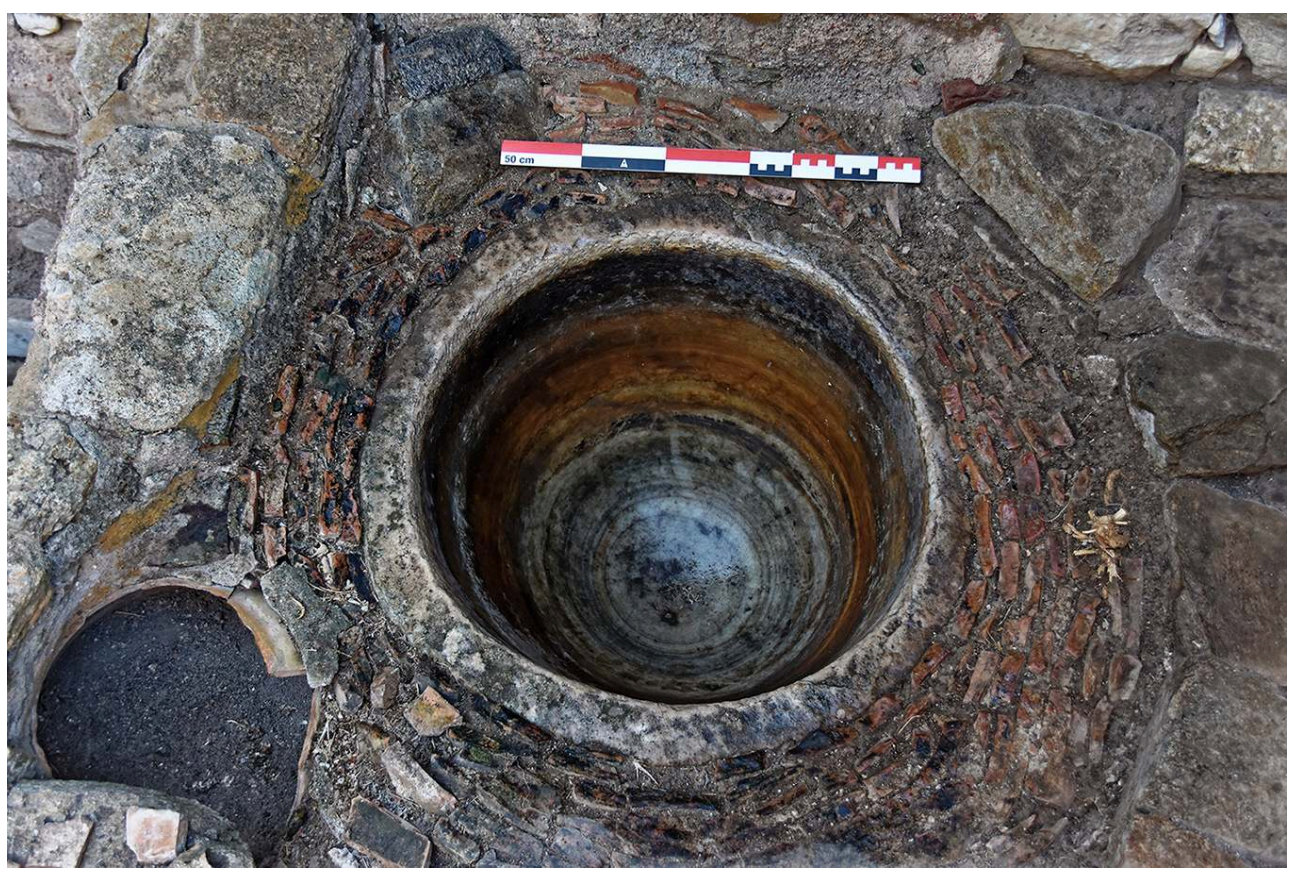

Vue du dessus et du sud.

Cliché N. Monteix / EFA.

Fig. 14. Détail du trou percé dans le vase à anse de panier pour y faire passer une corde.

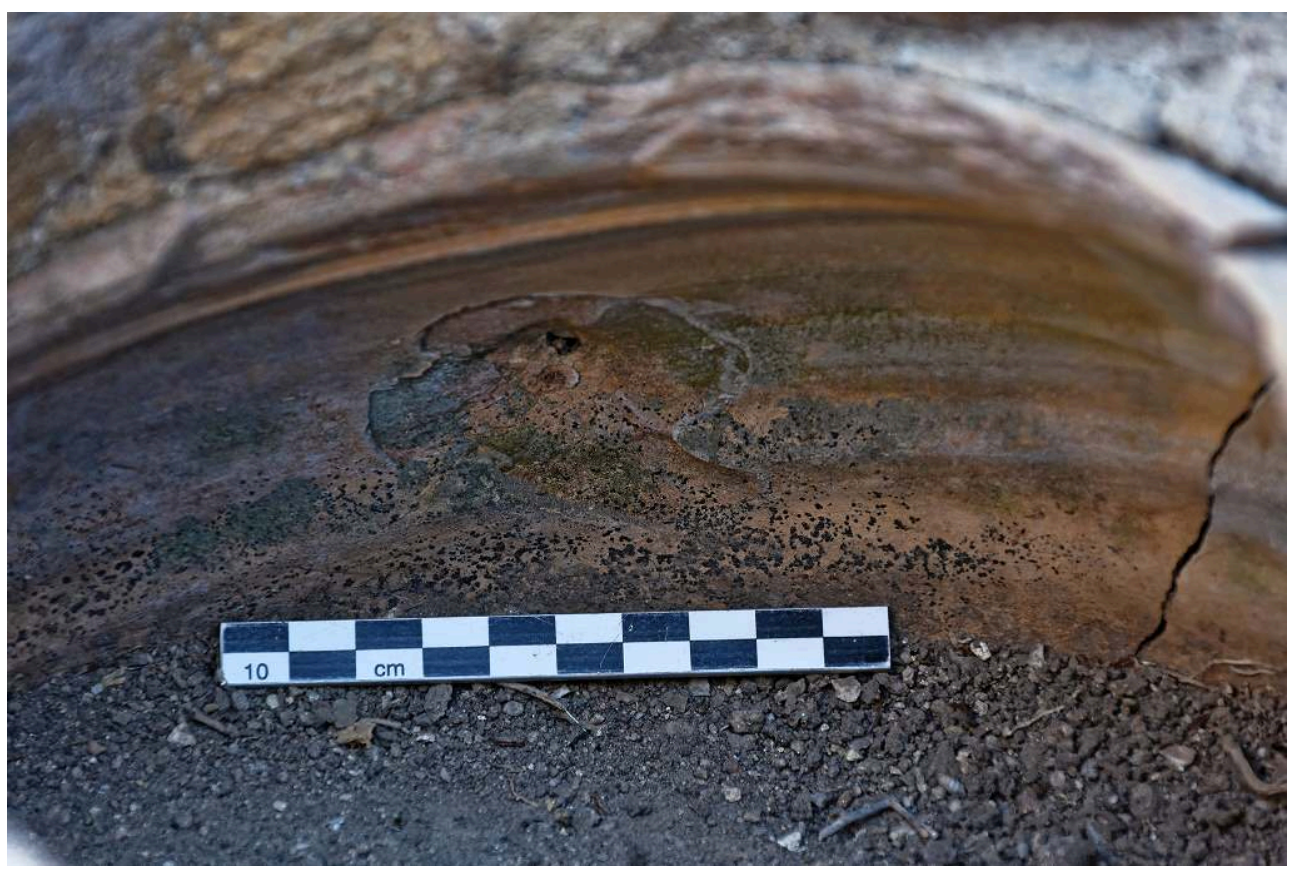

Vue du sud-ouest.

Cliché N. Monteix / EFA.

18 Contrairement à ce qui a été avancé précédemment à titre d'hypothèse, l'usage de ces récipients pour la vente de liquides ou de céréales, voire comme mortiers ${ }^{16}$, ne peut guère être démontré. En effet, le souci d'étanchéité - dont témoignent le béton de 
tuileau et l'enduit hydraulique - ainsi que la nécessité pour ces supposés aménagements de stockage d'être reliés à une canalisation d'évacuation menant vers l'extérieur restent inexpliqués et incompréhensibles. La «boutique » 1 de la Rue supérieure du Théâtre peut ainsi, sur la base de ces observations, être interprétée là encore comme un atelier de foulage.

Contrairement à l'atelier de la Rue 1 du Théâtre, dans cette foulerie, un système d'évacuation des liquides vers l'extérieur est conservé. Il permet une compartimentation stricte entre les zones soumises à la présence d'eau et les autres. Avec des formes différentes, on rencontre de tels aménagements dans les plus petits ateliers pompéiens ${ }^{17}$. De plus, dans le récipient en terre cuite à l'est, le nettoyage a permis de mettre en évidence des restes d'une substance blanchâtre déposés sur les parois du vase (fig. 15). Or, l'exemple de Pompéi montre qu'en étroite association avec les stalles, on trouve fréquemment des conteneurs céramiques pris dans les murets latéraux ou à l'extrémité de la rangée de stalles ${ }^{18}$. Dans plusieurs de ces récipients, on a également découvert une substance blanchâtre, interprétée comme de la terre à foulon, déjà bien connue des sources ${ }^{19}$. Tout ou partie des trois récipients céramiques dans cet atelier de Délos pouvaient donc constituer une réserve de détergents utilisés lors du foulage.

Fig. 15. Détail des restes d'une substance blanchâtre, probablement de la terre de foulon, déposés sur les parois du récipient en terre cuite le plus à l'est.

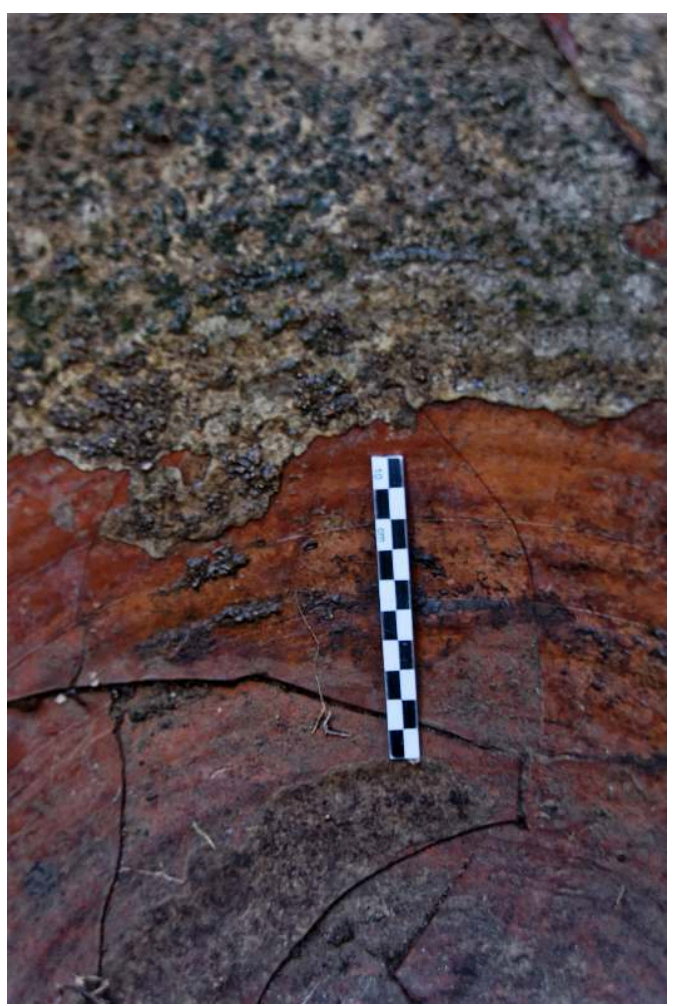

Vue de l'ouest.

Cliché N. Monteix / EFA.

En ce qui concerne la chronologie de cet atelier, Ph. Fraisse et J.-Ch. Moretti ont montré que la «boutique » 1 fut construite ou réaménagée après 69 av. J.-C., une fois le théâtre abandonné, puisque trois carreaux du mur de soutènement périphérique du koilon 
furent remployés dans son mur est ${ }^{20}$. Un tel terminus post quem (deuxième moitié du $\mathrm{I}^{\mathrm{er}} \mathrm{s}$. av. J.-C.) trouve une confirmation céramique par le remploi du vase à anse de panier dont la forme n'est attestée à Délos qu'à partir du début du $\mathrm{I}^{\mathrm{er}} \mathrm{s}$. av. J.-C..21.

\section{La foulerie de la Rue du Théâtre}

21 La « boutique » 4 (pièce à l'angle sud-ouest de la Maison IV A) de la Rue du Théâtre a été fouillée en 1873 lors des travaux de dégagement de la rue, et a aussi récemment été étudiée par P. Karvonis et J.-J. Malmary ${ }^{22}$. Mais là encore, l'interprétation que nous faisons des installations nettoyées dans cette pièce diverge de celles précédemment proposées.

22 La pièce se situe au croisement de la Rue du Théâtre et de la Rue 2 (fig. 1 et 16). À l'époque du fonctionnement de l'atelier, son entrée se faisait par l'ouest, depuis la Rue du Théâtre, où subsiste un seuil en gneiss situé à peu près au niveau du dallage de la rue, mais à $0,37 \mathrm{~m}$ au-dessus du niveau du sol actuel de la pièce. De nos jours, une autre entrée, ouverte dans le mur sud, permet d'accéder à la boutique depuis la Rue 2 par l'intermédiaire de deux marches. Cette entrée, retrouvée comblée au moment des fouilles, comme en témoignent les photographies et le plan publiés en 1906 par J. Chamonard ${ }^{23}$, pourrait n'être qu'une création moderne.

Dans l'angle sud-est de la pièce, seuls trois récipients encastrés dans le sol sont conservés in situ : deux en céramique et un en marbre (fig. 17). Dans l'angle nord-ouest, déjà visible sur les photographies de 1906, se trouve déposé sur le sol - aujourd'hui entièrement cimenté et restauré - un grand récipient en marbre très érodé, non lissé sur la paroi interne, et dont la paroi externe est seulement dégrossie à la pointe (fig. 18). Malheureusement, la stratigraphie de la pièce ayant été fortement perturbée par les fouilles et restaurations, il n'est pas possible de déterminer la relation de ces récipients avec un quelconque niveau de sol antique.

Fig. 16. La maison IV A au croisement de la Rue du Théâtre et de la Rue 2.

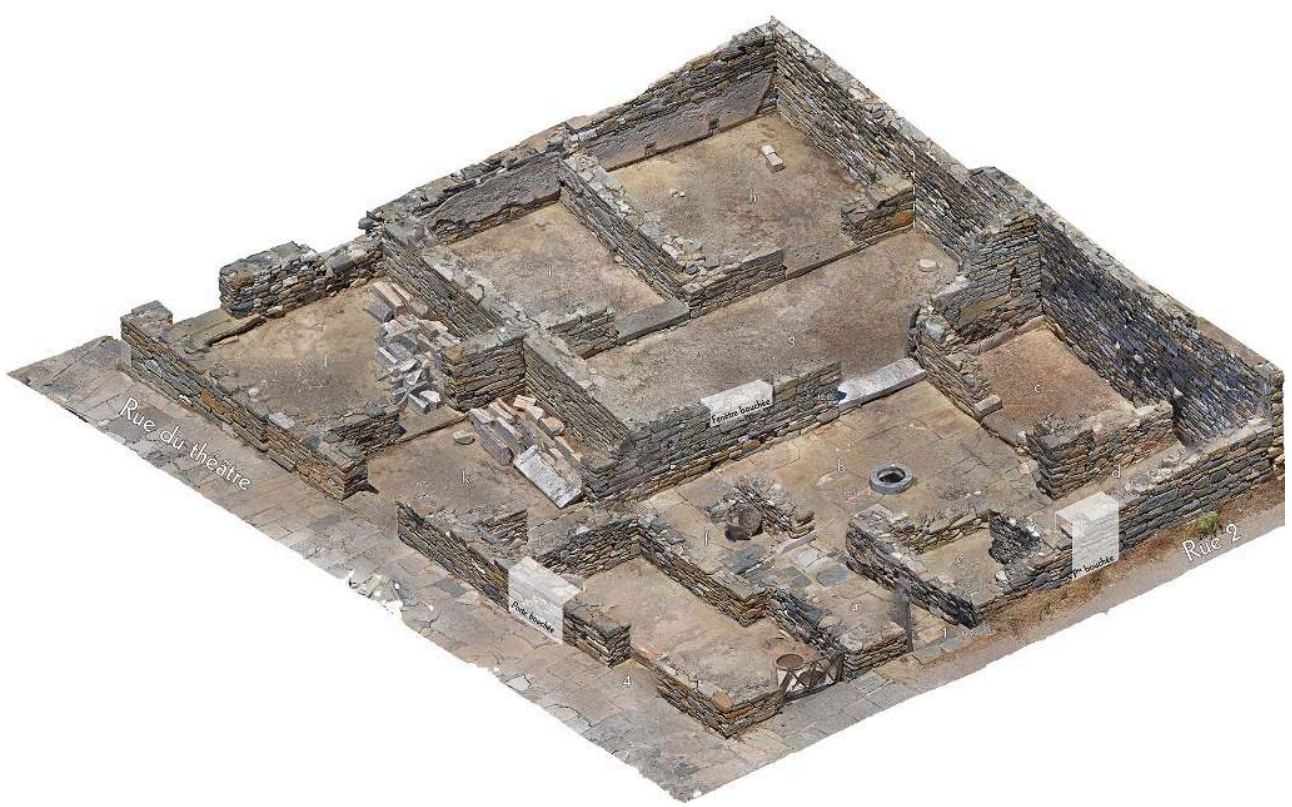

Vue perspective.

Réalisation N. Monteix, S. Zanella / EFA.

Bulletin archéologique des Écoles françaises à l'étranger , Grèce 
Fig. 17. Plan des trois vasques encastrées dans le sol de la « boutique » 4.

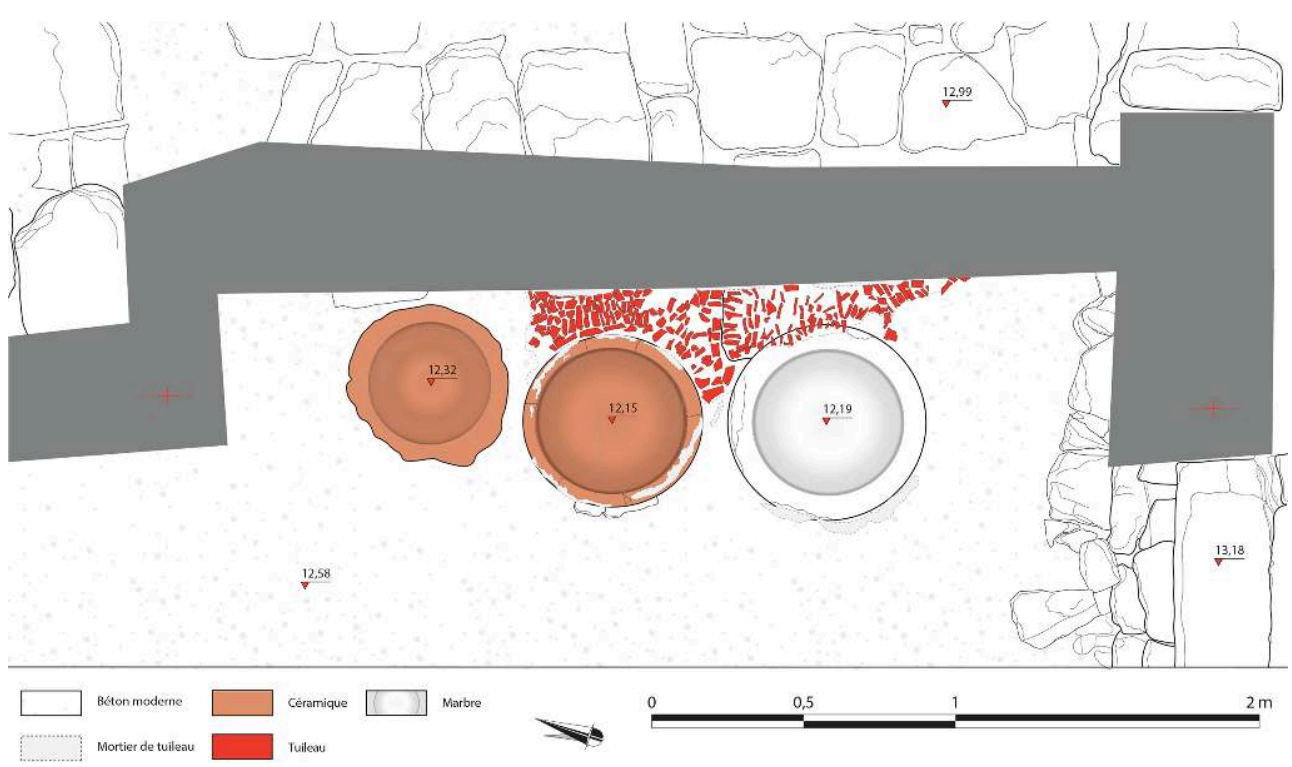

Échelle : 1/20.

Relevé, dessin E. Le Quéré / EFA.

Fig. 18. Grand récipient en marbre déposé dans l'angle nord-ouest de la pièce.

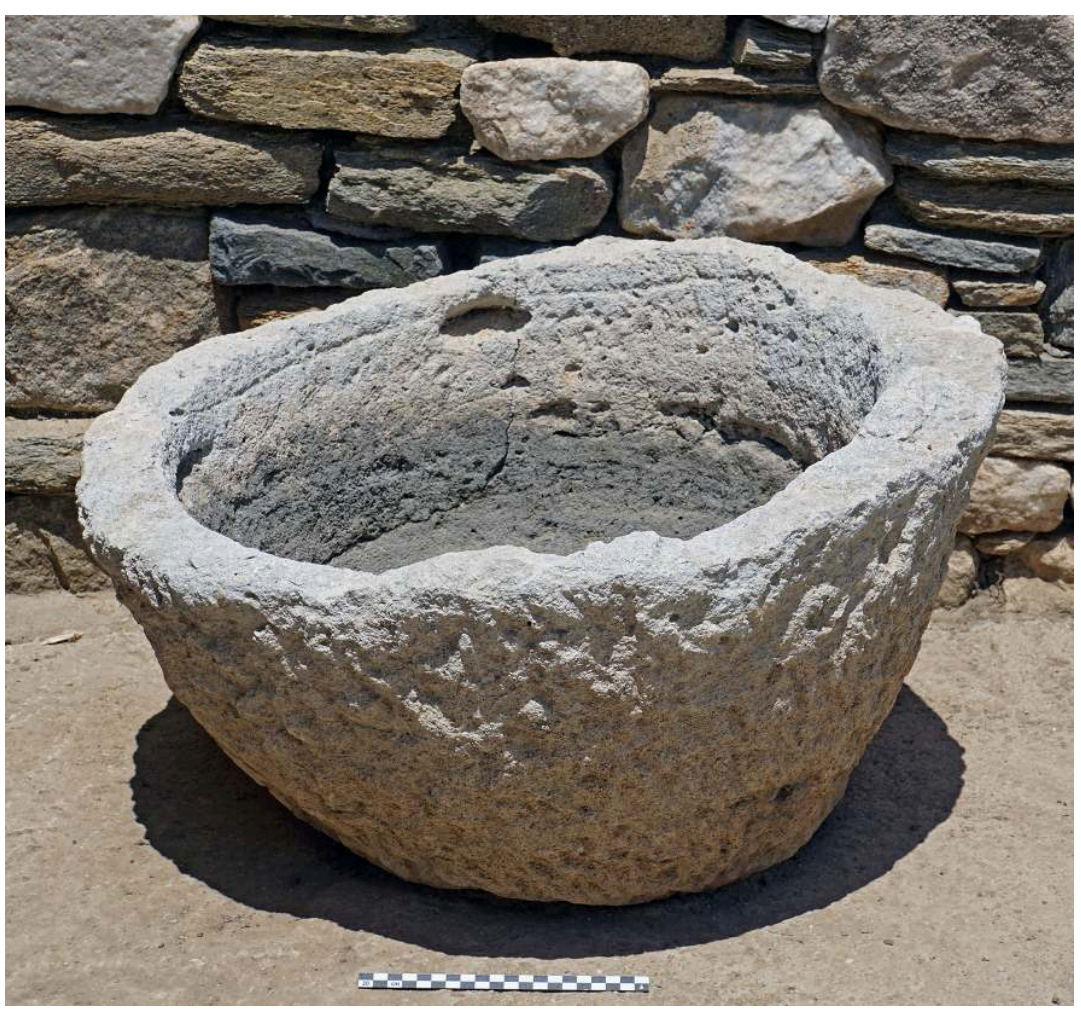

Vue du sud.

Cliché E. Le Quéré / EFA.

24 Les trois récipients sont disposés le long du mur oriental (fig. 19): la vasque septentrionale en céramique, à profil trapézoïdale, a une capacité de 21,88 litres; la 
cuve centrale en céramique, plus profonde et concave, présente un volume de 65,50 litres; tandis que la cuve méridionale en marbre, plus évasée, a une capacité de 52,49 litres $^{24}$. Ces deux dernières cuves étaient entourées d'un pourtour en béton de tuileau, comportant des inclusions de tessons céramiques de dimensions assez importantes - jusqu'à $8 \mathrm{~cm}$ de longueur -, là encore destiné à étanchéifier la structure. Bien conservé entre les cuves et la paroi orientale de la pièce, il a disparu ailleurs, mais on peut en déduire l'existence grâce aux traces de mortier de tuileau subsistant sur le pourtour de la cuve en céramique (fig. 20). Au niveau de ces deux cuves, un mortier de même nature a été appliqué sur le mur oriental: d'une épaisseur relativement importante $(c a .5 \mathrm{~cm})$, des traces en sont encore visibles jusqu'à environ $0,50 \mathrm{~m}$ audessus des cuves (fig. 19 et 21). L'épaisseur de ce mortier et le fait qu'il forme une jonction étanche au-dessus de la couronne en béton de tuileau interdisent de l'interpréter comme une simple couche préparatrice destinée à imperméabiliser la paroi avant d'y appliquer un décor pariétal ; il faut bien plutôt y voir un revêtement destiné à imperméabiliser l'intégralité de l'aménagement. Le piètre état de conservation de l'ensemble ne permet pas de savoir s'il faut étendre la présence de béton et de mortier de tuileau autour et au-dessus du récipient septentrional; on ne peut déduire non plus jusqu'à quelle hauteur le revêtement hydraulique couvrait la paroi orientale de la pièce.

Ces éléments avaient également été interprétés par J. Chamonard comme des pithoi servant à la conservation et/ou à la vente de denrées et de liquides, hypothèse également reprise par P. Karvonis et J.-J. Malmary ${ }^{25}$. Pour les mêmes raisons que celles évoquées à propos des deux ateliers précédents, nous pensons que ces trois aménagements correspondent plutôt à des stalles de foulerie.

Fig. 19. Coupe nord-sud sur les trois récipients disposés le long du mur oriental.

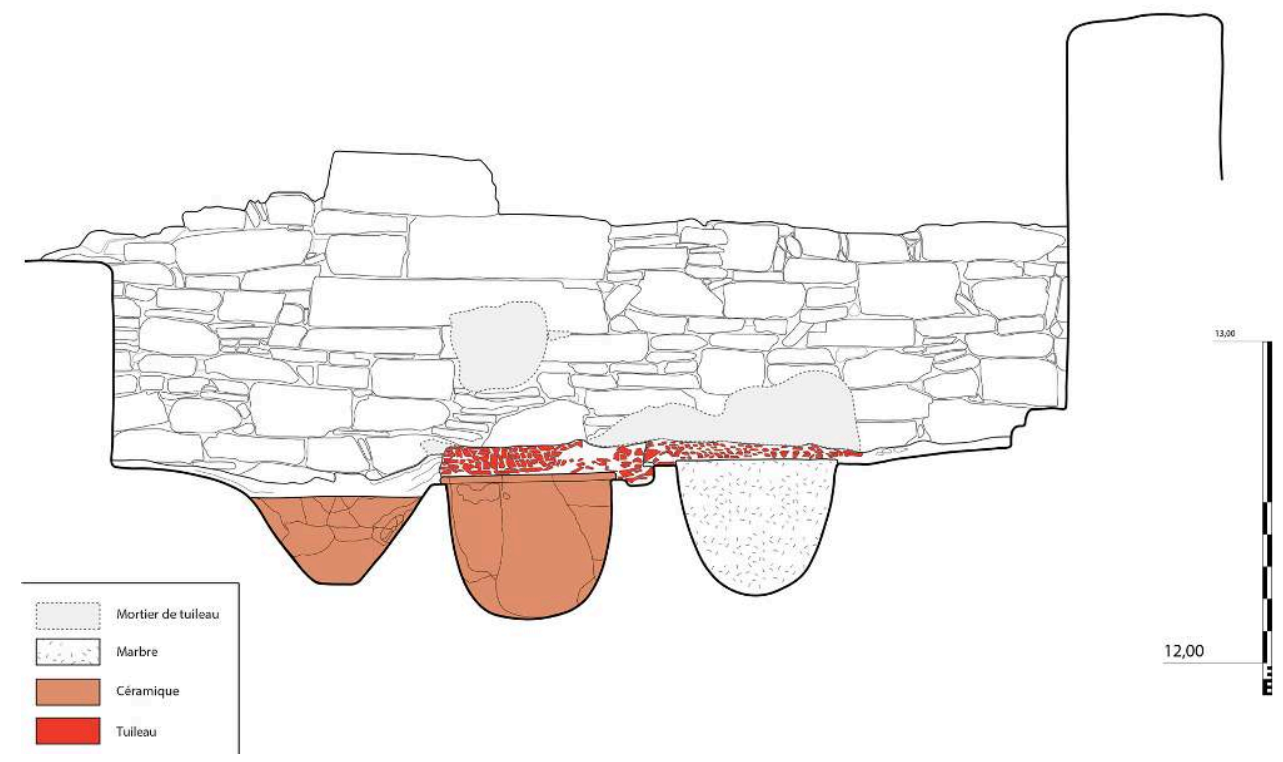

Relevé, dessin E. Le Quéré / EFA. 
Fig. 20. Traces de mortiers de tuileau sur le pourtour de la cuve en terre cuite.

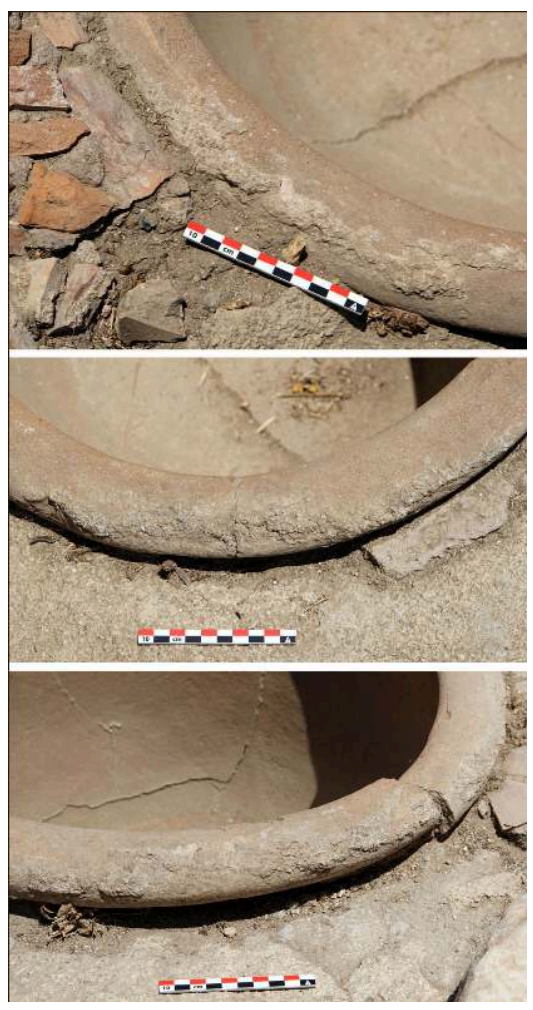

Vues du dessus.

Clichés E. Le Quéré / EFA.

Fig. 21. Les trois cuves et traces du mortier de tuileau sur le mur oriental.

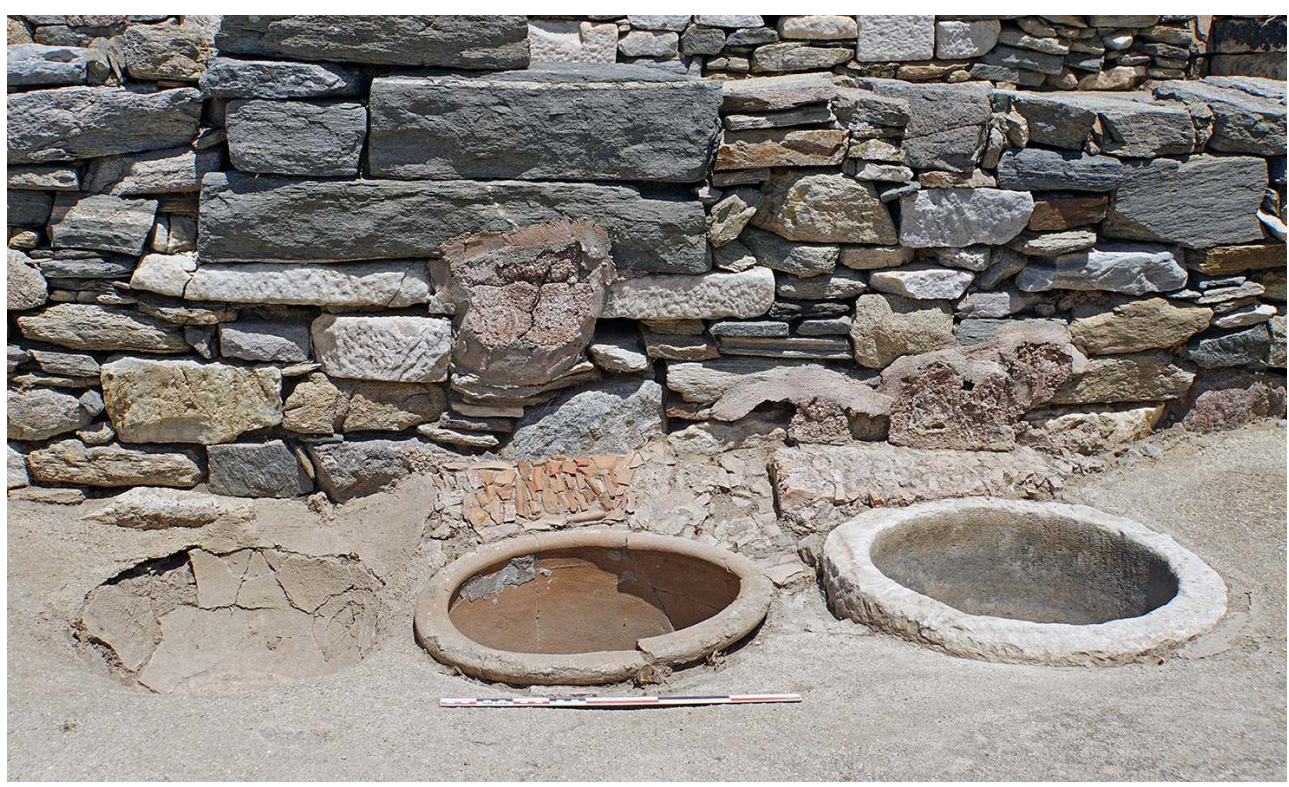

Vue de l'ouest.

Cliché E. Le Quéré / EFA.

26 Certes, l'absence de murets entre les vasques, sur lesquels les foulons appuyaient leurs avant-bras pour fouler les étoffes, interdit à première vue une telle interprétation. Mais en observant les vestiges de plus près, les traces d'une fine paroi - probablement en 
bois - séparant les deux vasques méridionales apparaissent très clairement en négatif au niveau du sol de béton de tuileau (fig. 22). Malheureusement, le mur oriental ayant été en grande partie restauré, il est impossible d'y relever d'autres traces pouvant correspondre à ce type de structure, à l'instar des encoches observées dans la foulerie de la Rue 1 du Théâtre. La présence de l'épais mortier de tuileau sur la paroi orientale de la pièce ne fait que renforcer cette hypothèse, permettant probablement de restituer là des bassins dont les vasques, seules conservées aujourd'hui, constituent le fond.

Fig. 22. Négatif d'une paroi au niveau du sol de béton de tuileau.

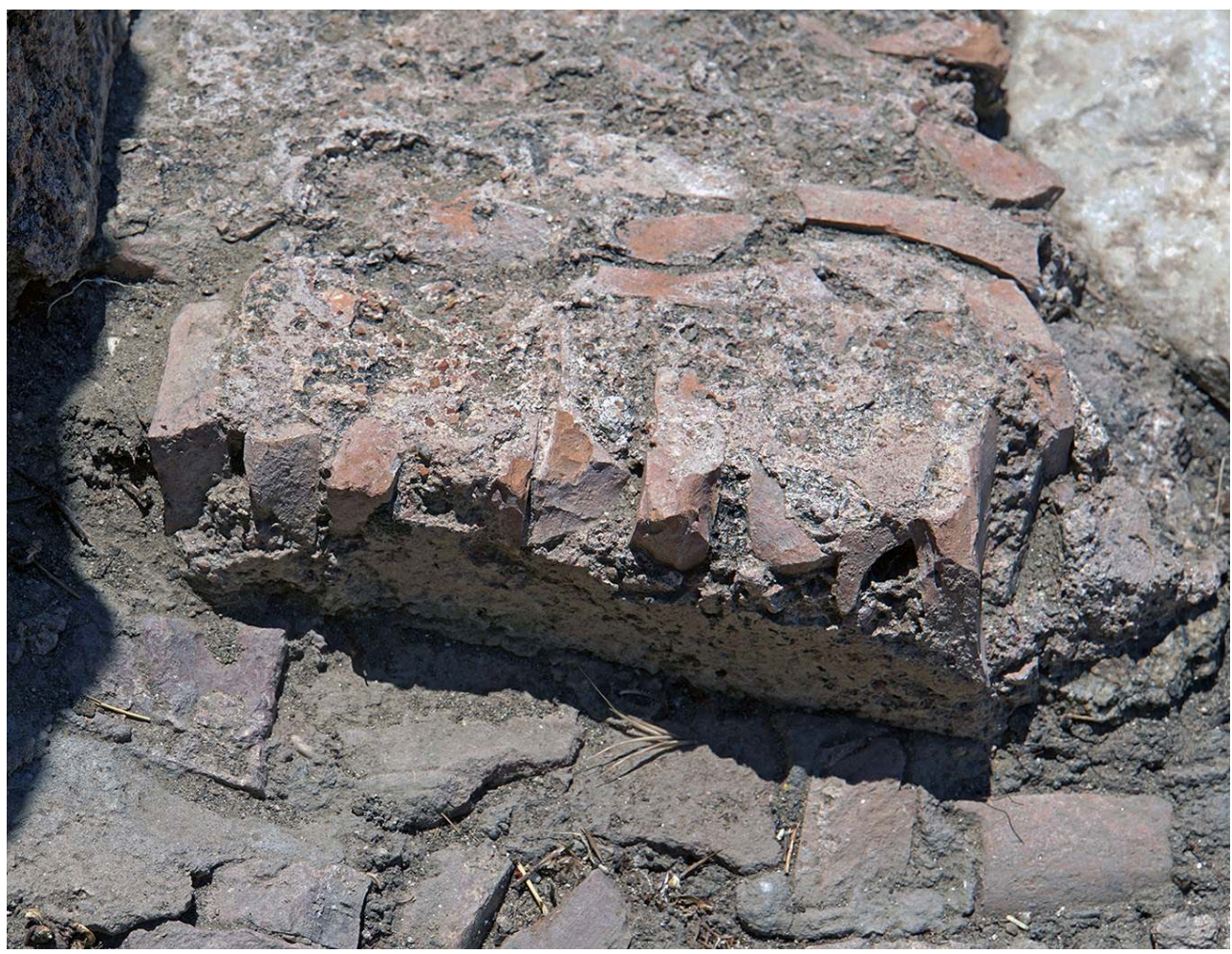

Vue du nord et du dessus

Cliché E. Le Quéré / EFA.

27 Par ailleurs, si le niveau du seuil à l'ouest correspond au niveau du sol antique ${ }^{26}$, les stalles se trouvaient alors très fortement en dessous du niveau de circulation : par conséquent, les murets ou installations sur lesquels les foulons prenaient appui pouvaient être d'une faible hauteur, à l'image de ce que l'on observe, là encore, dans la foulerie de la Rue 1 du Théâtre. Les analogies avec cette dernière sont par ailleurs particulièrement frappantes. On y observe en effet le même nombre de vasques (trois), la même orientation et la même succession dans la combinaison des tailles et des matériaux des cuves (tabl. 2) : une vasque septentrionale en céramique ou en matériau périssable (?) ${ }^{27}$, plus large et moins profonde que les deux autres, une vasque centrale en céramique, puis une dernière en marbre, de tailles et de profondeurs similaires. 
Tableau 2. Comparaison des dimensions (en mètres) des trois vasques de la foulerie de la Rue 1 du Théâtre et de celle de la Rue du Théâtre.

\begin{tabular}{|c|c|c|c|c|c|}
\hline & & $\begin{array}{l}\text { Foulerie de } \\
\text { Théâtre } \\
\text { (« boutique » 1) }\end{array}$ & la Rue 1 du & $\begin{array}{l}\text { Foulerie de } \\
\text { Théâtre } \\
\text { (« boutique » 4) }\end{array}$ & la Rue du \\
\hline & Matériau & $\begin{array}{l}\text { Diamètre } \\
\text { intérieur } \\
\text { de la vasque }\end{array}$ & $\begin{array}{l}\text { Profondeur } \\
\text { de la vasque }\end{array}$ & $\begin{array}{l}\text { Diamètre } \\
\text { intérieur } \\
\text { de la vasque }\end{array}$ & $\begin{array}{l}\text { Profondeur } \\
\text { de la vasque }\end{array}$ \\
\hline $\begin{array}{ll}\text { Vasque } & 1 \\
\text { (septentrionale) }\end{array}$ & céramique & $\begin{array}{l}0,54 \quad \text { (max. } \\
\text { cons.) }\end{array}$ & $\begin{array}{l}0,28 \quad \text { (max. } \\
\text { cons.) }\end{array}$ & $\begin{array}{l}0,50 \quad \text { (max. } \\
\text { cons.) }\end{array}$ & $\begin{array}{l}0,26 \quad \text { (max. } \\
\text { cons.) }\end{array}$ \\
\hline Vasque 2 (centrale) & céramique & 0,42 & 0,42 & 0,49 & 0,43 \\
\hline $\begin{array}{l}\text { Vasque } \\
\text { (méridionale) }\end{array}$ & marbre & 0,28 & $\begin{array}{l}0,12 \quad \text { (max. } \\
\text { cons.) }\end{array}$ & 0,51 & 0,39 \\
\hline
\end{tabular}

En l'état actuel de notre documentation et de nos connaissances, il est impossible de proposer une datation, ne serait-ce que relative, pour ces vestiges. Néanmoins, nos premières observations architecturales concernant l'économie générale de la Maison IV A, à laquelle la "boutique » 4 appartenait dans l'un de ses états et avec laquelle elle communiquait auparavant, nous ont conduits à déduire que l'espace fermé de l'atelier, totalement indépendant de la maison et ouvert uniquement sur la rue, a été installé dans la dernière phase de l'aménagement de ce secteur. Le secteur sud de l'édifice (pièces $a-f$ et $j$ ) semble en effet être le fruit d'un réaménagement de l'ancienne cour de la maison IV A (fig. 16). Comme l'a déjà souligné M. Trümper ${ }^{28}$, une Normalhaus est aisément reconnaissable dans l'édifice, organisée autour d'une cour pavée (b). Selon la restitution proposée par M. Trümper, la partie nord de l'édifice, dans laquelle il faut reconnaître une partie résidentielle (pièces $g$ et $i$ ) et deux boutiques (pièces $l$ et $k$ ) n'aurait pas subi de changements majeurs. Pour la partie sud en revanche (fig. 23), en observant le dallage de la cour, l'hypothèse est avancée que, dans une première phase, la maison s'étendait jusqu'à la façade sud donnant sur la Rue 2 du Théâtre et englobait donc l'espace occupé par la suite par la foulerie. Les pièces $c-e$ auraient déjà été prévues dans cette première phase. L'angle sud-ouest, où la foulerie est installée, aurait été aménagé, quant à lui, lors d'une phase ultérieure. Pendant la campagne 2019, les premières observations effectuées sur ces espaces, bien qu'elles doivent être complétées lors de la prochaine campagne, permettent de proposer d'autres hypothèses quant à l'évolution de l'édifice. 
Fig. 23. Reconstitution proposée par M. Trümper et plan actuel de la partie sud de la Maison IV A.

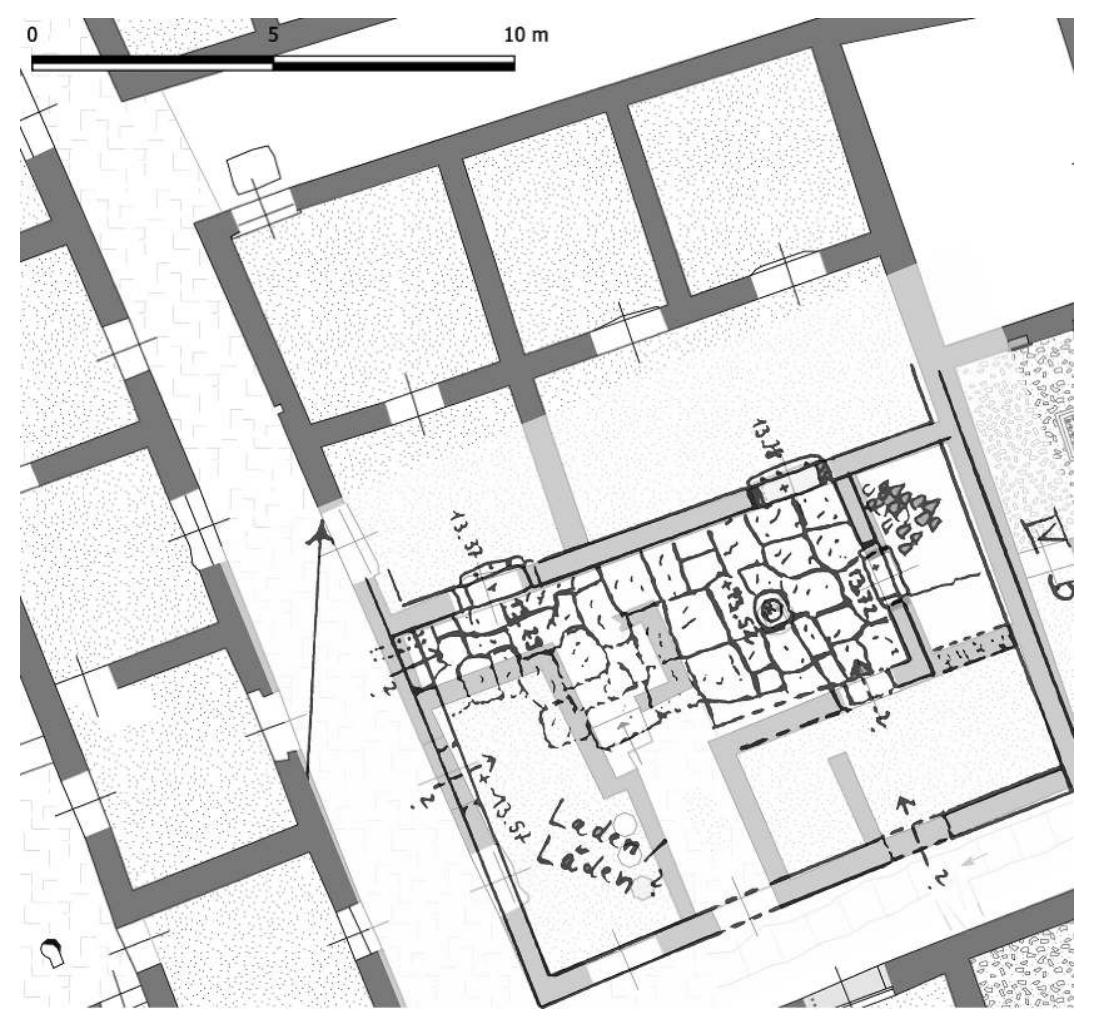

D’après tRÜMPER 1998, fig. 48 et https://sig-delos.efa.gr/.

Comme l'a souligné M. Trümper, les reconstructions modernes ont fortement modifié l'aspect originel des élévations et des parcours de circulation. En confrontant les photographies publiées par J. Chamonard ${ }^{29}$, il est en effet possible d'affirmer que la porte de communication entre la Rue 2 et la «boutique » 4 ne correspond pas à l'état ancien. Lors de la fouille, les murs de l'angle sud-ouest de l'îlot furent en effet retrouvés au niveau des fondations et aucun élément ne permet d'affirmer qu'une ouverture était ménagée en ce point. On doit par conséquent considérer cette porte comme une invention moderne, puisqu'aucun élément visible in situ ni dans la documentation d'archive ne permet d'en assurer l'existence.

L'observation des élévations, quant à elle, a permis d'isoler trois types d'appareils qui, dans l'attente d'une analyse plus fine, peuvent se différencier en fonction de la mise en œuvre, des dimensions et de la nature des éléments qui les composent (fig. 24). Si les deux premiers types ont des caractéristiques assez semblables et se différencient seulement par les dimensions des éléments utilisés, le troisième type, lui, se caractérise par un usage important de moellons en remploi qui impliquent une mise en œuvre irrégulière. 
Fig. 24. Les trois types d'appareil observés dans les élévations de la Maison IV A.

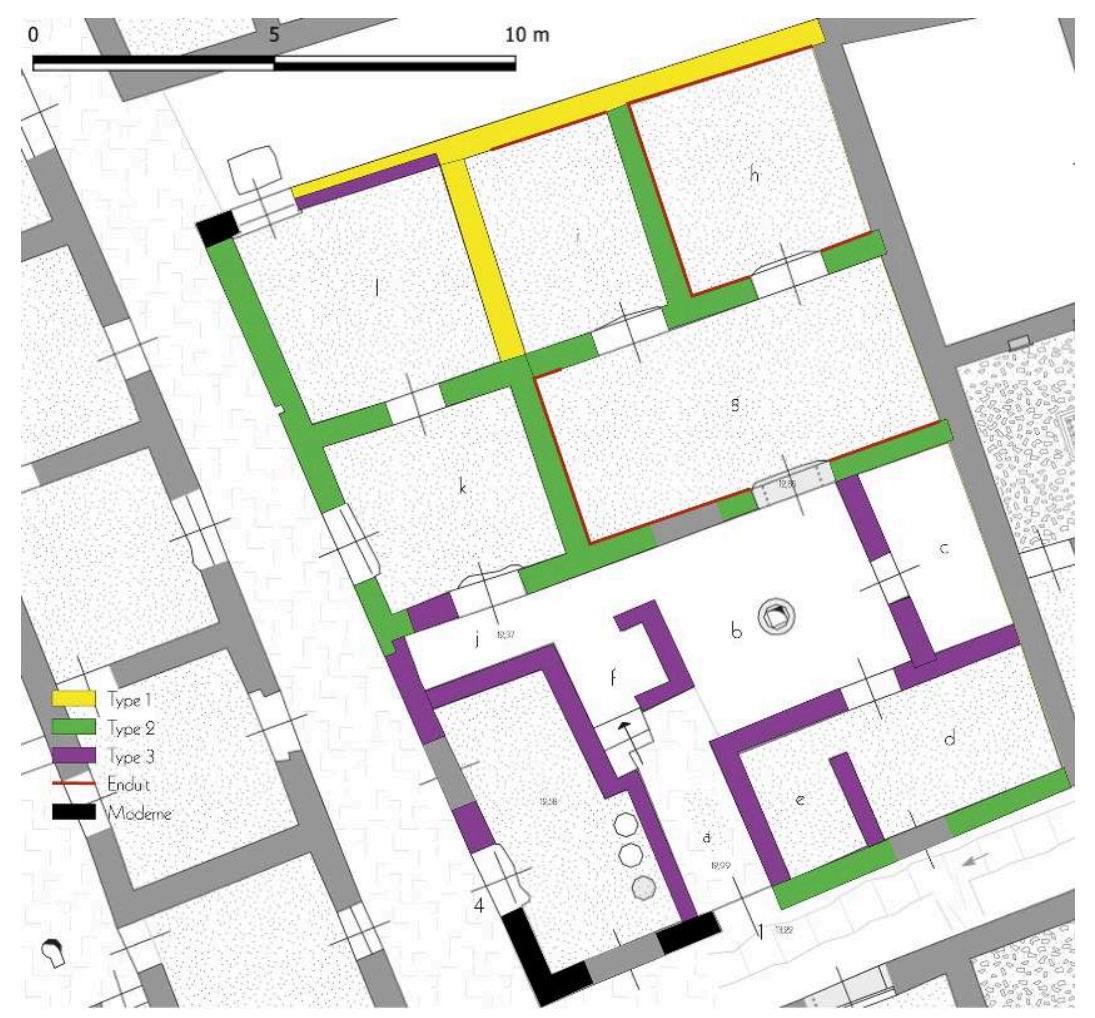

Plan, dessin S. Zanella / EFA.

Les relations stratigraphiques entre les différents pans de murs permettent également d'avancer quelques considérations générales, notamment en ce qui concerne l'organisation des espaces autour de la cour $b$. En suivant la restitution de M. Trümper, l'actuel dallage de la cour s'appuie contre les murs des pièces $c-d, g$ et $k$, alors que les murs de la cage d'escalier $f$ ainsi que le mur qui sépare la maison de la foulerie 4 reposent sur ce même dallage, établissant ainsi un rapport de postériorité avec ce dernier. D'autre part, les murs des pièces $c-e$, non seulement sont réalisés avec des moellons de remploi, mais s'appuient contre le mur oriental de la maison, qui la sépare de la maison IV B, et contre le mur sud, en définissant ainsi également des rapports de postériorité avec ces derniers. Cela implique que l'espace de la cour a dû subir, entre sa première phase et la réalisation de la foulerie, une reconstruction complète dont témoigne l'aménagement des pièces $c-d$. De cette première phase, seule la porte d'entrée primitive demeure. Elle est probablement à reconnaître, comme le suggère M. Trümper, dans la porte bouchée à l'est de l'entrée (1), en axe avec la porte de la pièce $g$. Rien ne semble subsister de l'organisation interne de la cour qui devait probablement déjà prendre place dans ce secteur de la maison car, comme nous l'avons $\mathrm{vu}$, les pièces à l'ouest et au sud sont aménagées dans une phase ultérieure. Il est intéressant de remarquer que le dallage de la cour présente une pente très importante du sud et de l'est vers l'ouest, depuis l'entrée actuelle (1) vers la pièce $j$. Cette dernière présente, à la base de son mur occidental, une évacuation pour les eaux de la cour qui devaient se déverser dans l'égout de la Rue du Théâtre. En observant le mur septentrional de la cour, on remarque que la création de la cour avec ce fort pendage a nécessité d'abaisser le niveau du sol entre la pièce $c$ et la Rue du Théâtre. Le mur entre la pièce $g$ et la cour présente une assise de réglage au niveau du seuil entre les deux 
pièces (altitude locale absolue : 12,85 m) (fig. 16). L'aménagement de la cour a donc amené à mettre à nu une partie des fondations du mur septentrional. Pour cette phase, cohérente avec la réalisation des pièces $c$-e, nous n'avons pas d'élément pour restituer l'organisation de l'espace à l'angle sud-ouest de l'édifice, où la foulerie fut installée dans un moment ultérieur. Une autre modification ponctuelle mais importante pour la circulation a été observée : l'ouverture de la porte entre les pièces $j$ et $k$. La technique de construction permet en effet d'avancer l'hypothèse que cette porte est le fruit d'un réaménagement postérieur à une première phase comme le montrent bien les traces laissées par les opérations de découpage du mur nord-sud.

\section{Les ateliers de la bordure sud de l'Agora des Italiens}

\section{La boutique 103}

Les boutiques et ateliers situés le long du côté sud de l'Agora des Italiens (GD 52) (fig. 25) ont été dégagés par L. Bizard en 1904, campagne au cours de laquelle il mit au jour, « vers l'angle sud-ouest, un atelier de marbrier $»^{30}$. D'après É. Lapalus, cet atelier correspond aux pièces $\mathrm{n}^{\text {os }} 106$ et 103, les plus à l'ouest de cette rangée de boutiques, dans lesquelles une grande quantité de marbres restés à l'état d'ébauche a été retrouvée $^{31}$. Dans l'angle nord-est de la pièce 103 subsistent de nos jours deux grands récipients en marbre blanc encastrés dans le sol, aux parois très épaisses $(7-8 \mathrm{~cm})$, et dont l'intérieur seul est poli (fig. 26). Notons néanmoins qu'à l'époque de leur découverte, ces vasques étaient au nombre de trois ${ }^{32}$. De forme conique, elles sont relativement profondes $(c a .0,50 \mathrm{~m})$ et d'un diamètre interne, au sommet, respectivement de $0,44 \mathrm{~m}$ (vasque septentrionale) et de $0,42 \mathrm{~m}$ (vasque méridionale). Le sol de cette pièce étant aujourd'hui totalement cimenté et en l'absence de tout autre structure conservée, il n'est guère possible de proposer une interprétation quant à la fonction de ces récipients. Notons cependant que le rebord de chacune de ces vasques présente des traces de mortier de tuileau (fig. 27), invitant à restituer à ce niveau un enduit hydraulique constituant peut-être le sol antique dans lequel elles étaient encastrées. D'infimes traces de mortier de tuileau subsistent également sur la paroi orientale de la pièce, au-dessus du récipient septentrional et un peu plus au sud, au niveau du troisième récipient disparu. 
Fig. 25. Emplacement des boutiques 103 et 89 sur le long du côté sud de l'Agora des Italiens.

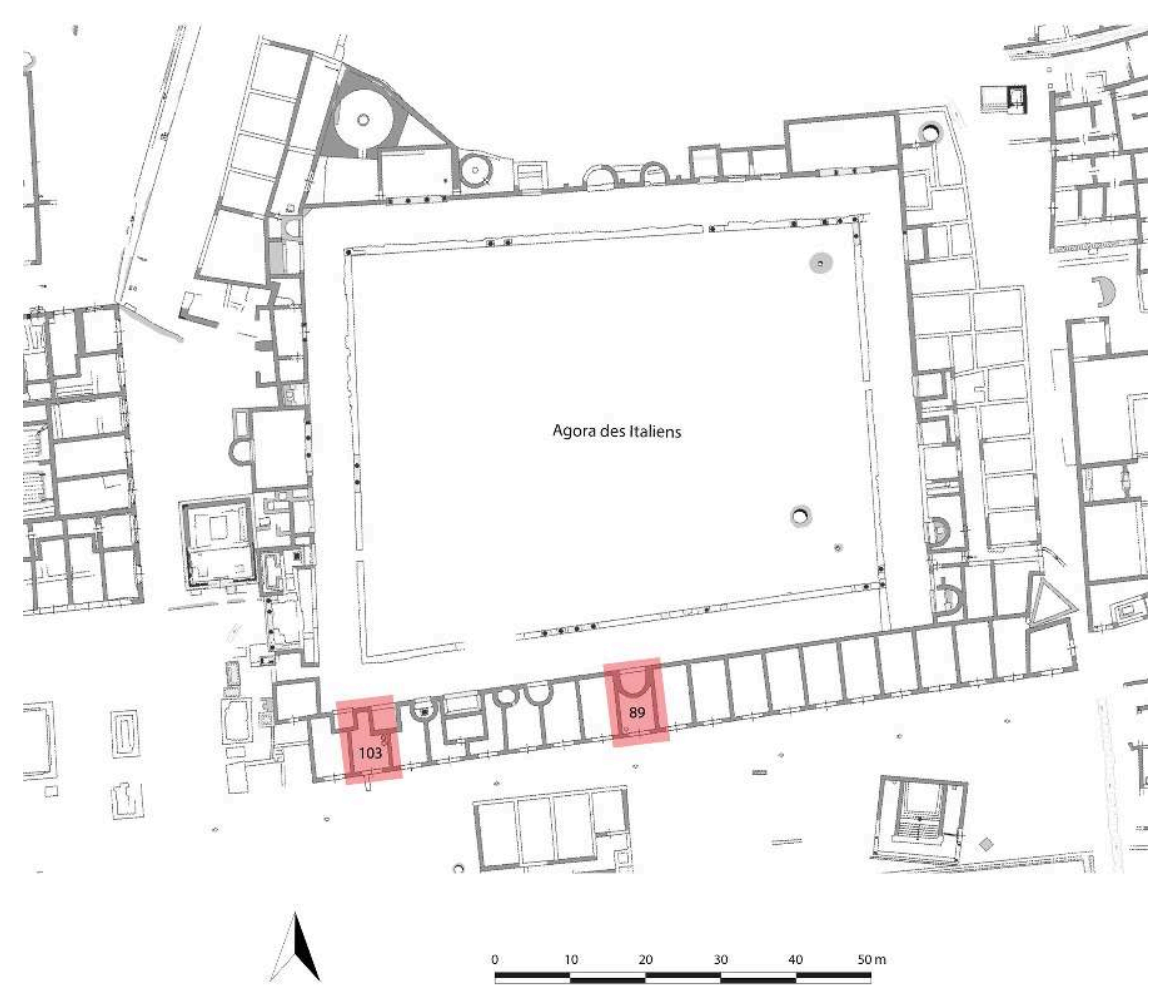

D’après https://sig-delos.efa.gr/.

Fig. 26. Les deux récipients en marbre blanc dans l'angle nord-est de la boutique 103.

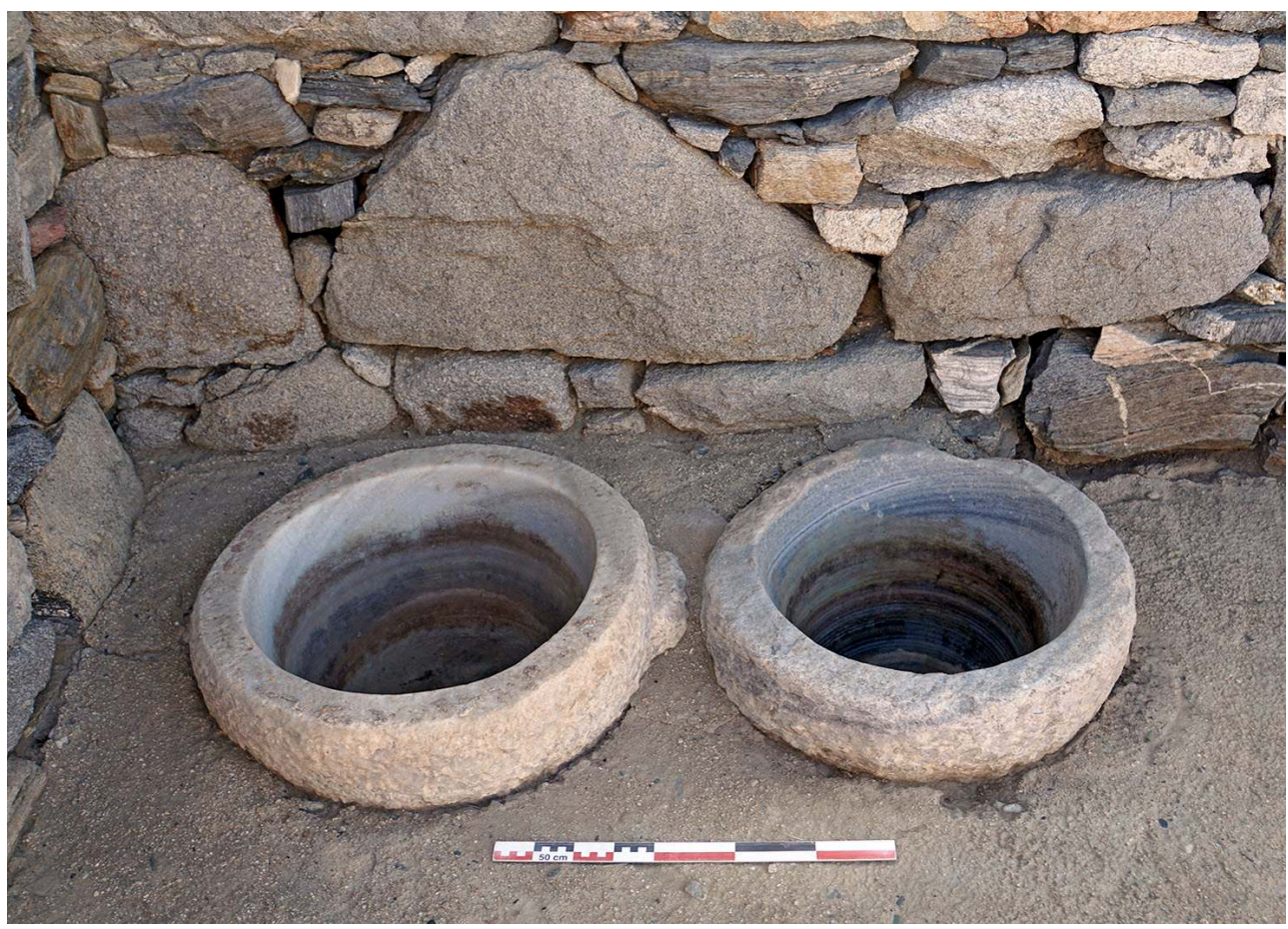

Vue de l'ouest.

Cliché E. Le Quéré / EFA. 
Fig. 27. Traces de mortier de tuileau sur le pourtour des récipients en marbre.
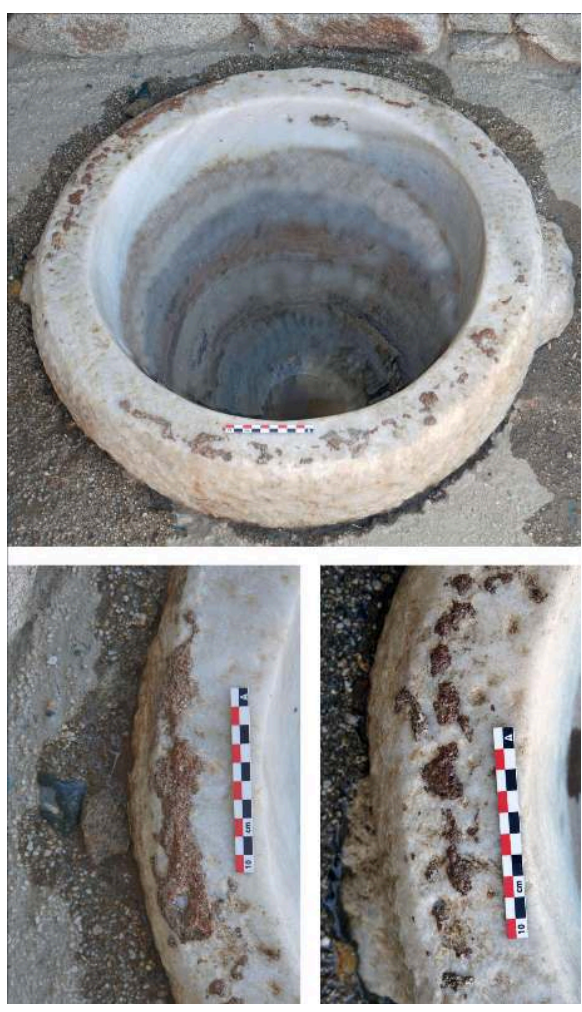

Vues du dessus.

Clichés E. Le Quéré / EFA.

P. Karvonis, à la suite de Ph. Jockey, note que ces cuves ont pu servir « au stockage de l'eau nécessaire dans un atelier de sculpture pour le travail des modèles en terre cuite et pour le refroidissement des outil $\aleph^{33}$. Cependant, plusieurs phases, et donc plusieurs fonctions, ont pu se succéder dans ou à l'emplacement de cette boutique. En effet, les arguments déployés pour l'interpréter comme un atelier de marbrier - à savoir la découverte d'une trentaine de sculptures en marbre inachevées sous une couche de poussière de marbre ${ }^{34}$ - ne prennent jamais en compte la remarque d'ordre stratigraphique avancée par É. Lapalus. Il note en effet qu'une " couche de poussière de marbre haute de 0,10 $\mathrm{m}$ » a été retrouvée dans la pièce 103, mais elle se trouvait « un peu au-dessous du niveau des fondations $»^{35}$. Si tel est bien le cas, ces déchets de travail du marbre proviendraient d'un état antérieur à la construction des boutiques, et ne seraient donc pas contemporains de l'utilisation des récipients en marbre ${ }^{36}$. Par ailleurs, le sol actuel se situe à un niveau bien inférieur à celui du seuil de la boutique, ce qui tend à démontrer que les niveaux antiques ont été surcreusés au moment des fouilles - et donc détruits -, comme le prouvent également les photographies prises en 1904 avant le dégagement complet des boutiques ${ }^{37}$. Le niveau de sol antique correspondant à l'utilisation des vasques est ainsi à restituer au niveau de la surface de ces dernières - c'est-à-dire là où des traces de mortier de tuileau ont été observées -, et non $0,20 \mathrm{~m}$ en dessous, comme cela est le cas actuellement. En dépit de ces remarques, en l'état actuel de notre documentation, il n'est guère possible d'assigner à ces vasques une fonction précise.

Enfin, l'installation des récipients en marbre date très probablement de l'une des dernières phases d'aménagement de la boutique. En effet, l'exèdre $n^{\circ} 102$, construite 
dans un deuxième temps sur l'Agora des Italiens, est venue empiéter sur le mur de fond de la boutique, redéfinissant ainsi l'espace de la pièce en réduisant sa surface et en créant un angle dans lequel les vasques ont été installées ${ }^{38}$. Le début du $\mathrm{I}^{\mathrm{er}} \mathrm{s}$. av. J.-C. apparaîtrait alors comme un terminus post quem pour la mise en place d'une activité de production en rapport avec ces récipients.

\section{La boutique 89}

Un peu plus à l'est, la pièce $\mathrm{n}^{\circ} 89$ présente quant à elle un aménagement différent. Là encore, l'intégralité de son sol a été cimentée lors de travaux de restauration, ce qui limite fortement les possibilités d'observation et d'interprétation. Seule subsiste à l'entrée, dans l'angle sud-ouest, une vasque céramique, de forme concave (fig. 28). Ses caractéristiques morphologiques et ses dimensions (diam. int $0,44 \mathrm{~m}$; prof. $0,45 \mathrm{~m}$ ) sont très proches de celles des vasques céramiques des fouleries précédemment citées. Cette vasque était entourée d'un épais sol en béton de tuileau, comportant des inclusions de tessons céramiques, là encore de dimensions importantes (jusqu'à $0,12 \mathrm{~m}$ de longueur) (fig. 29). Il n'en reste aujourd'hui des vestiges qu'au sud et à l'ouest, mais il entourait à l'origine tout le récipient, comme en témoignent la description d'é. Lapalus en $1939^{39} \mathrm{et}$ les traces de mortier de tuileau encore visibles sur ses rebords au nord et à l'est (fig. 29). Ce sol ainsi rendu étanche, appuyé sur les premières assises des murs ouest et sud, formait un pendage d'environ 45 degrés autour de la vasque : la déclivité ainsi créée permettait de faire retomber dans le récipient le liquide utilisé lors de l'utilisation de ce dernier.

Fig. 28. Vasque en terre cuite à l'angle sud-ouest de la boutique 89.

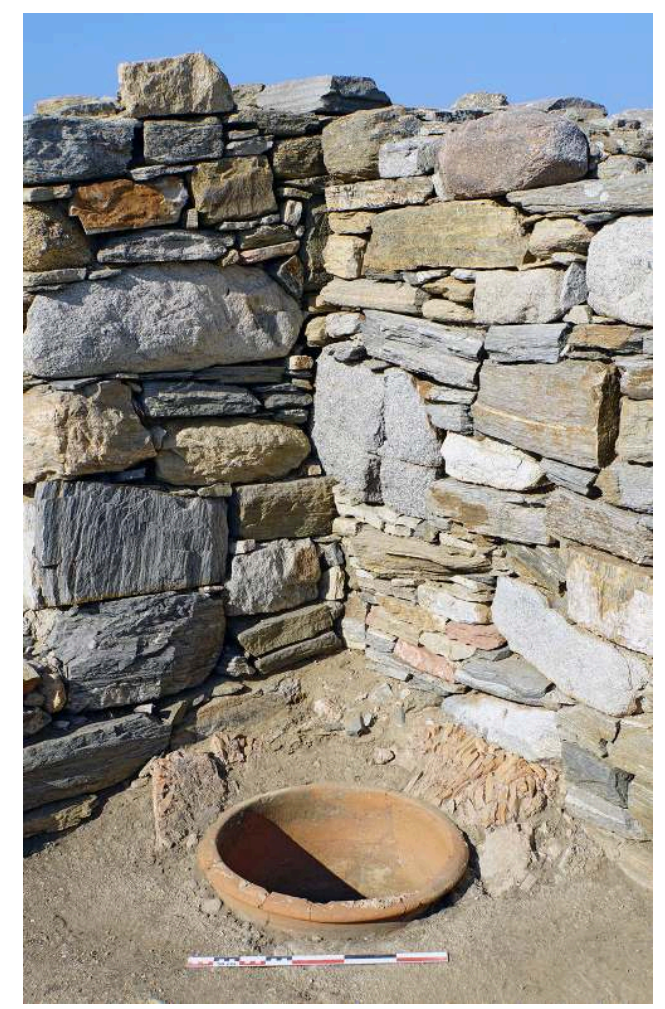

Vue du nord-est.

Cliché E. Le Quéré / EFA. 
Fig. 29. Béton de tuileau entourant le récipient en terre cuite et traces de mortier de tuileau sur son pourtour.
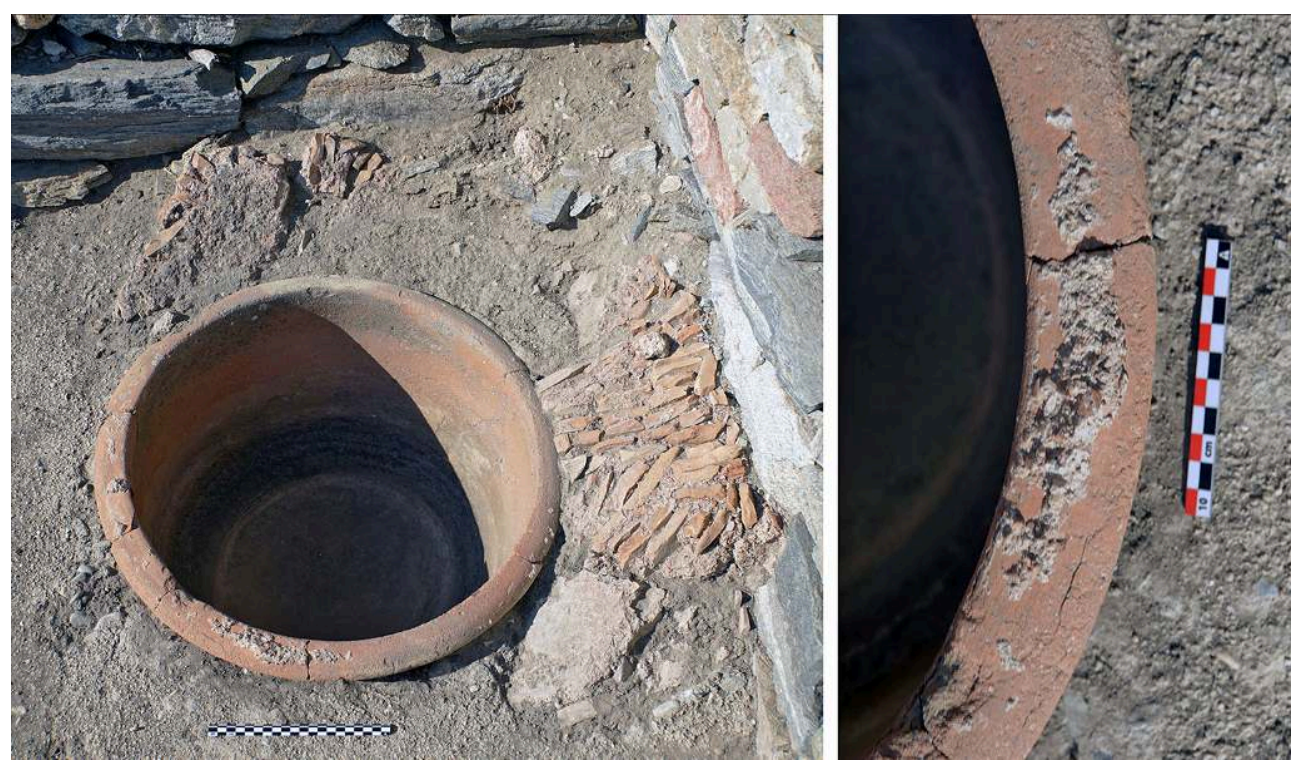

Vue du nord et détail.

Clichés E. Le Quéré / EFA.

Là encore, le sol actuel se trouve à un niveau bien inférieur à celui du seuil de la boutique, ce qui ne permet pas de restituer le niveau de circulation au moment de l'utilisation de la vasque. Par ailleurs, aucune trace de revêtement ne subsiste sur les parois des murs de la pièce et aucun autre élément n'est conservé sur place : toute observation ou interprétation est de ce fait rendue difficile. Les similitudes que cette structure présente avec certaines des vasques précédemment décrites pourraient éventuellement conduire à y voir une stalle de foulerie, mais les éléments sont bien maigres pour pouvoir l'affirmer.

\section{Une teinturerie à l'est de l'Établissement des Poséidoniastes de Bérytos}

Dans le Quartier du Lac, nous avons procédé au nettoyage et à l'étude de quatre pièces ( ${ }^{\text {os }} 1-2$ et 4-5) situées au sud-est de l'Établissement des Poséidoniastes (GD 57) (fig. 30-31 $)^{40}$. Dégagées par P. Chatzidakis dans les années $1990^{41}$, les pièces $\mathrm{n}^{\mathrm{os}} 1$ à 3 , disposées en enfilade, sont situées au croisement de deux rues et n'étaient accessibles que depuis la rue à l'est, depuis la pièce $\mathrm{n}^{\circ} 1$. 
Fig. 30. Emplacement des quatre pièces étudiées au sud-est de l'Établissement des Poséidoniastes.

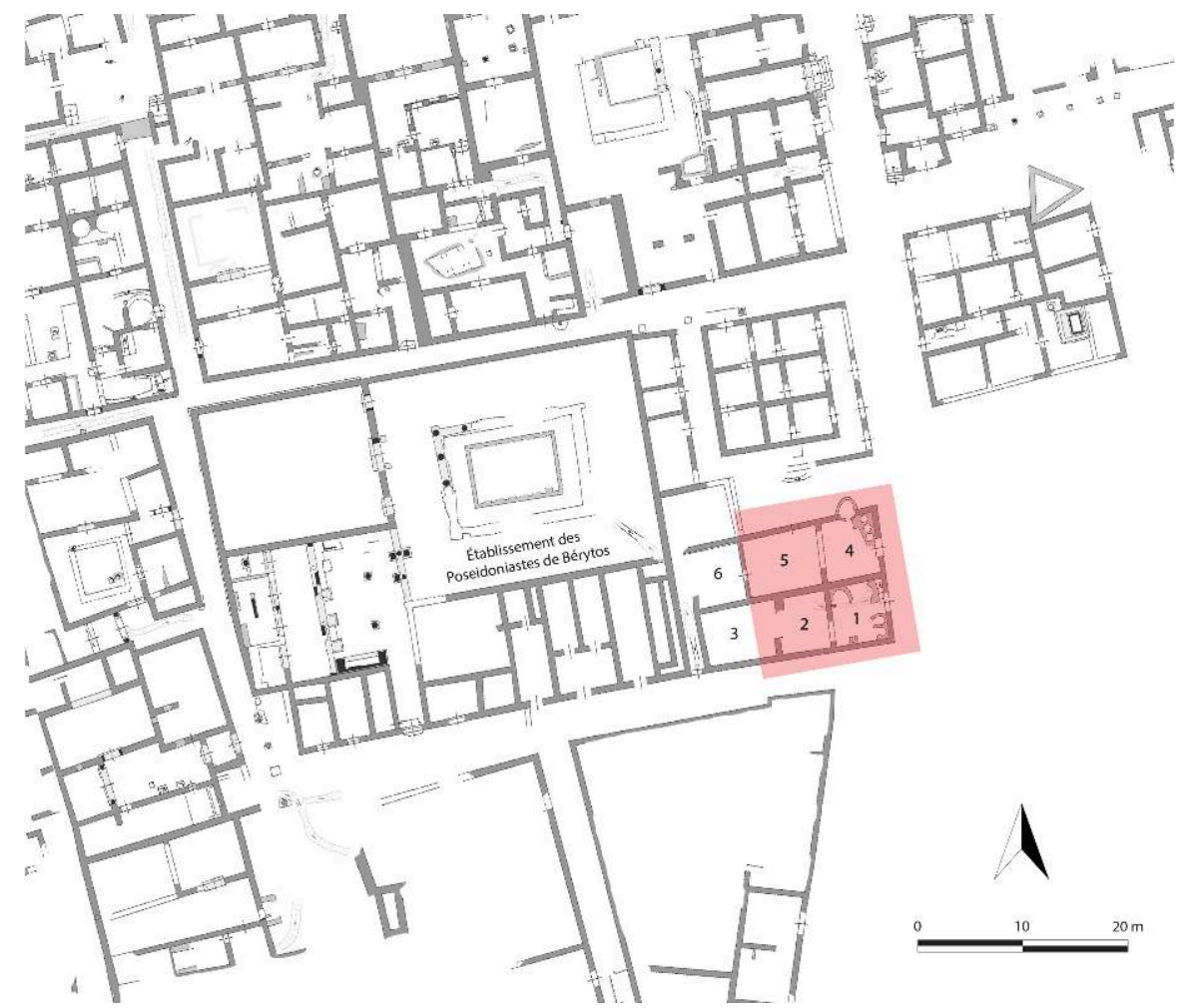

D’après https://sig-delos.efa.gr/. 
Fig. 31. Plan général des quatre pièces étudiées au sud-est de l'Établissement des Poséidoniastes.

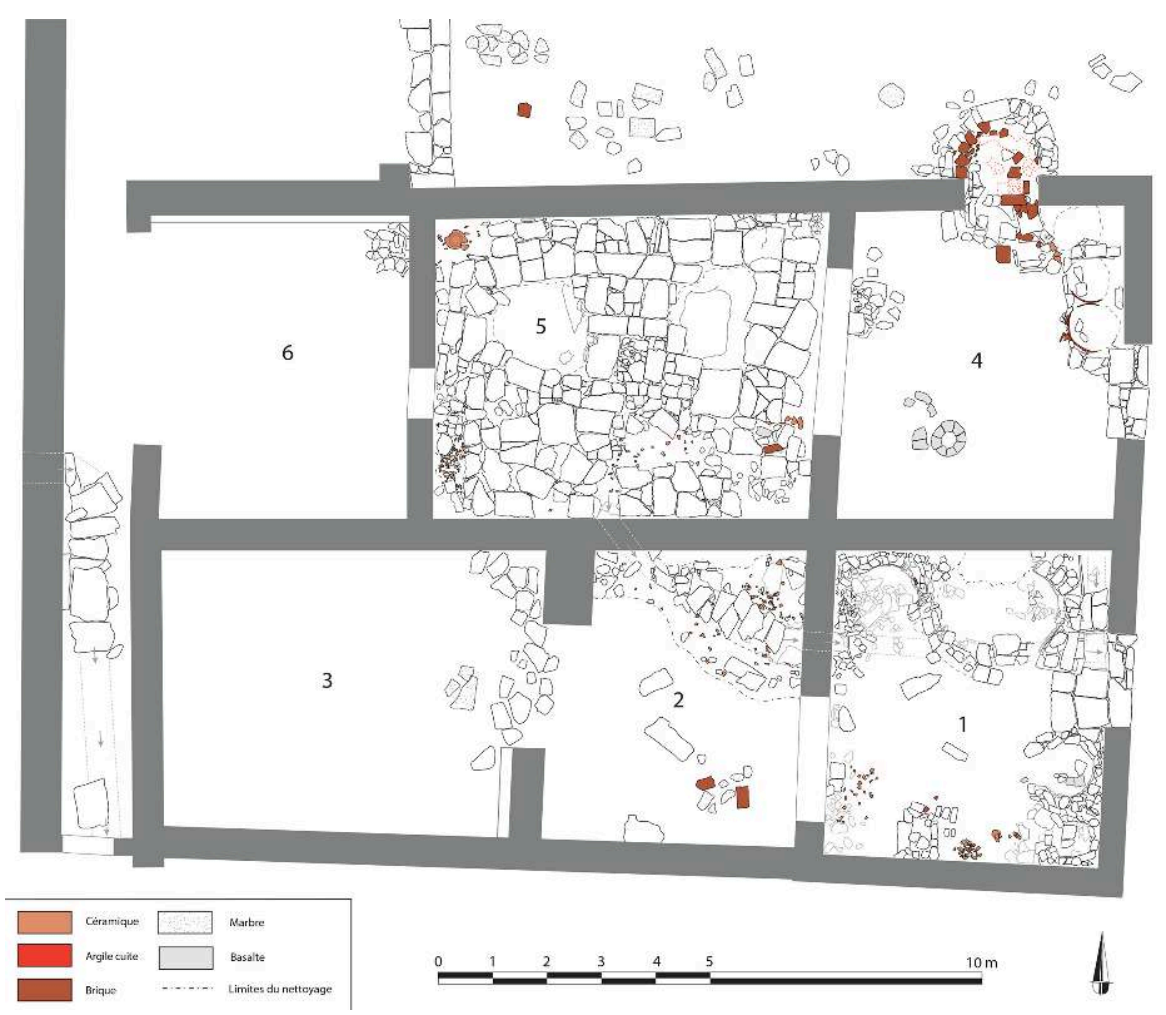

Échelle : 1/100.

Relevé, dessin E. Le Quéré / EFA.

\section{La pièce $n^{0} 1$}

39 À l'entrée de cette dernière se trouve un dallage de gneiss, tandis que le reste du local pourrait avoir été en terre battue (fig. 32). Dans l'angle sud-est de la pièce, deux aménagements circulaires en moellons de gneiss, de 1,00 $\mathrm{m}$ de diamètre, aux parois d'environ 0,10 $\mathrm{m}$ d'épaisseur, sont appuyés contre les murs sud et est. Celui situé dans l'angle est très endommagée, la plupart des blocs s'étant effondrés. Les parois internes de ces deux constructions sont rougies par l'action du feu. Tout porte à croire que nous sommes donc en présence de deux fourneaux ou de deux chaudières, dont les ouvertures étaient situées à l'ouest. 
Fig. 32. Plan de la teinturerie située dans la pièce $n^{\circ} 1$, au sud-est de l'Établissement des Poséidoniastes.

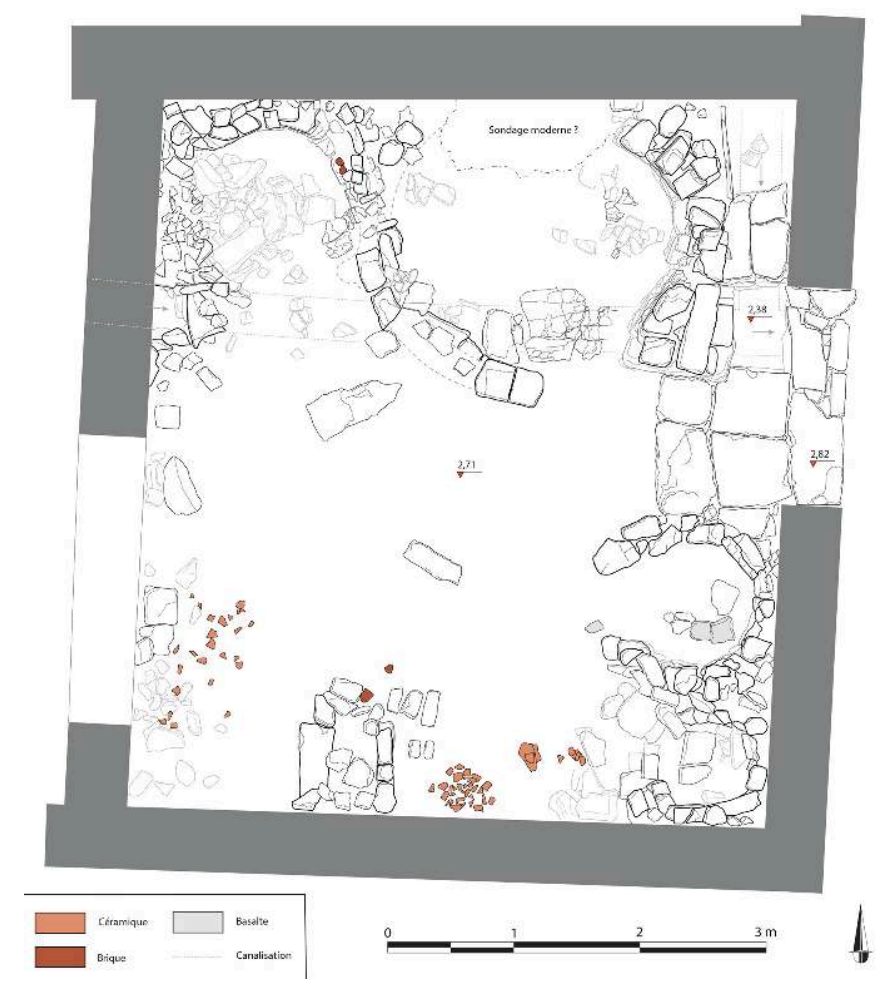

Échelle : $1 / 40$.

Relevé, dessin E. Le Quéré / EFA.

De l'autre côté de la pièce, deux autres constructions circulaires beaucoup plus massives, également construites en moellons de gneiss d'environ 0,15 m d'épaisseur, sont appuyées contre les murs nord et ouest de la pièce. Le diamètre de celle située à l'angle nord-ouest est restituable ( $c a .1,20 \mathrm{~m})$, ainsi que sa hauteur maximale conservée $(c a .0,80 \mathrm{~m})$, mais les blocs sont à présent complètement effondrés. De l'autre construction circulaire, il ne reste plus qu'un arc de cercle à l'est (diam. restitué ca. $1,70 \mathrm{~m}$ ), le reste ayant déjà été détruit dans l'Antiquité, ou peut-être lors des fouilles, car un sondage semble avoir été ouvert à cet emplacement, contre le mur nord. Là encore, les parois internes de ces constructions sont rougies sous l'action du feu : il s'agirait de deux grands fourneaux, dont les ouvertures étaient situées au sud. Dans l'angle nord-est de la pièce, un étroit passage de 0,50 $\mathrm{m}$ de large est aménagé entre la construction centrale et le mur est, revêtu de dalles de gneiss situées au-dessus du niveau du sol: on peut éventuellement restituer ici une ou deux marches, permettant d'accéder plus facilement à cet aménagement.

Il faut très probablement reconnaître dans ces installations la présence d'un atelier de teinturerie, en restituant dans les petits et grands fourneaux des cuves en métal, aujourd'hui disparues, permettant de réaliser les différentes opérations de teintures. Les parallèles pompéiens montrent que les plus grands ateliers, à savoir les teintureries de grand teint, disposent toujours d'une chaudière de taille supérieure, servant au mordançage, éventuellement d'une seconde grande chaudière destinée à des teintures par fermentation, ainsi que de deux ou trois autres chaudières de taille plus réduite et regroupées, servant à la teinture de petit teint ${ }^{42}$. Les aménagements de l'atelier de Délos 
concorderaient ainsi sensiblement avec ceux de Pompéi, tout en soulignant que la plus grande des «cuves » de la pièce $\mathrm{n}^{\circ} 1$, qui aurait servi au mordançage, est relativement plus grande que les plus grands exemples pompéiens, dont le diamètre maximal est de $1,23 \mathrm{~m}$.

En l'état actuel de la documentation, il est bien difficile d'aller au-delà de ces quelques hypothèses. Il faudrait pour cela véritablement fouiller ces différentes pièces : en effet, les travaux réalisés par $\mathrm{P}$. Chatzidakis ont essentiellement consisté à déblayer l'amoncellement de remblais provenant du dégagement de l'Établissement des Poséidoniastes de Bérytos.

\section{La pièce $n^{\circ} 2$}

Dans la pièce $\mathrm{n}^{\circ} 2$, nous nous sommes rendu compte que seule la canalisation avait été dégagée lors des travaux de $\mathrm{P}$. Chatzidakis, le reste de la pièce n'ayant encore pas fait l'objet d'une fouille. Nous nous sommes donc contentés de nettoyer cette canalisation, recouverte de dalles de gneiss (fig. 33). Partant de la pièce $n^{\circ} 4$, elle passe sous le mur nord de la pièce $n^{\circ} 2$, se dirige en diagonale vers le mur est, passe en dessous par l'intermédiaire d'une évacuation aménagée dans le mur, et continue sa trajectoire dans la pièce $\mathrm{n}^{0} 1$ pour ensuite se déverser dans l'égout de la rue à l'est. Un bras secondaire de cette canalisation, partiellement couvert de dalles de gneiss, longe le mur oriental avant de rejoindre le bras principal ${ }^{43}$.

Fig. 33. La canalisation de la pièce $n^{\circ} 2$, recouverte de grandes dalles de gneiss.

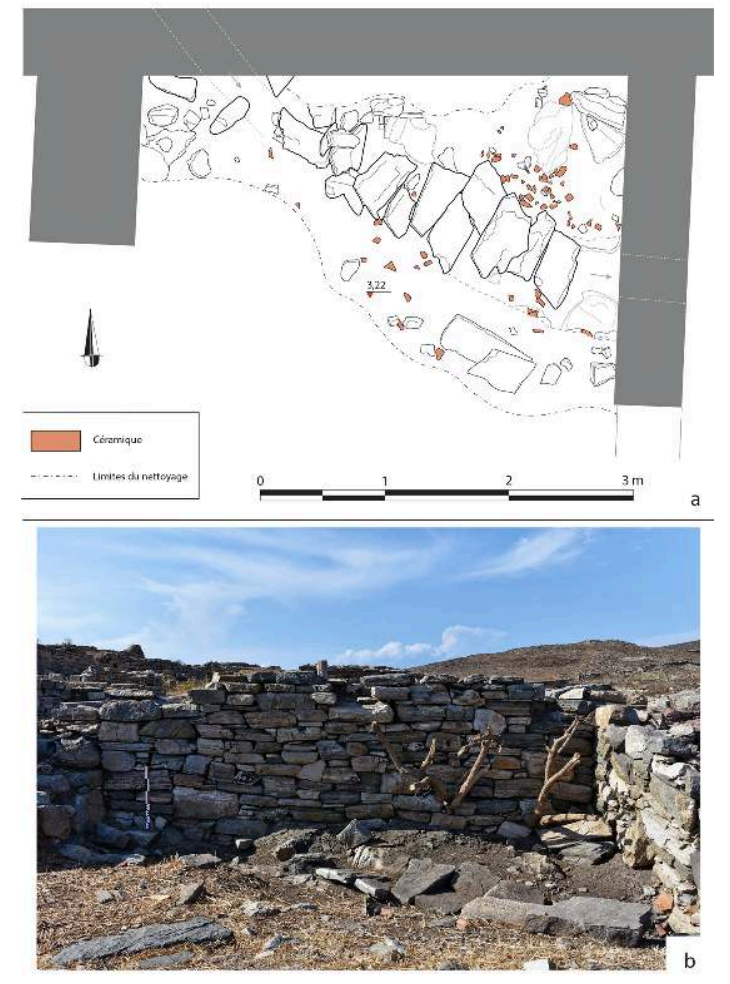

A. Plan. Échelle : $1 / 40$; B. Vue du sud.

Relevé, dessin E. Le Quéré / EFA ; Cliché N. Monteix / EFA. 


\section{Les espaces urbains liés à la production alimentaire}

\section{Les meuneries-boulangeries de l'édifice commercial au nord du Lac}

Pour appréhender les espaces urbains liés à la production alimentaire, nous avons entrepris l'étude de quatre pièces situées à l'angle nord-est et à l'ouest (fig. 34, $\mathrm{n}^{\mathrm{os}} 1,2$, 4 et 34) de l'édifice commercial se trouvant immédiatement au nord du Lac (GD 56), abritant des espaces liés aux activités de meunerie et de boulangerie ${ }^{44}$.

Fig. 34. Emplacement des quatre pièces étudiées dans l'édifice commercial au nord du Lac.

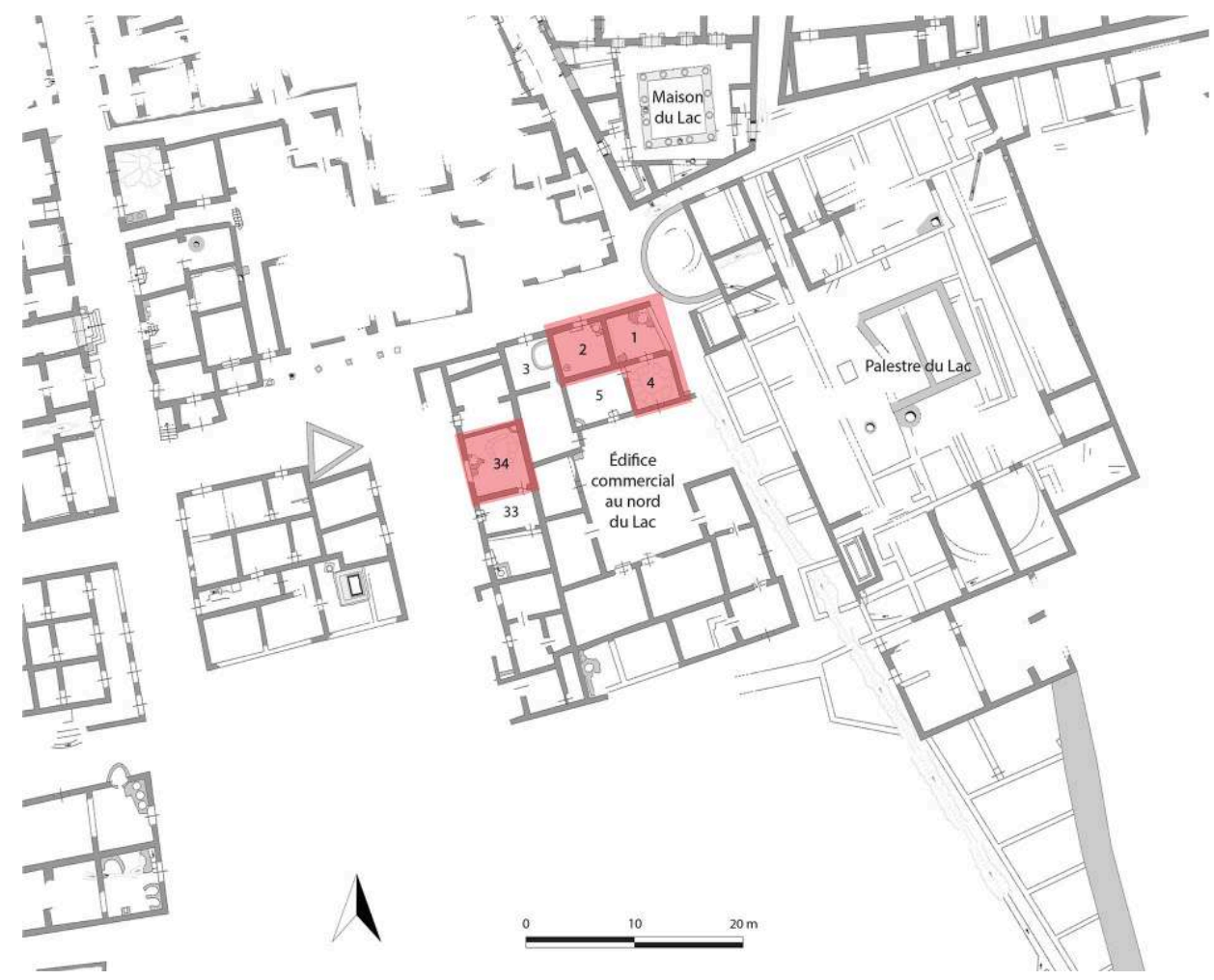

D’après https://sig-delos.efa.gr/

\section{La pièce $\mathrm{n}^{\circ} 2$ : une boulangerie}

Dans l'édifice commercial au nord du Lac, la pièce $\mathrm{n}^{\circ} 2$ est isolée : on y accédait depuis la rue passant au nord de l'édifice (fig. 35). Cette pièce fut fouillée jusqu'au sol de terre battue, désormais recouvert d'une couche d'abandon moderne. Peu d'éléments sont conservés sur place, ce qui rend toute observation ou interprétation difficile. 
Fig. 35. Plan de la pièce $n^{\circ} 2$, au nord de l'édifice commercial.

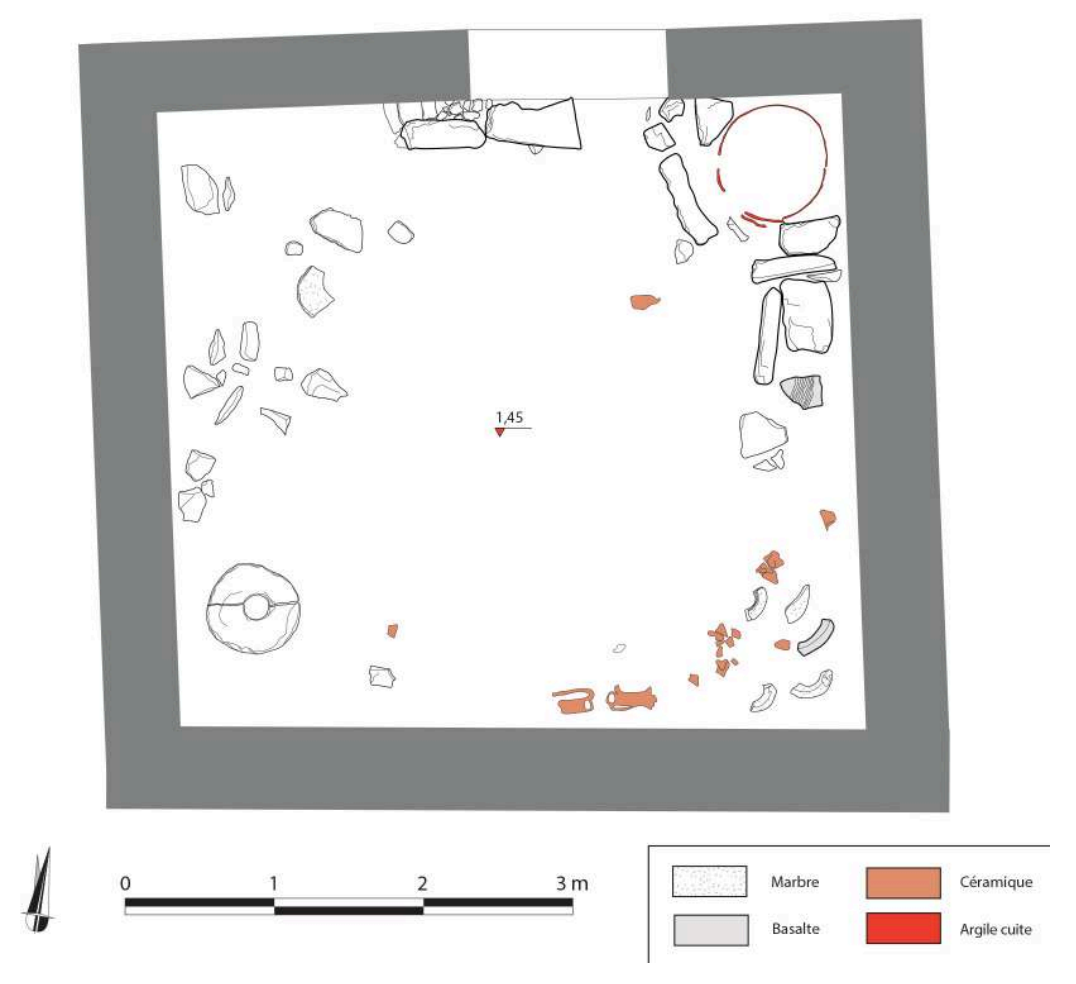

Échelle : 1/50.

Relevé, dessin E. Le Quéré / EFA.

Seule une construction est remarquable : dans l'angle nord-est de la pièce, le nettoyage a mis en évidence de fines parois d'argile cuite de 1 à $2 \mathrm{~cm}$ d'épaisseur, formant un cercle de $0,72 \mathrm{~m}$ de diamètre. Ces parois sont appliquées sur une construction en terre, elle-même entourée de petits murets en moellons de gneiss sur ses côtés ouest et sud, et directement appuyée contre les murs nord et est de la pièce (fig. 36). En raison de la grande fragilité et friabilité de la terre cuite, nous n'avons pas nettoyé cet aménagement jusqu'au fond, de manière à ne pas mettre en péril sa conservation. Néanmoins, des clichés pris par P. Chatzidakis au moment des fouilles permettent d'identifier des parois circulaires en argile cuite, reposant sur un sol à fond légèrement concave, en terre. Contrairement à ce qui est généralement avancé, il ne s'agit pas là d'un pithos: les parois en terre cuite sont beaucoup trop fines pour être associées à un vase de stockage. On reconnaîtra plutôt un four de type klibanos - tannur ou taboun dans les exemples ethnologiques ${ }^{45}$. Vraisemblablement très courants mais rarement reconnus et publiés ${ }^{46}$, il s'agit de fours à air chaud dont la sole est verticale car constituée par les parois internes: la pâte à cuire est plaquée sur la paroi de terre préalablement chauffée par un foyer situé sur le fond du four ${ }^{47}$. 
Fig. 36. Le four (klibanos) dans l'angle nord-est de la pièce $n^{\circ} 2$.

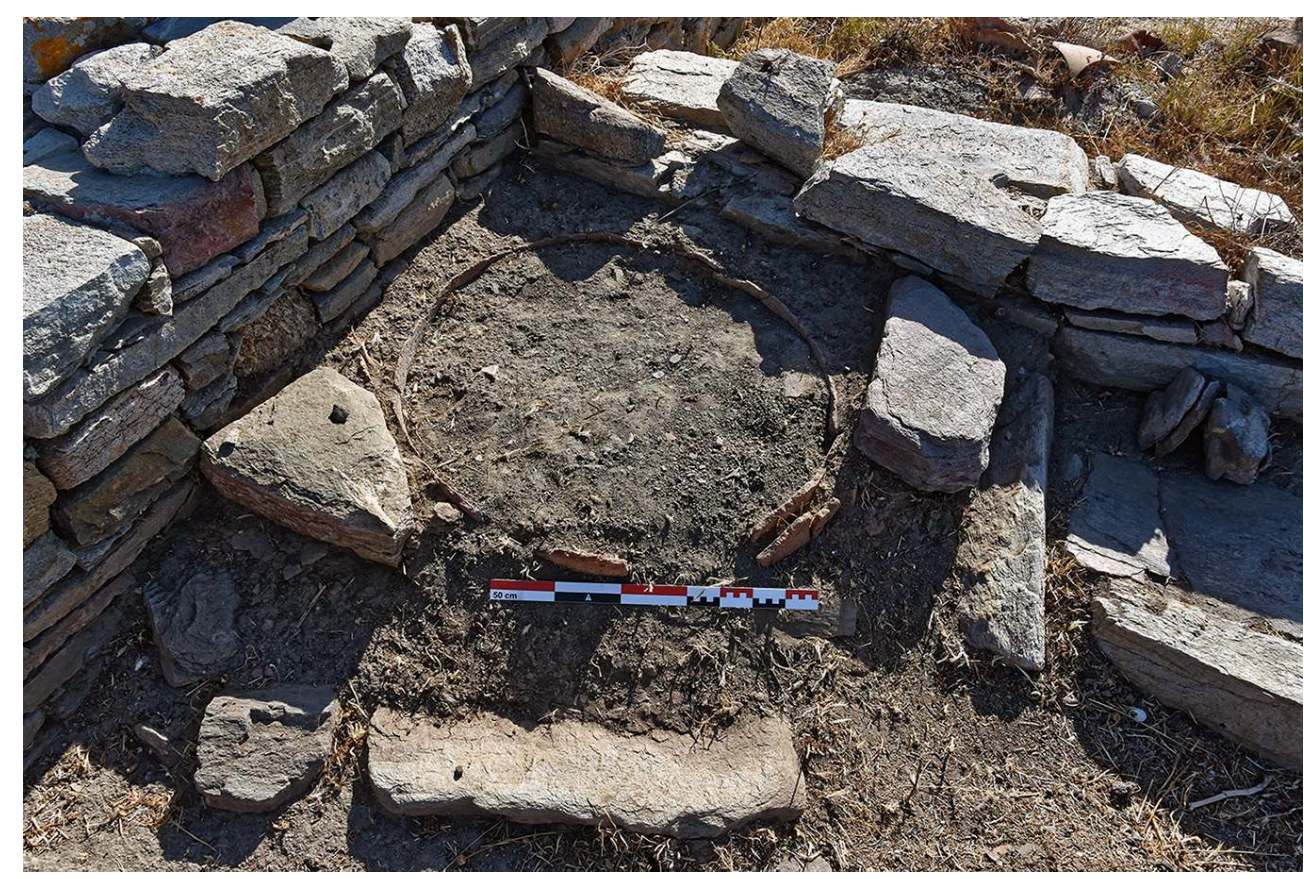

Vue du sud-ouest.

Cliché E. Le Quéré / EFA.

47 Un détail intéressant a été observé : dans l'angle sud-ouest du klibanos, on remarque deux parois différentes en argile cuite. Cela est probablement à mettre sur le compte de la réalisation rapide de ce type de fours : une armature en terre était préalablement réalisée, sur laquelle on appliquait une couche relativement fine d'argile crue qui séchait et cuisait pendant la cuisson des pains. Des réparations pouvaient être effectuées assez rapidement en appliquant une nouvelle couche de terre crue sur tout ou partie de la paroi endommagée.

Dans l'angle sud-ouest de la pièce, un anneau en gneiss (diam. ext. 0,60 m; diam. int. $0,16 \mathrm{~m}$ ) d'une épaisseur de $2 \mathrm{~cm}$, aujourd'hui brisé en deux, est déposé sur le sol (fig. 37). Si, en l'état actuel de la documentation, il est difficile d'en comprendre la fonction, il ne faut pas écarter l'hypothèse qu'il s'agisse d'une crapaudine permettant l'installation d'un moulin, éventuellement de type délien. De même, dans l'angle sudest de la pièce, plusieurs fragments de pierre, de marbre et de basalte en forme d'arcs de cercle gisent sur le sol. Certains pourraient provenir de meules, de moulins ou de pétrins, mais là encore, aucune interprétation ne peut être avancée quant à leur présence en cet endroit. Pour l'heure, sous réserve de consultation de la documentation antérieure, voire de procéder à un nettoyage plus en profondeur, nous considérerons que cet espace abritait donc au moins une boulangerie. 
Fig. 37. Anneau en gneiss posé sur le sol, dans l'angle sud-ouest de la pièce $n^{\circ} 2$.

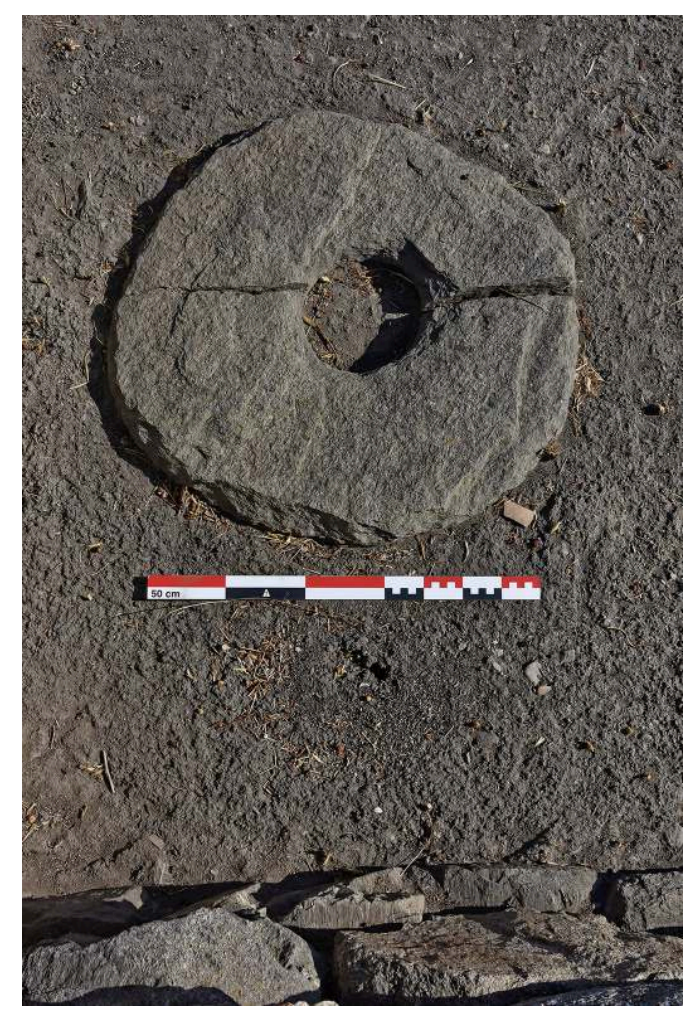

Vue du sud.

Cliché N. Monteix / EFA.

\section{Les pièces $n^{\text {os }} 1,4$ et $5:$ une meunerie-boulangerie}

$49 \mathrm{Au}$ nord-est de l'édifice commercial, les pièces $\mathrm{n}^{\mathrm{os}} 1,4$ et 5 forment un ensemble cohérent (fig. 34). Depuis la grande cour centrale, on accédait d'abord à la pièce $n^{\circ} 5$ par une entrée située au milieu de son mur sud. Cette pièce communiquait avec la pièce $\mathrm{n}^{\circ} 4$ par un passage aménagé dans son angle nord-est. On accédait ensuite à la pièce $n^{\circ} 1$ par une porte ouverte dans le mur nord de la pièce $n^{\circ} 4$. Les pièces $n^{\text {os }} 1$ et 4 n'étaient pas, semble-t-il, accessibles depuis la rue. La pièce $n^{\circ} 4$ avait possédé une ouverture qui donnait directement sur la grande cour au sud, mais elle fut par la suite murée.

Dans la pièce $\mathrm{n}^{\circ} 1$, le nettoyage ne fut pas aisé, en raison de la présence de nombreuses amphores encore in situ, gisant çà et là sur le sol, dans un piètre état de conservation, et qui risquaient d'être endommagées si nous tentions de les étudier (fig. 38). Nous avons donc décidé de limiter notre nettoyage au seul angle nord-est de cette pièce, où ont été observés les restes d'un autre klibanos, tout à fait similaire à celui précédemment décrit, même si d'un diamètre légèrement supérieur $(0,86 \mathrm{~m})$, et que nous n'avons pas vidé pour les mêmes raisons liées à sa conservation. 
Fig. 38. Plan de la pièce $n^{\circ} 1$ de l'édifice commercial.

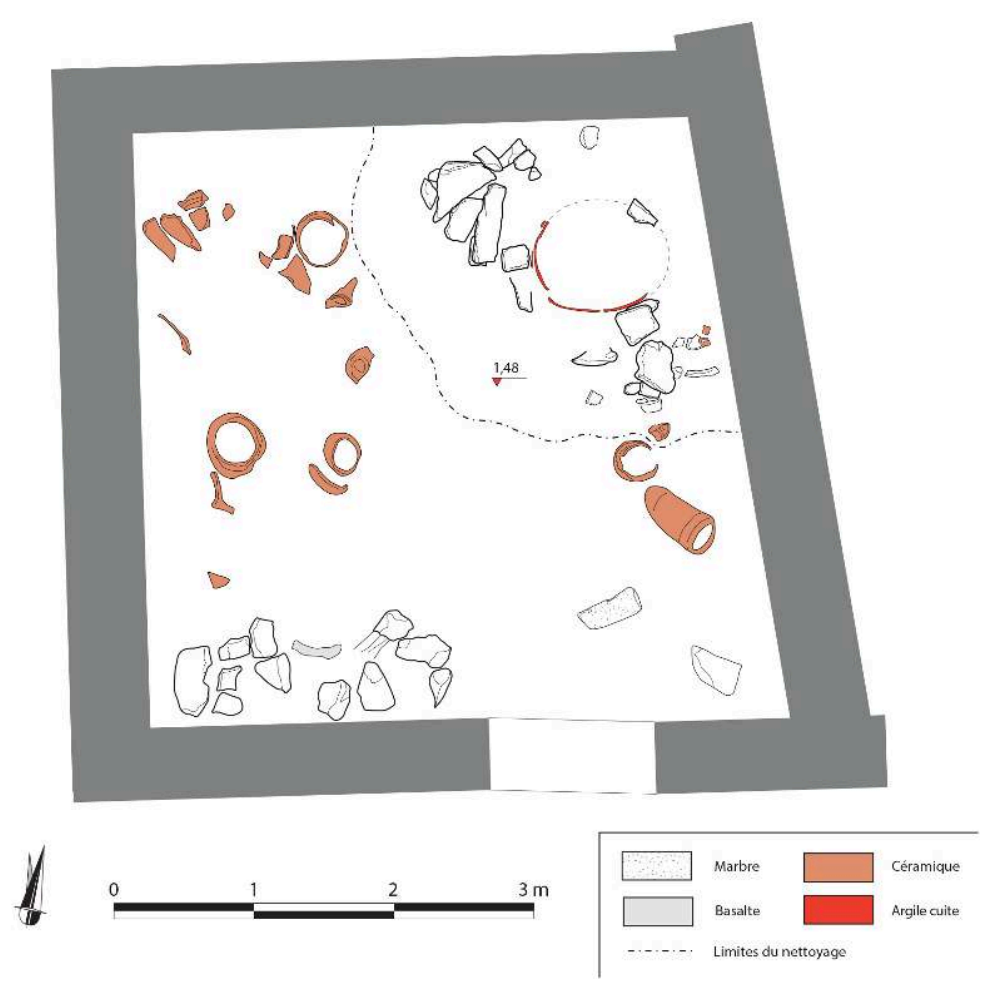

Échelle : $1 / 50$.

Relevé, dessin E. Le Quéré / EFA.

51 Immédiatement au sud de la pièce $n^{\circ} 1$, et communiquant avec elle, se situe la pièce $\mathrm{n}^{\circ} 4$. Elle est entièrement occupée par un dallage de gneiss en forme de grand anneau (diam. ext. ca. 3,56 m; diam. int. ca. 2,00 m), installation attestée dans de nombreux locaux à Délos et indiquant l'emplacement d'un moulin rotatif (fig. 39) ${ }^{48}$. Cela porte à croire qu'il s'agit d'une meunerie, en dépit de l'absence de restes des éléments constituant une meule.

52 Par ailleurs, dans l'angle nord-est de la pièce gît une amphore cnidienne, qui devait être complète au moment de sa découverte, mais qui est aujourd'hui brisée en plusieurs fragments. Dans l'angle sud-est, trois amphores, collées les unes contre les autres, sont enfoncées verticalement dans le sol. On ne peut pour l'instant déterminer si elles sont à mettre en rapport avec le fonctionnement de la meunerie ou si elles étaient destinées à un autre usage. 
Fig. 39. Plan de la meunerie située dans la pièce $n^{\circ} 4$ de l'édifice commercial.

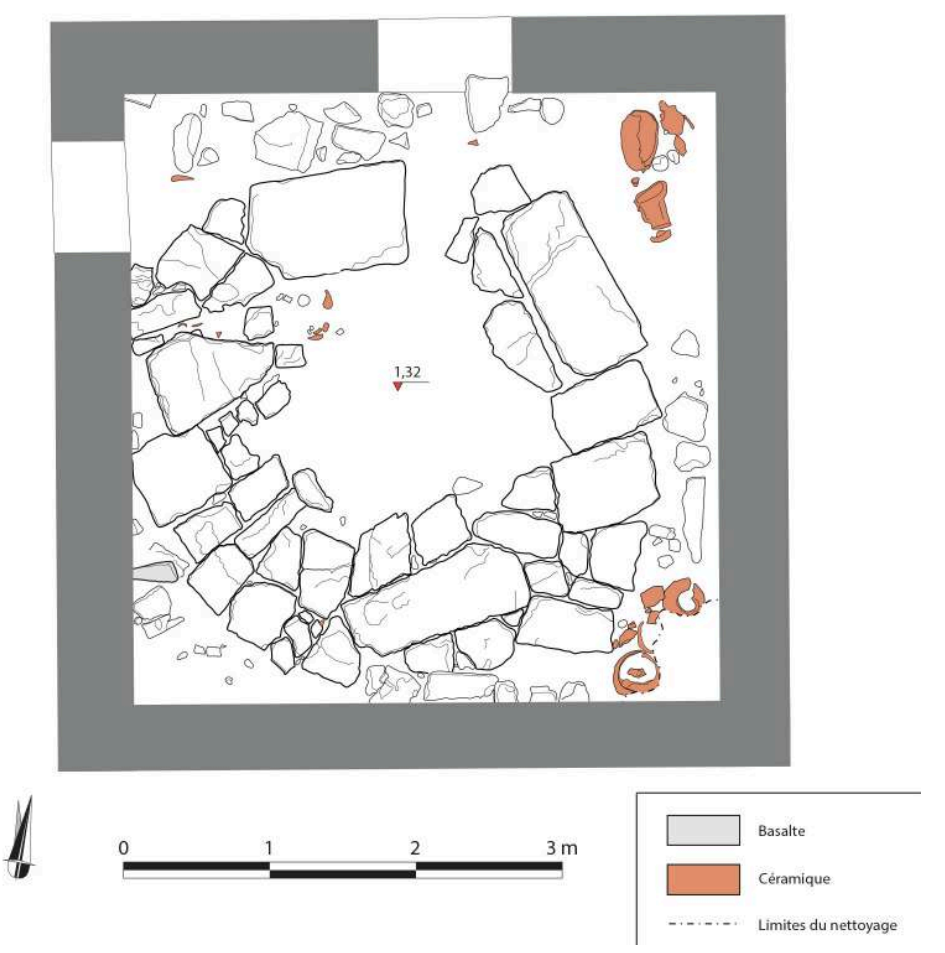

Relevé, dessin E. Le Quéré / EFA.

\section{La pièce $n^{\circ} 34$ : une autre meunerie-boulangerie}

Dans la pièce $n^{\circ} 34$, le nettoyage fut relativement aisé car son sol a été presque entièrement cimenté lors de travaux de restauration, à l'exception de trois structures, qui ont fait l'objet de notre étude. Cette pièce ne possédait pas, tout du moins dans un premier temps, d'ouverture sur la rue - la brèche située au milieu de son mur occidental ne semble avoir été créée que par un effondrement du mur. On y accédait depuis la pièce adjacente sud ( $\left.n^{\circ} 33\right)$, par une porte située dans son angle sud-est (fig. 40). 
Fig. 40. Plan de la meunerie-boulangerie située dans la pièce $n^{\circ} 34$ de l'édifice commercial.

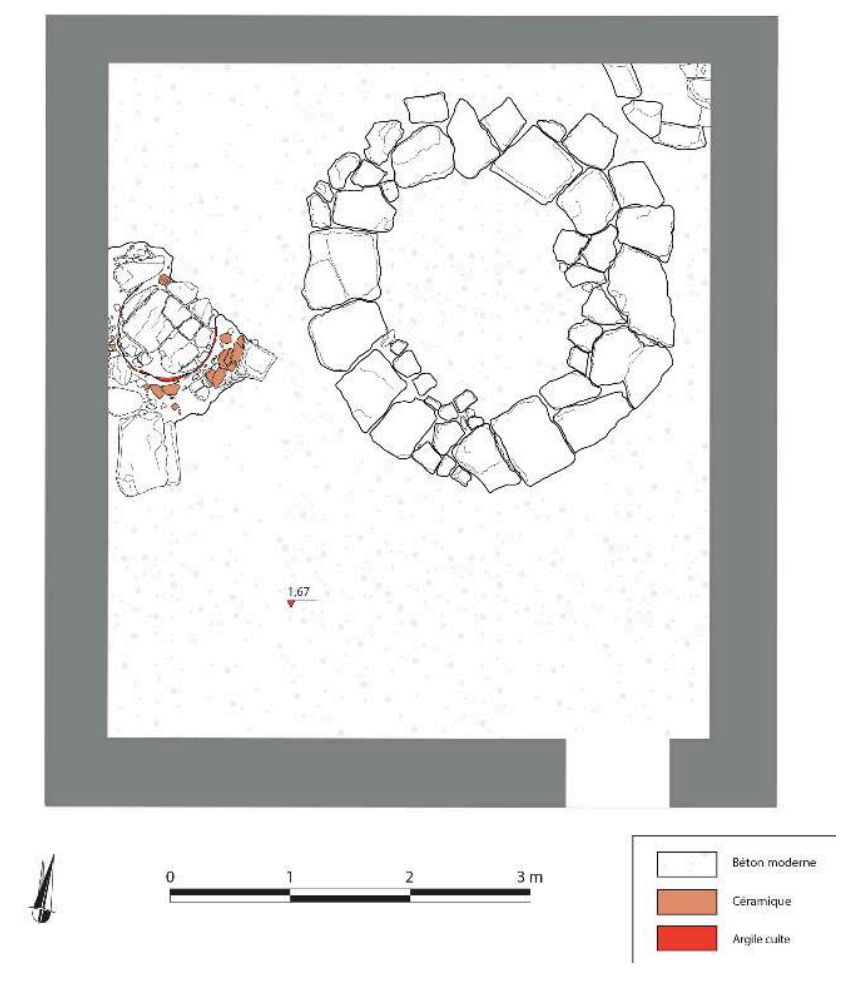

Échelle : 1/50.

Relevé, dessin E. Le Quéré / EFA.

54 Le quart nord-est de la pièce est là encore occupé par un dallage de gneiss en forme d'anneau, plus petit néanmoins que celui de la pièce $n^{\circ} 4$ (diam. ext. 3,08 $\mathrm{m}$; diam. int. ca. $1,74 \mathrm{~m}$ ), indiquant probablement que nous sommes de nouveau en présence d'une meunerie. La deuxième installation conservée est un aménagement circulaire qui vient s'appuyer contre le mur occidental de la pièce. Son sol, situé au même niveau que le sol aujourd'hui cimenté et que le dallage du moulin, est composé d'un cercle de 0,82 $\mathrm{m}$ de diamètre revêtu d'un dallage de gneiss. Tout autour, sur les trois-quarts de sa surface, s'élèvent des parois construites en terre mêlée à de petites pierres, à de petits moellons de gneiss et à de nombreux tessons d'amphores de grande dimension, la plupart roulés (fig. 41). Le quart nord-est de cette installation est en revanche vide de toute construction. Son mauvais état de conservation ne permet pas de restituer son élévation originelle; sa hauteur conservée ne dépasse pas une trentaine de centimètres. D'après ce qu'il reste in situ, il semble que cette construction ait été originellement entourée d'un muret fait en moellons de gneiss au nord et au sud, tandis qu'à l'ouest elle s'appuie directement contre le mur de la pièce. Une fine couche de terre cuite de 1 à $2 \mathrm{~cm}$ d'épaisseur est également visible sur les parois internes de la maçonnerie, dans sa partie sud et sud-est, la mieux conservée. Aussi sommes-nous là encore en présence d'une boulangerie dotée d'un klibanos, concentrant cette fois-ci dans la même pièce les activités de mouture et de cuisson. 
Fig. 41. Le four (klibanos) situé contre le mur occidental de la meunerie-boulangerie.

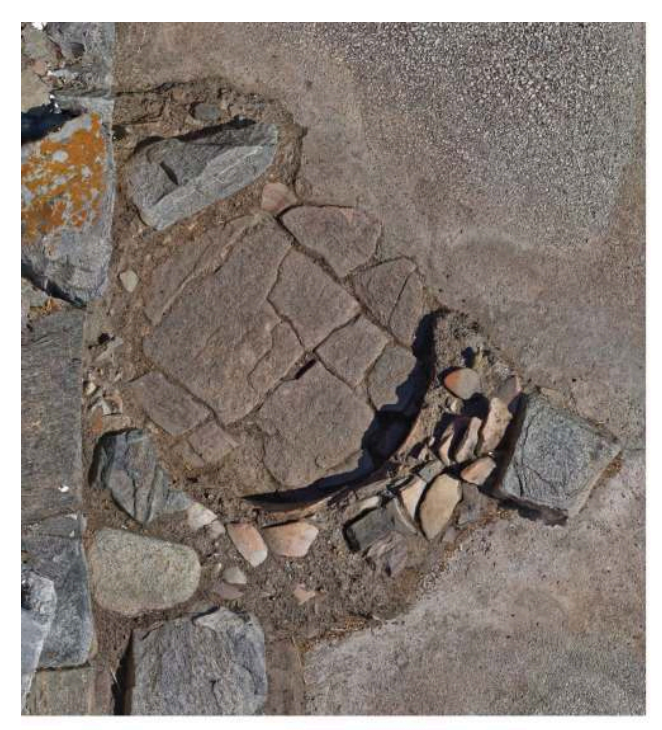

0
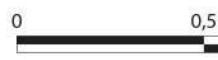

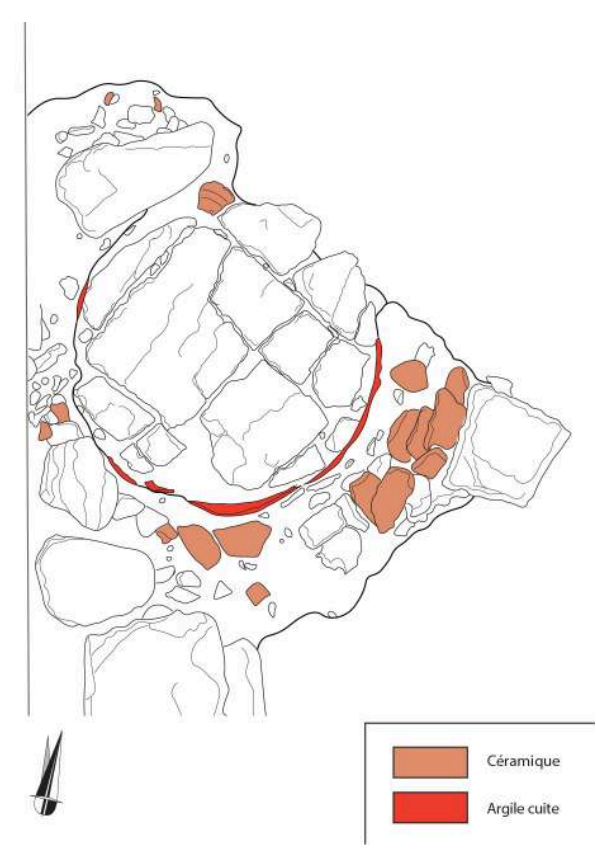

Échelle : 1/20, vue zénithale.

Orthophotogrammétrie N. Monteix ; relevé, dessin E. Le Quéré / EFA.

Enfin, dans l'angle nord-est de l'atelier, trois blocs de gneiss sont disposés en arc de cercle, fermant ainsi l'angle de la pièce. Le même type d'aménagement, mieux conservé, a été observé dans l'angle sud-ouest de la pièce $\mathrm{n}^{\circ} 5:$ un petit muret de cinq assises de moellons de gneiss (h. ca. 0,45 m) forme un arc de cercle, au-dessus duquel devait être posée la plaque de marbre aujourd'hui tombée à l'arrière du muret (fig. 42a). Tout porte à identifier ces plateformes semi-circulaires construites dans l'un des angles de ces deux ateliers à des installations pour des moulins à trémie dits " d'Olynthe ", telles qu'attestées par exemple en Israël à Gamla, Naḥal Ḥaggit ou encore Fahura (fig. 42b-c) ${ }^{49}$. Ces trouvailles prouvent qu'à Délos comme en Israël - et comme sans doute dans de nombreux autres sites de Méditerranée orientale où ces installations n'ont pas encore été identifiées comme telles - le levier des moulins à trémie pouvait aussi être fixé dans un trou du mur à l'angle d'une pièce (fig. 42d), et non arrimé à un axe vertical (en bois ou en fer?) sur une table, comme traditionnellement admis d'après la représentation qui en est faite sur le «bol mégarien " provenant de Thèbes, aujourd'hui conservé au Louvre ${ }^{50}$. Ces observations sont d'autant plus intéressantes qu'elles prouveraient que deux types de moulins - à trémie de type olynthien et rotatif de type délien -, et par conséquent deux types de moutures, pouvaient être utilisés conjointement au sein d'un même atelier (la meunerie-boulangerie $n^{\circ} 34$ et l'atelier formé par les pièces $n^{\text {os }} 1,4$ et 5). Nous approfondirons ces questions ultérieurement en reprenant l'étude à l'échelle de toutes les meuneries de l'île. 
Fig. 42. a. Muret en arc de cercle dans l'angle sud-ouest de la pièce $n^{\circ} 5$ de l'édifice commercial ; b. Moulin « d'Olynthe » trouvé in situ à Gamla ; c. Installation pour un moulin « d'Olynthe » à Fahura ; d. Restitution de l'utilisation du moulin « d'Olynthe » à Gamla.
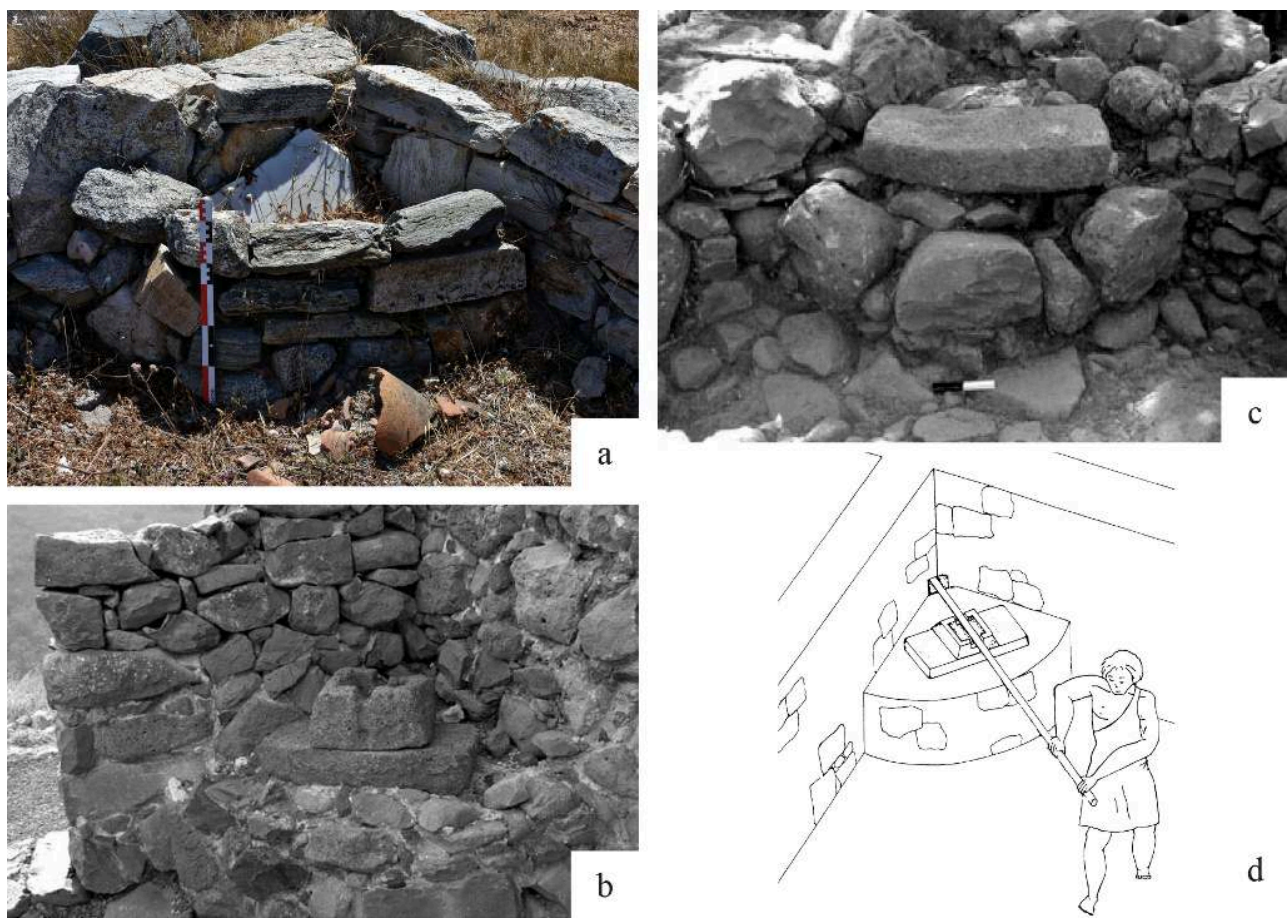

A. Vue du nord-est.

A. Cliché N. Monteix / EFA ; B. D'après frankel, syon 2016, fig. 11.6 ; c. D'après FrankEL, syon 2016, fig. 11.11 ; D. D'après FRANKEL 2003, p. 8, fig. 6.

\section{Une meunerie-boulangerie à l'est de l'Établissement des Poséidoniastes de Bérytos}

Toujours dans le Quartier du Lac, dans les ateliers situés à l'est de l'Établissement des Poséidoniastes, les pièces $\mathrm{n}^{\circ \mathrm{s}} 4$ à 6 , au nord de celles précédemment décrites, sont aussi en enfilade (fig. 30-31). On y accédait à l'est par la pièce $n^{\circ} 4$, et vraisemblablement aussi à l'ouest, par la pièce $n^{\circ} 6$, par l'intermédiaire d'une petite ruelle partant de la rue sud et longeant l'Établissement des Poséidoniastes.

Dans la pièce $\mathrm{n}^{\circ} 4$ (fig. 43), immédiatement au nord de l'entrée, le long du mur est, se trouvent deux structures circulaires qui se sont révélées être des fours de type klibanos, de $0,94 \mathrm{~m}$ de diamètre, collés l'un contre l'autre (fig. 44). De facture tout à fait similaire à ceux précédemment décrits, ils étaient entourés d'une construction en moellons de gneiss au nord, à l'ouest et au sud, et appuyés directement contre le mur est de la pièce. Pour les mêmes raisons liées à leur conservation, nous ne les avons pas nettoyés jusqu'au fond; il ne nous a donc pas été possible d'observer l'éventuelle présence à leur base d'une ouverture facilitant le tirage. Les plans restituent dans l'angle nord-est de la pièce une troisième construction circulaire d'un diamètre identique aux deux klibanoi. Or, le nettoyage n'a pas permis de mettre en évidence un troisième klibanos (absence de tout fragment de paroi verticale en argile cuite) (fig. 45). Il semble que l'on ait plutôt affaire à une fosse antique ou créée artificiellement lors des fouilles, dont on ignore, en 
l'état, la fonction, bien qu'elle ait réceptionné des fragments d'argile cuite déposés en vrac.

Fig. 43. Plan de la boulangerie située dans la pièce $n^{\circ} 4$.

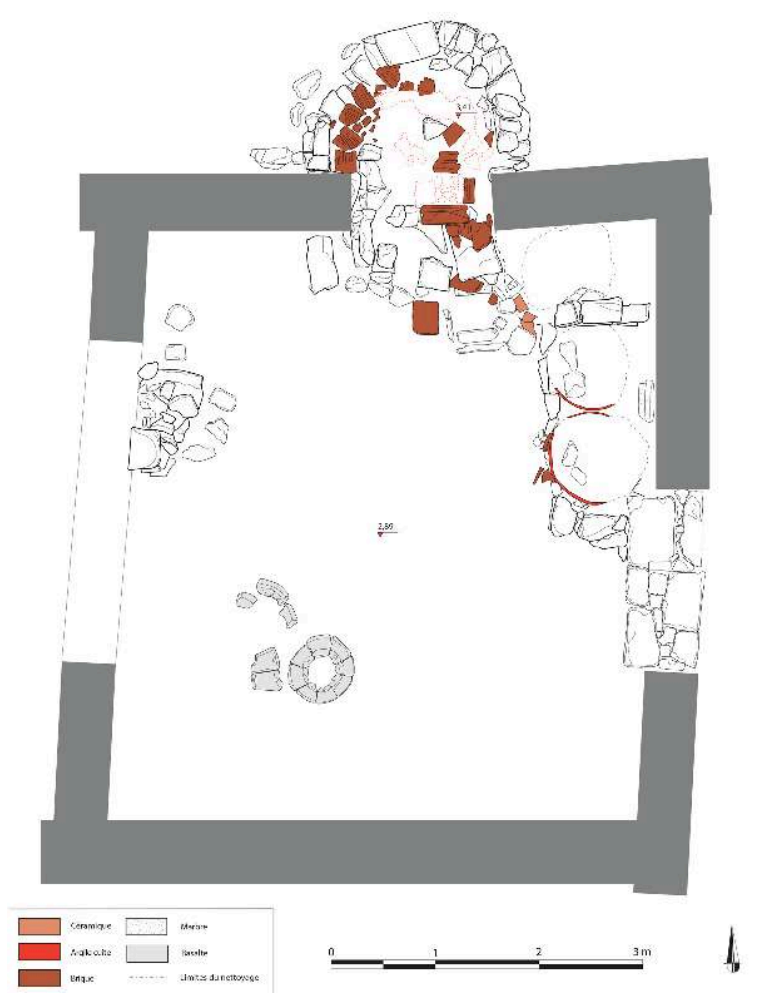

Échelle : $1 / 40$.

Relevé, dessin E. Le Quéré / EFA. 
Fig. 44. Les deux klibanoi à l'est de la pièce $n^{\circ} 4$.

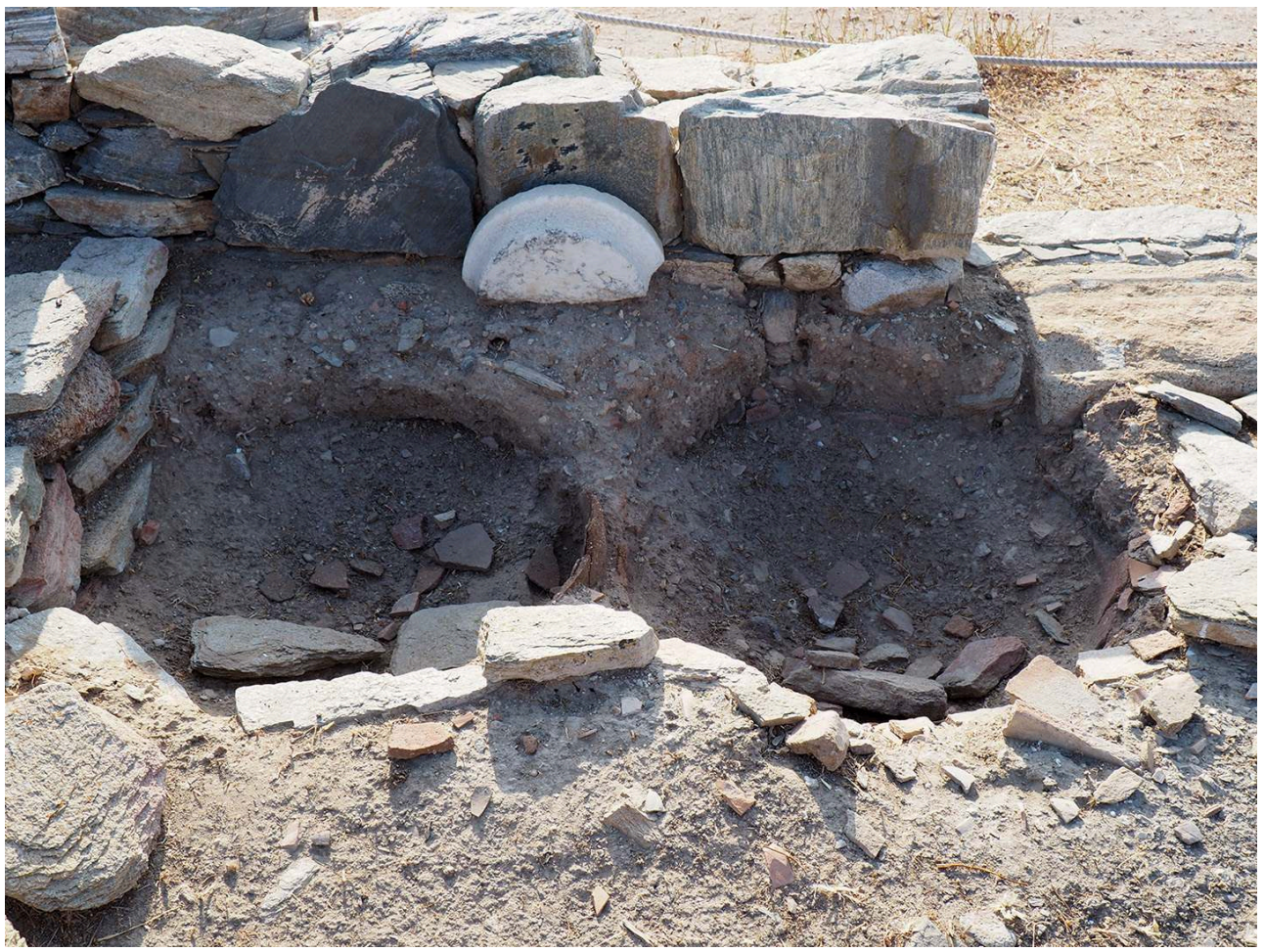

Vue de l'ouest.

Cliché N. Monteix / EFA.

Fig. 45. Les deux klibanoi et la « fosse » dans l'angle nord-est de la pièce $n^{\circ} 4$.

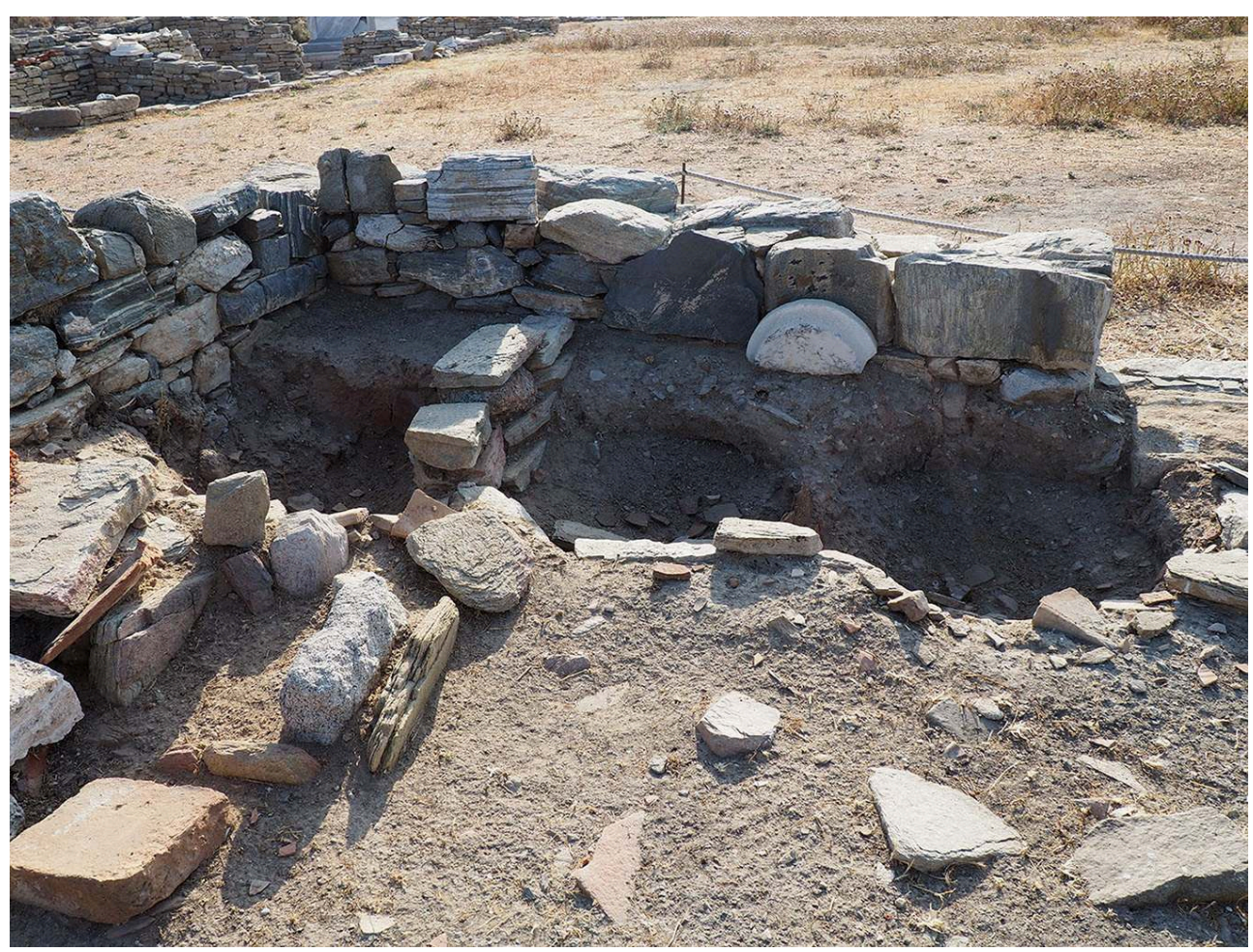

Vue de l'ouest.

Cliché N. Monteix / EFA. 
médiatement au nord de ces klibanoi, on a inséré au milieu du mur nord, semble-t-i lors d'une phase plus tardive, une autre construction circulaire. Une maçonnerie en moellons de gneiss forme en effet un arc de cercle au nord du mur (diam. ext. 2,18; diam. int. 1,60 m). Contre ses parois ont été appliquées des briques épaisses et de grande dimension, identiques à celles ayant servi à la construction du four de potier de la Palestre de Granit, et que nous avons étudiées lors de la campagne 2017 (fig. 46). Certaines de ces briques sont noircies ou en partie fondues sous l'effet de la chaleur. Tout indique que nous avons là un four à coupole, permettant la cuisson de pain levé, dont la gueule ouvre au sud. Par endroits, le fond du four est visible, constitué d'une argile très dure et friable, noircie sous l'effet des multiples cuissons.

Plusieurs fragments de meules en basalte ont été déposés au centre de la pièce $\mathrm{n}^{\circ} 4$, provenant de moulins rotatifs de type délien, fabriqués en pièces détachées (fig. 47$)^{51}$. Elles n'ont pas été trouvées in situ, mais proviennent des espaces alentour. Trois pièces (dont une en deux fragments) proviennent de meules dormantes, huit pièces de meules actives de grand module - dont certaines ont conservé leurs attaches en fer -, et deux pièces proviennent d'un moulin de plus petit module. L'observation des traces d'usure sur les huit pièces de grand module, qui auraient pu former une meule active entière, permettent d'avancer l'hypothèse qu'elles proviennent d'au moins trois moulins différents.

Fig. 46. Le four à coupole dans le mur nord de la pièce.

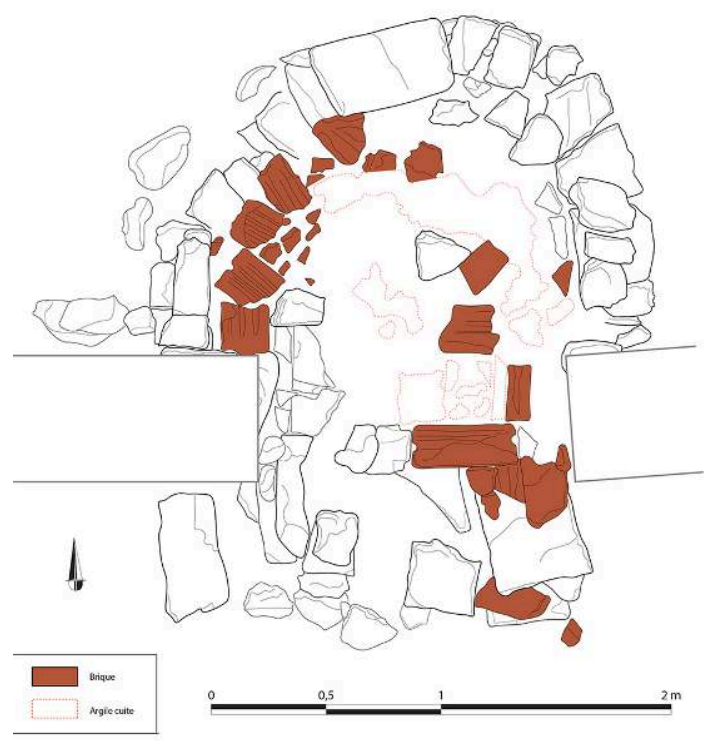

a

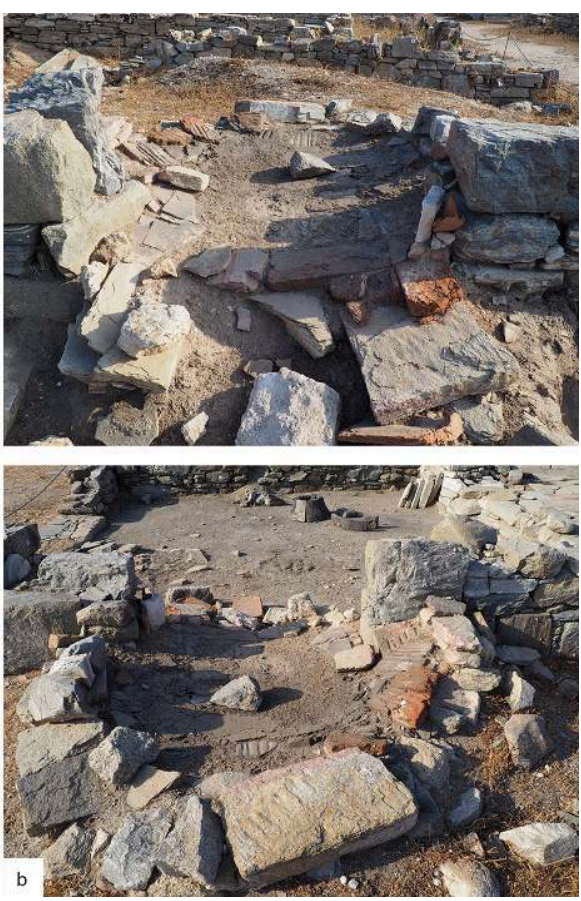

№ 4. A. Plan. Échelle : $1 / 20$; B. Vues du sud et du nord.

No 4. A. Relevé, dessin E. Le Quéré / EFA; B. Clichés N. Monteix / EFA.

Bulletin archéologique des Écoles françaises à l'étranger , Grèce 
Fig. 47. Pièces détachées en basalte provenant de moulins rotatifs, déposées dans la pièce $n^{\circ} 4$.

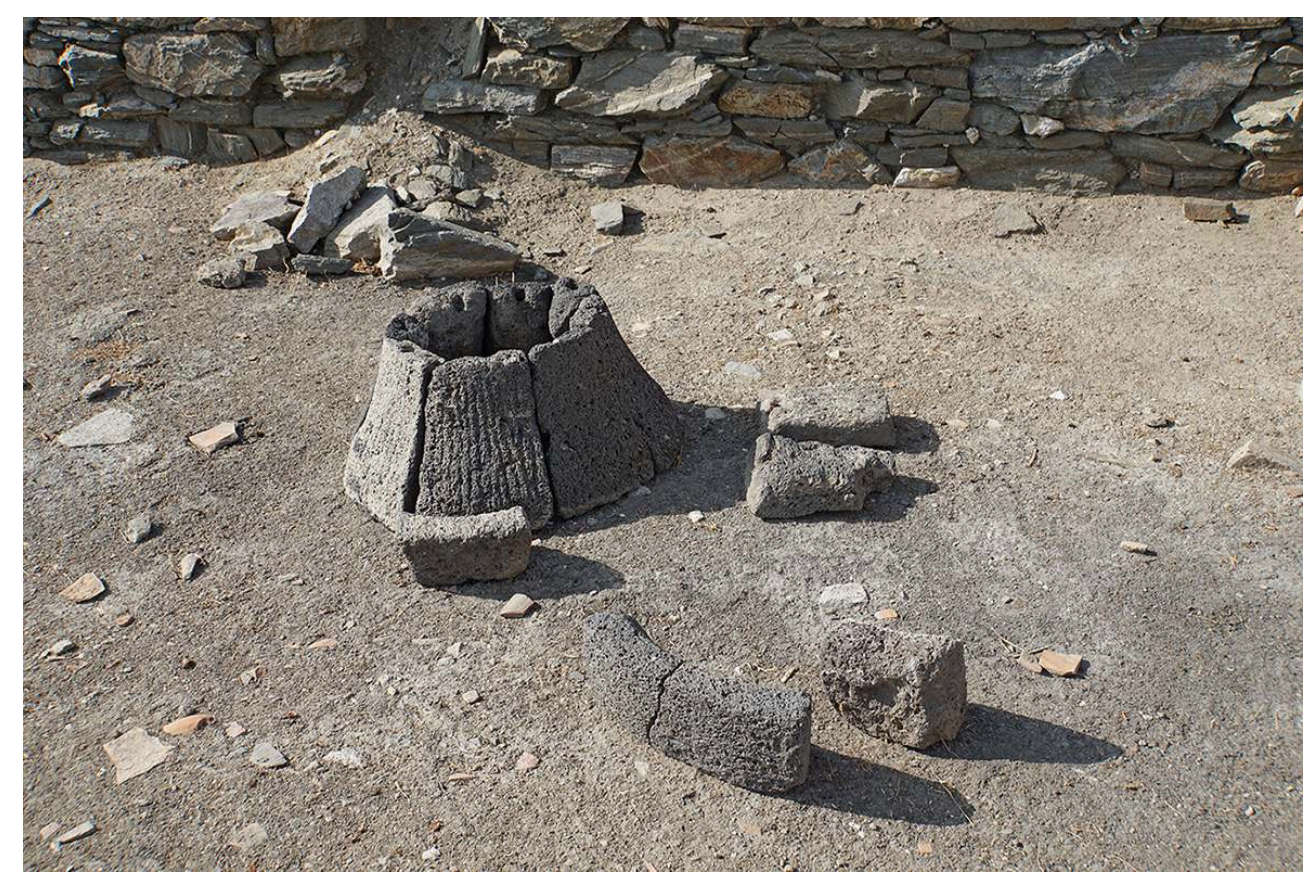

Vue du nord.

Cliché N. Monteix / EFA.

Dans la pièce $\mathrm{n}^{\circ} 5$, le nettoyage fut plus aisé car elle avait été intégralement dégagée lors des fouilles de 2002-2003. On y accédait par la pièce $\mathrm{n}^{\circ} 4$ à l'est ou par la pièce $\mathrm{n}^{\circ} 6$ à l'ouest. Une porte a également existé au milieu de son mur nord, mais fut par la suite murée. Le sol de la pièce est entièrement dallé de gneiss, à l'exception de deux larges fosses circulaires, creusées à même le rocher, l'une à l'ouest d'environ $1,58 \mathrm{~m}$ de diamètre, l'autre à l'est d'environ $1,38 \mathrm{~m}$ de diamètre (fig. 48). Tout porte à croire que nous sommes en présence d'une meunerie où étaient disposés deux moulins rotatifs. Cependant, l'architecture de cette meunerie diffère de celle qu'on observe traditionnellement à Délos, où seul un anneau autour du moulin est dallé. Plus rares sont les meuneries entièrement dallées comme ici ou comme celle de la Maison des Sceaux (GD 59 D). Toutefois, il est pour l'instant impossible de déterminer si certaines des pièces de moulins déposées dans la pièce voisine $\mathrm{n}^{\circ} 4$ appartenaient à l'un ou l'autre des moulins de la meunerie. 
Fig. 48. Plan de la meunerie située dans la pièce $n^{\circ} 5$.

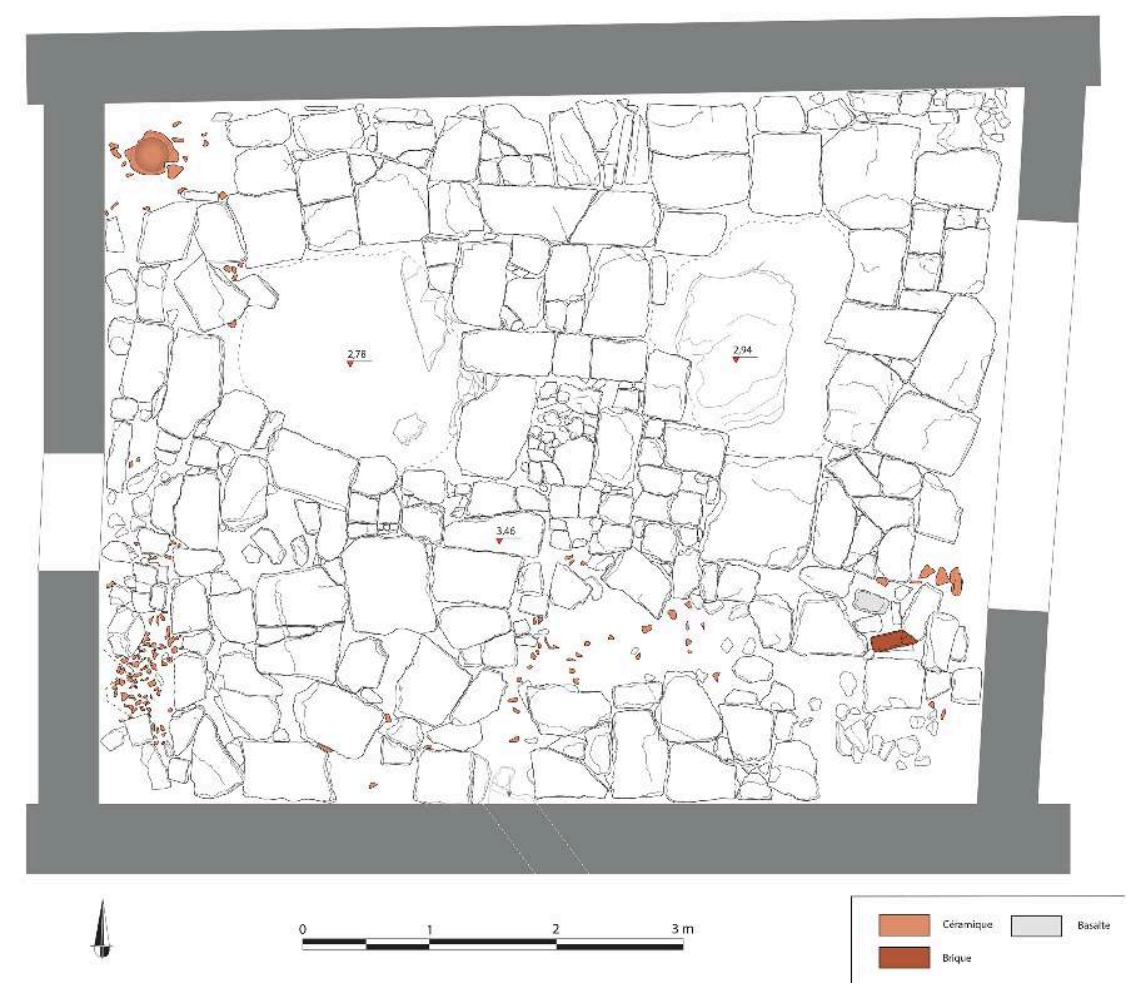

Échelle : $1 / 40$.

Relevé, dessin E. Le Quéré / EFA.

61 Ces fosses constituent par ailleurs une fenêtre d'observation pour établir, à terme, une chronologie relative pour l'installation du dallage. On y observe en effet un épais remblai constitué de nombreux tessons, dont certains pourraient fournir un terminus post quem. En ce qui concerne l'ensemble de cette meunerie-boulangerie, il n'est pour l'instant pas possible de déterminer la chronologie de ces installations, même relative. Des fouilles seraient indispensables pour déterminer les phases d'utilisation de la pièce $\mathrm{n}^{\circ} 4$, car seule la couche de surface a été dégagée lors des opérations de 2002-2003. Il serait très important de pouvoir déterminer si les deux modes de cuissons du pain - en klibanos pour des galettes et en four fermé pour du pain levé - étaient utilisés de manière contemporaine ; ou bien si ces installations correspondent à une évolution technique - et peut-être aussi des habitudes de consommation - dans le temps, ce qui prouverait un maintien des mêmes activités dans un seul atelier sur un temps plus long.

\section{L'atelier situé au sud-est de l'Agora des Compétaliastes}

Enfin, dans le Quartier du Théâtre, situé à l'entrée de la Rue du Théâtre, au sud-est de l'Agora des Compétaliastes (GD 2) (fig. 49), l'atelier que nous avons nettoyé comporte en l'état actuel quatre pièces, dont les relations sont difficiles à restituer dans les détails en raison des réaménagements successifs qu'elles subirent dès l'époque antique $^{52}$. Les interprétations possibles sont d'autant plus malaisées que le sol de ces pièces - à l'exception de la pièce $\mathrm{n}^{\circ} 2-\mathrm{a}$ été entièrement cimenté lors de travaux de 
restauration. Nous devons donc nous contenter de quelques descriptions et observations.

Fig. 49. Emplacement de l'atelier à l'entrée de la Rue du Théâtre, au sud-est de l'Agora des Compétaliastes.

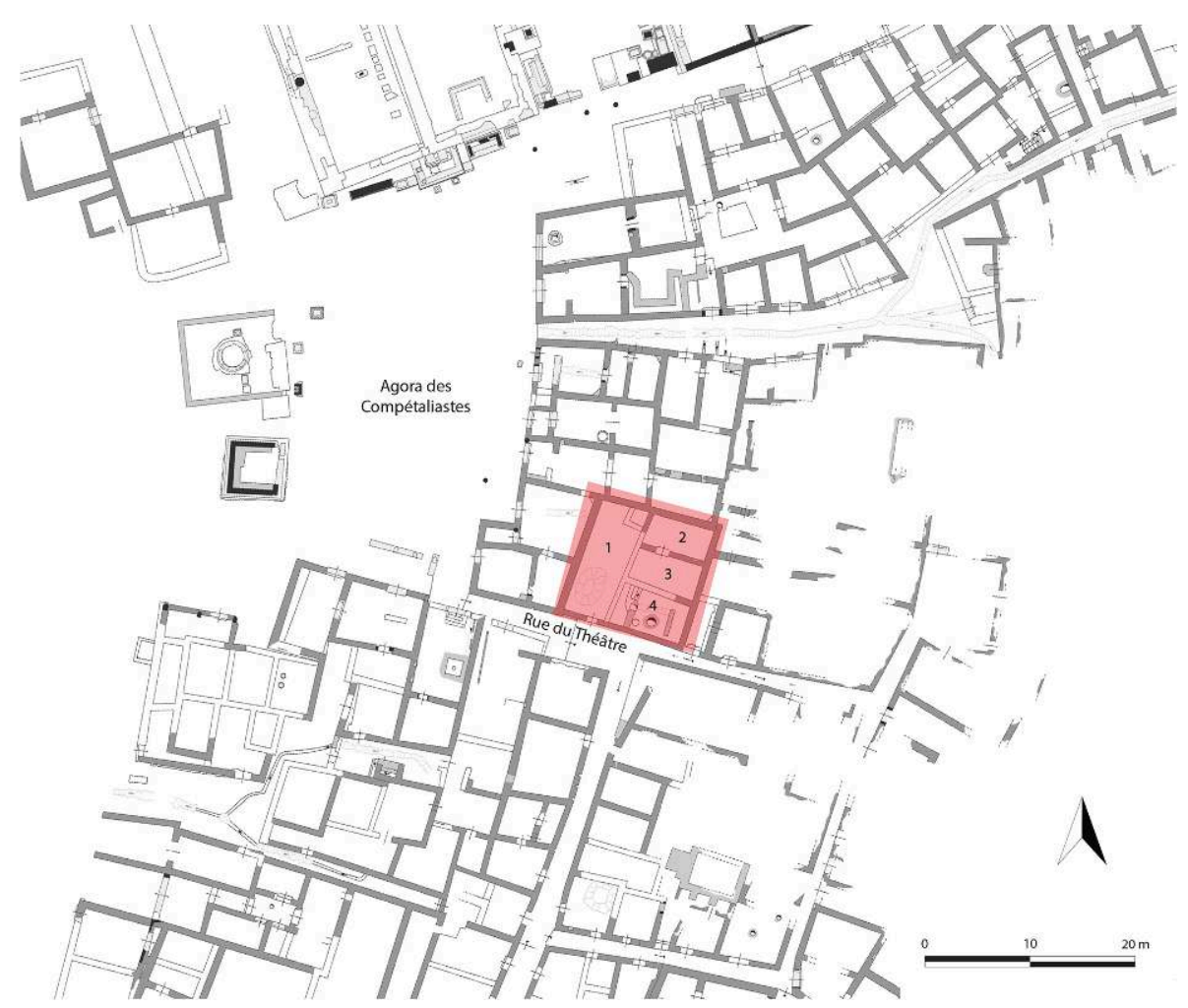

D’après https://sig-delos.efa.gr/.

63 On accédait à l'atelier par la Rue du Théâtre, par une entrée aménagée dans la paroi sud de la pièce $\mathrm{n}^{\circ} 1$. À environ $1,00 \mathrm{~m}$ de cette entrée se trouve un dallage de gneiss formant un grand anneau ovale (diam. ext. ca. 3,60 x 2,60 m; diam. int. ca. 2,50 x 1,00 m), très largement restauré (fig. 50). Cette installation indique là encore l'emplacement d'un moulin rotatif : la pièce $\mathrm{n}^{\circ} 1$ correspond donc à une meunerie, tout du moins dans sa partie méridionale. Une meule tournante (catillus) de type pompéien - en forme de clepsydre -, en roche basaltique rouge vacuolaire, actuellement déposée au centre de cet anneau (fig. 51), invite à mettre ces vestiges en relation ${ }^{53}$. Toutefois, les petites dimensions de ce moulin (diam. 0,41 m; haut. 0,40 m) ne permettent en aucun cas d'en restituer le fonctionnement avec le dallage de gneiss. Si tant est que son lieu de provenance n'ait pas été modifié au cours des nombreux travaux de réaménagement et de restauration ayant eu lieu tout au long $\mathrm{du} \mathrm{xx}^{\mathrm{e}}$ siècle, cet objet appartient donc à une autre structure (il manque par ailleurs la meta correspondante) qu'il faut restituer ailleurs. Parmi les nombreux objets trouvés lors des fouilles et déposés actuellement de manière éparpillée dans la pièce $\mathrm{n}^{\circ} 1$, cinq pièces de meule tournante et deux pièces de meule dormante provenant de moulin(s) de type délien, pourraient éventuellement être mises en relation avec cette installation de mouture (fig. 52-53) ${ }^{54}$. Plusieurs autres éléments - avec les mêmes réserves sur leur provenance originale - sont également à mettre en relation avec des activités de meunerie et de boulangerie (fig. 52) : deux pieds de table(s) en marbre blanc, un mortier en marbre blanc possédant deux oreilles 
quadrangulaires, opposées et saillantes, un grand mortier en calcaire, une meule (ou un broyeur) circulaire en basalte. Dans l'angle nord-est de cette même pièce, deux murets conservés sur une très faible hauteur $(c a .0,20 \mathrm{~m})$ délimitent un petit espace quadrangulaire d'environ $1,50 \mathrm{~m}$ de côté dont on ignore la fonction. Sont actuellement déposés dans cet espace d'autres instruments de mouture : outre les pièces provenant d'un moulin de type délien, précédemment citées, on y trouve également un fragment de molette à trémie quadrangulaire en basalte (fig. 53), peut-être à associer au fragment de table en basalte actuellement déposé dans l'angle nord-ouest de la pièce.

Fig. 50. La meunerie située dans la partie méridionale de la pièce $n^{\circ} 1$ et la pièce $n^{\circ} 4$ avec canalisation et klibanos.

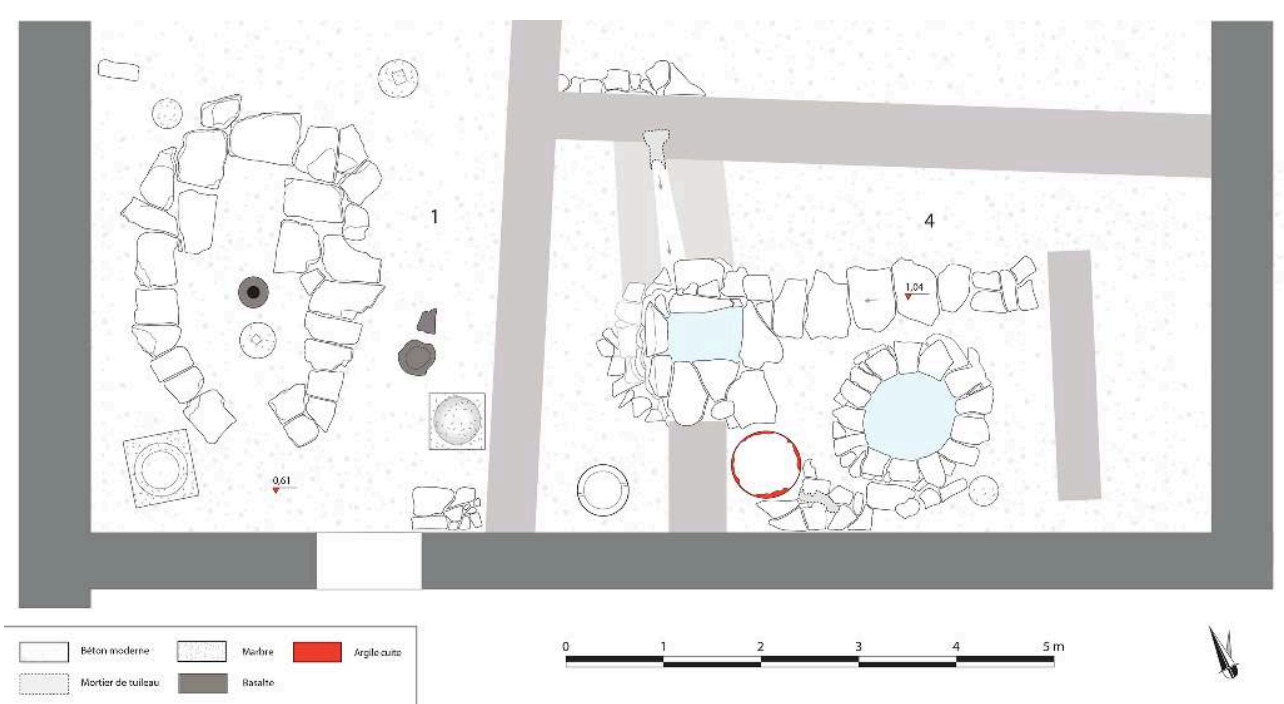

Échelle : $1 / 50$.

Relevé, dessin E. Le Quéré / EFA.

Fig. 51. Catillus d'un moulin de type pompéien en roche basaltique rouge vacuolaire, déposé dans la meunerie.
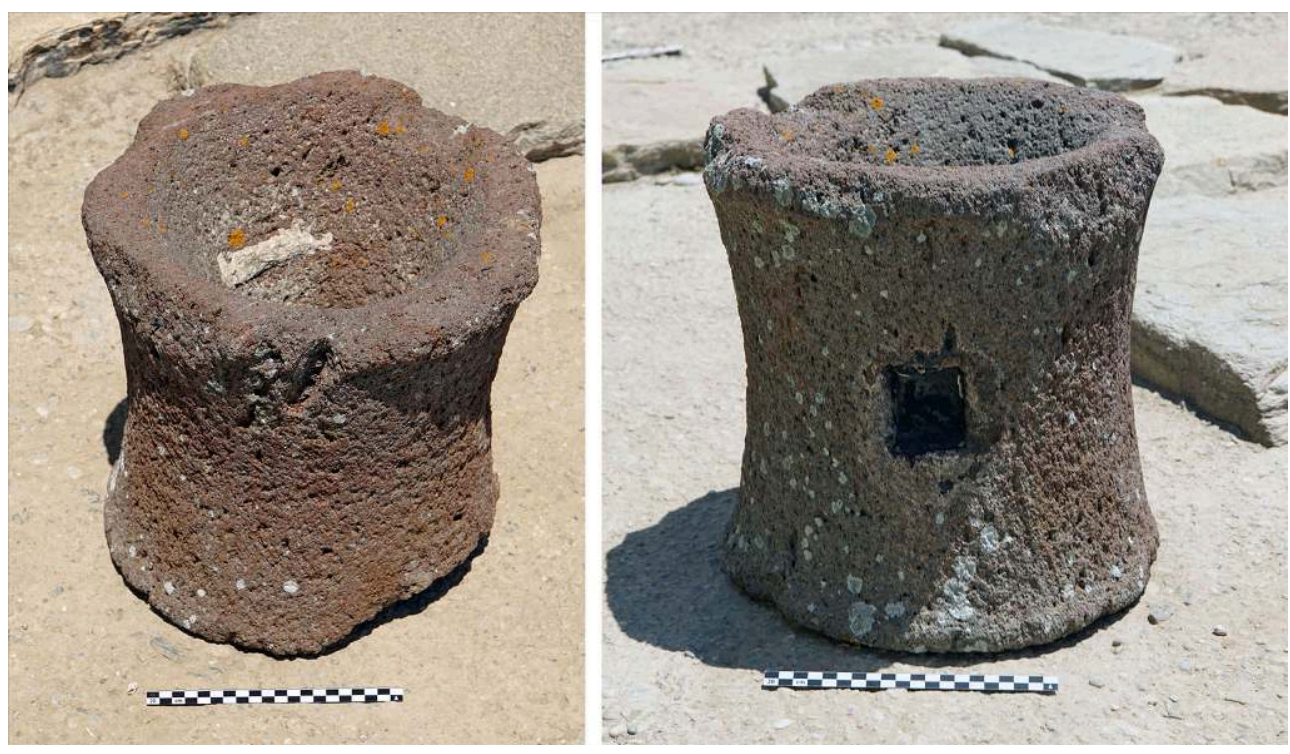

Clichés E. Le Quéré / EFA. 
Fig. 52. Instruments déposés dans la pièce $\mathrm{n}^{\circ} 1$ pouvant être mis en rapport avec des activités de meunerie et de boulangerie.
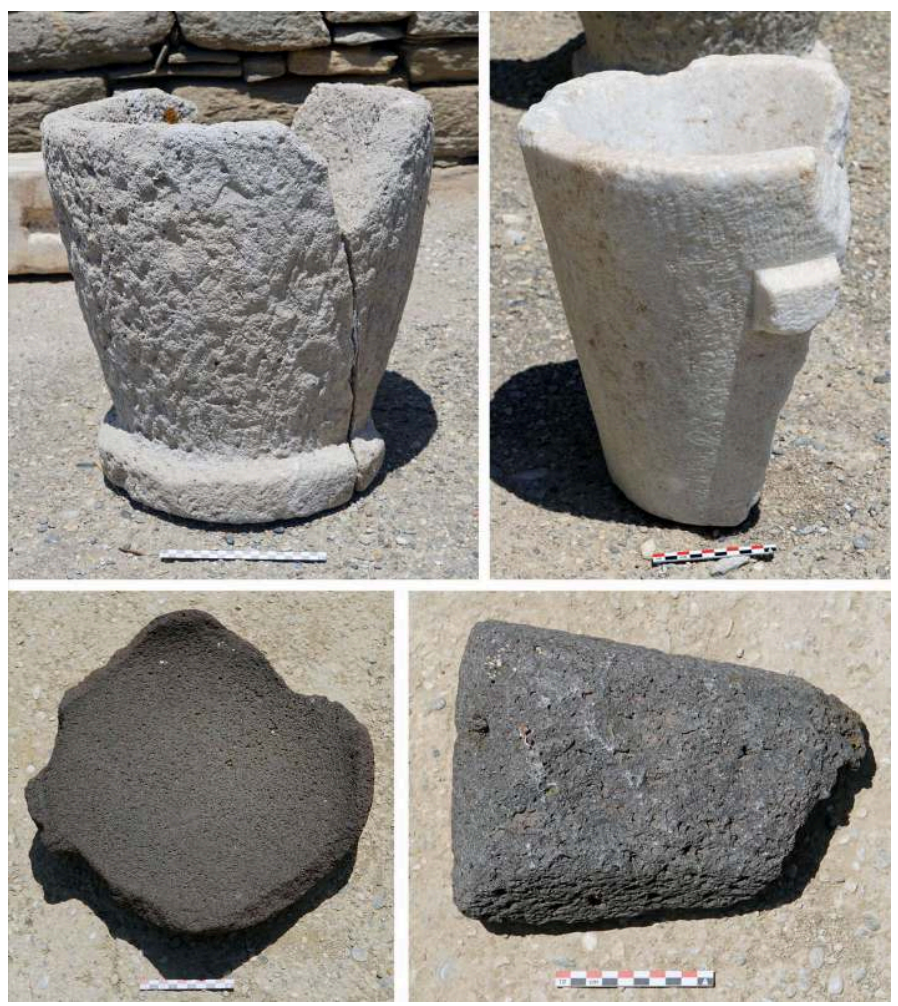

Clichés E. Le Quéré / EFA.

Fig. 53. Instruments de mouture déposés dans l'angle nord-est de la pièce $n^{\circ} 1$, dont un fragment de molette à trémie.
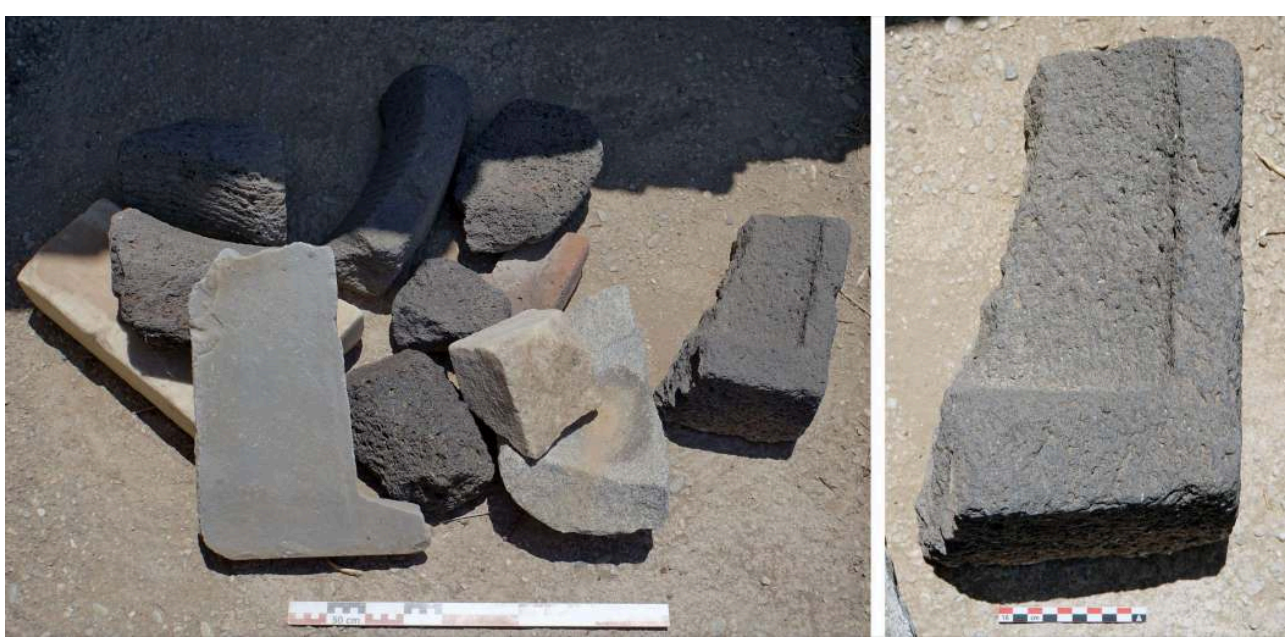

Vue de l'ouest et du dessus.

Clichés E. Le Quéré / EFA.

Immédiatement au sud de cet espace quadrangulaire, dans une phase tardive semble-til, un passage fut aménagé dans la paroi orientale de la pièce $n^{0} 1$, donnant accès à la pièce $\mathrm{n}^{\circ} 2$. Il n'est pas sûr que cet espace ait été intégralement fouillé. Aucune structure particulière n'est actuellement visible, mise à part une niche aménagée dans le mur 
méridional et dont les parois sont entièrement recouvertes de mortier de tuileau. Par ailleurs, là encore, plusieurs instruments de mouture ont été déposés en amas dans l'angle nord-ouest de la pièce, parmi lesquels on distingue en particulier deux fragments de molettes à trémie quadrangulaires en basalte, de deux modules différents (fig. 54).

Fig. 54. Instruments de mouture déposés dans l'angle nord-ouest de la pièce $n^{\circ} 2$.

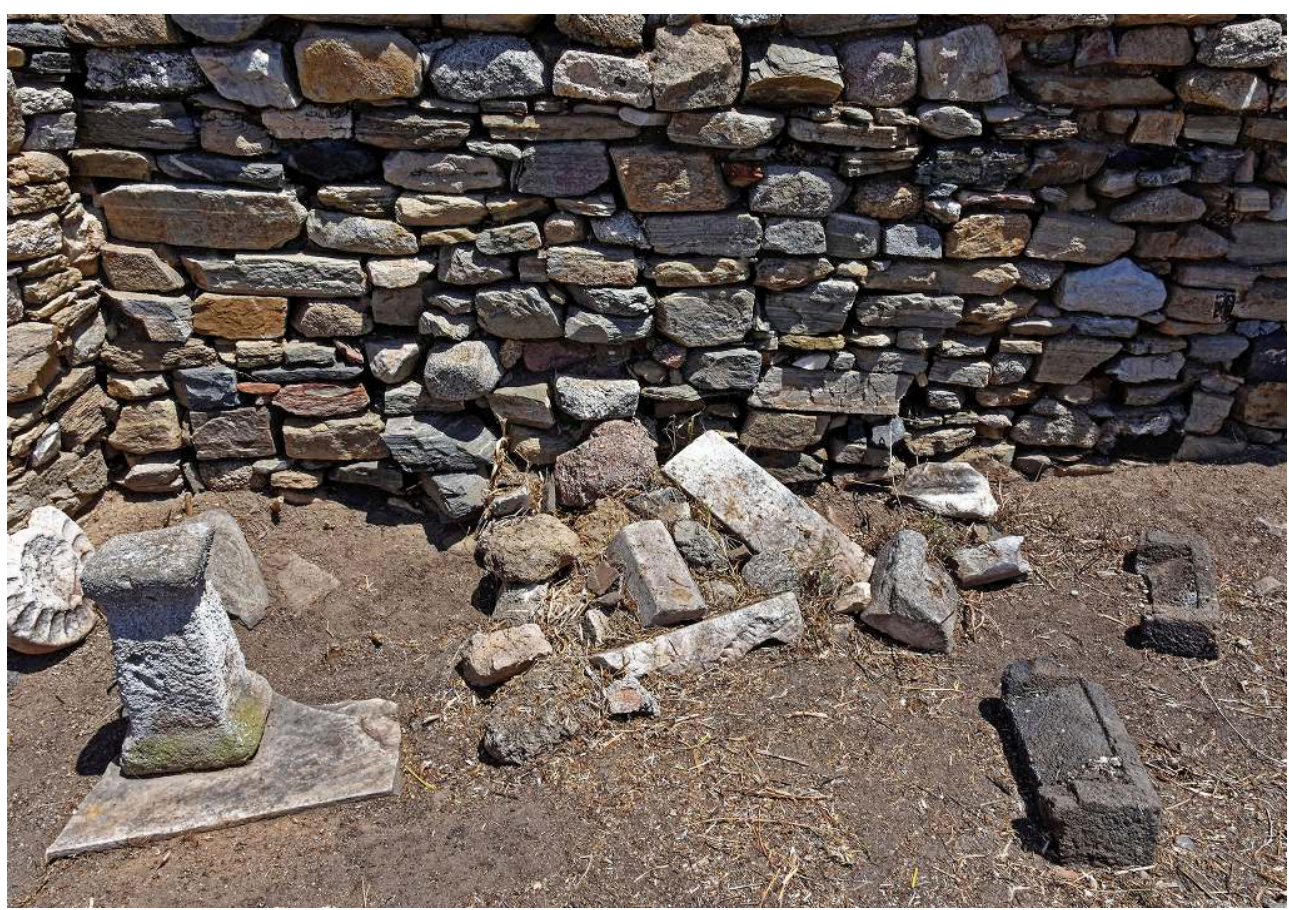

Vue du sud.

Cliché E. Le Quéré / EFA.

Du passage entre les pièces $\mathrm{n}^{\text {os }} 2$ et 3 subsiste un large seuil en gneiss, aujourd'hui fissuré en son milieu. La pièce $n^{\circ} 3$ ne présente en l'état actuel aucun aménagement remarquable. Un accès vers la pièce $n^{\circ} 4$ fut très certainement aménagé dans son mur méridional, aujourd'hui très largement arasé, mais l'état actuel des vestiges ne permet pas de le déterminer avec précision.

La pièce $\mathrm{n}^{\circ} 4$ présente des structures diverses appartenant très probablement à différentes phases de fonctionnement de l'édifice, et dont il est difficile de percevoir les liens. Au centre de l'espace, légèrement décalé vers le sud, se trouve un large puits appareillé, dont l'ouverture au sol est entourée de dalles de gneiss. Immédiatement à l'ouest de ce puits, installé dans l'angle de deux murets construits vraisemblablement lors d'une phase ultérieure, se trouve un four de type kliabanos (fig. 50 et 55), de facture similaire à ceux, précédemment décrits, du Quartier du Lac. Il y avait donc là une activité de boulangerie. Seule la partie supérieure conservée de ce four a pu être observée, puisqu'il a été intégralement comblé par du ciment lors de sa restauration. Les parois de terre cuite contre lesquelles on plaquait la pâte à cuire sont très fines ( $c a$. $2 \mathrm{~cm})$. 
Fig. 55. Le four (klibanos) situé à l'ouest du puits de la pièce $n^{\circ} 4$.

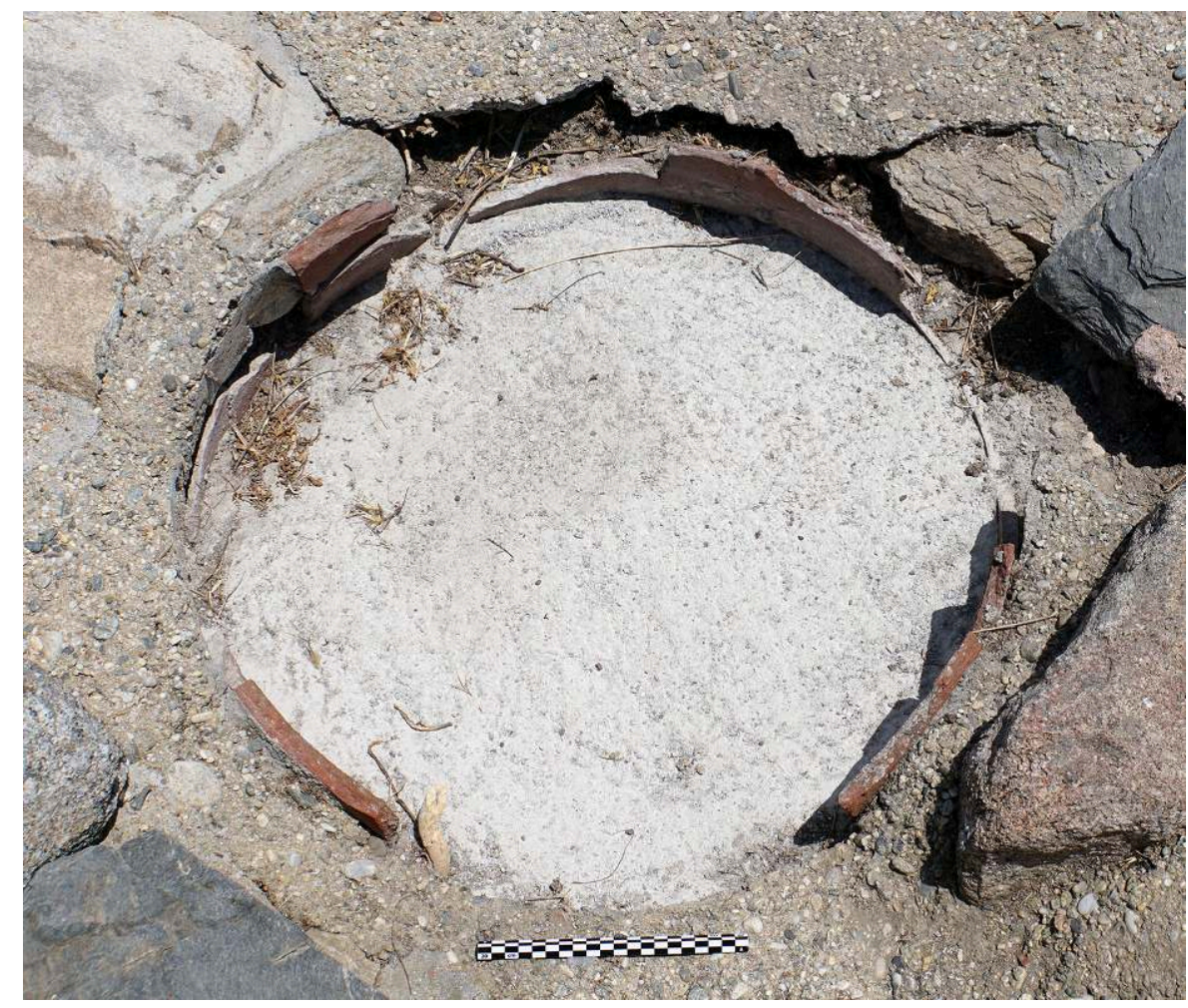

Vue du sud-ouest.

Cliché E. Le Quéré / EFA.

67 Les autres structures repérables dans cette même pièce sont, en l'état actuel, d'interprétation délicate. Un muret nord-sud plus tardif - car constitué de nombreux remplois - a été construit à $1,25 \mathrm{~m}$ du mur oriental de la pièce, tandis qu'une canalisation, partant de l'extrémité septentrionale de ce muret et recouverte de dalles de gneiss, traverse la pièce d'est en ouest pour se déverser dans une citerne de forme quadrangulaire, située à environ $1,50 \mathrm{~m}$ à l'est du puits. Enfin, une canalisation vraisemblablement aménagée tardivement, car elle aussi constituée de nombreux remplois, et dont les parois étaient recouvertes d'un très épais mortier de tuileau, court du nord au sud depuis le mur méridional de la pièce pour se déverser dans la citerne (fig. 50 et 56).

68 Une étude architecturale complète des quatre pièces constituant cet atelier, ainsi qu'une analyse rigoureuse du bâti restent donc à faire pour tenter de déterminer les différentes phases de fonctionnement de cet espace. 
Fig. 56. Canalisation nord-sud se déversant dans la citerne de la pièce $n^{\circ} 4$ et détail de l'épais mortier de tuileau avec remploi d'une pièce de moulin délien.
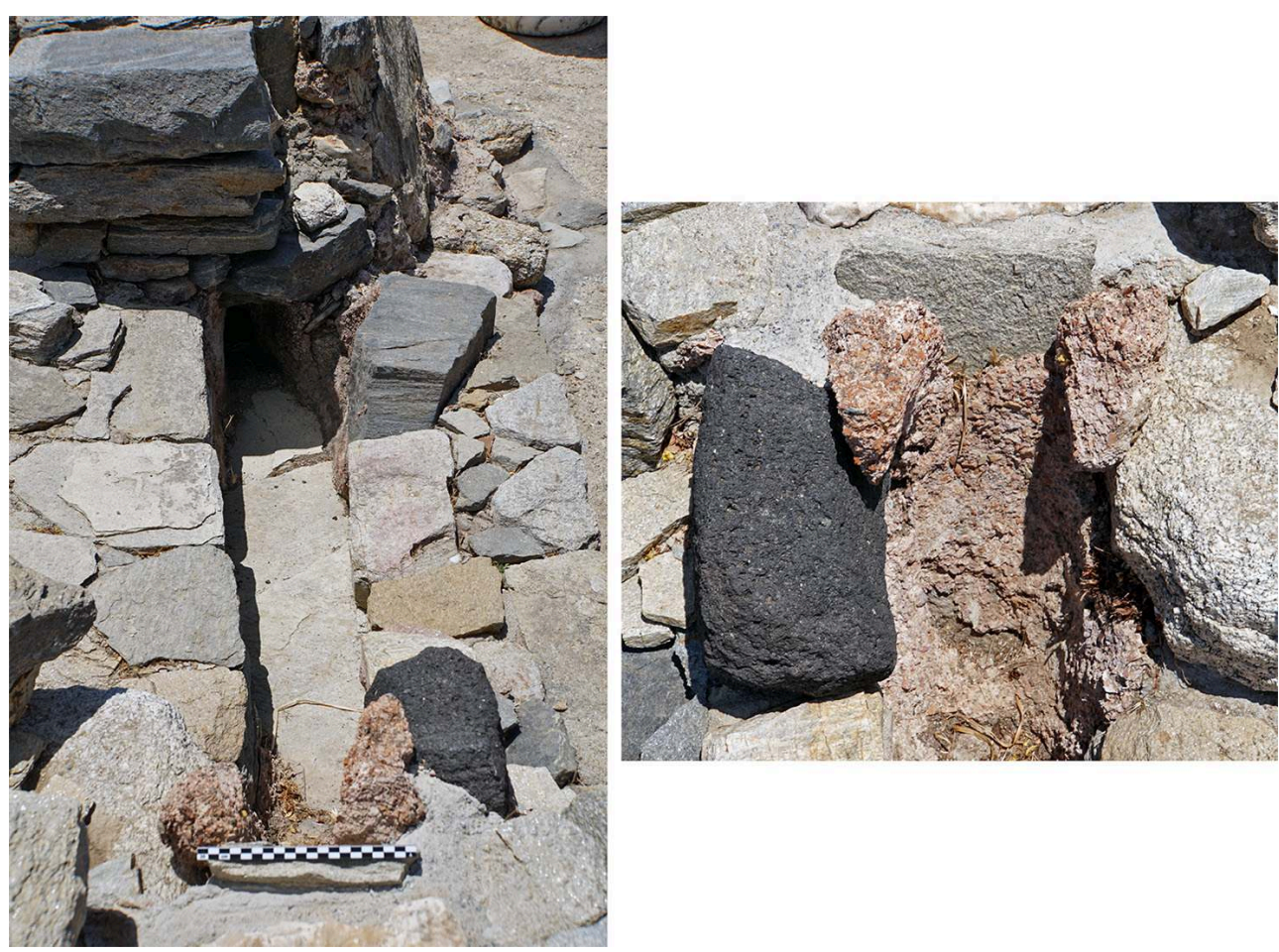

Vue du nord; détail : vue du sud.

Clichés E. Le Quéré / EFA.

\section{BIBLIOGRAPHIE}

Amouretti 1986

Marie-Claire Amouretti, Le pain et l'huile dans la Grèce antique. De l'araire au moulin, Paris, Les Belles Lettres, Annales littéraires de l'Université de Besançon 328, 1986.

Amouretti 1995

Marie-Claire Amouretti, « La mouture des céréales : du mouvement alternatif au mouvement rotatif », in Marie-Claire Amouretti, Georges Comet (éd.), La transmission des connaissances techniques, Cahier d'histoire des techniques 3, 1995, p. 33-47.

BARBERAN et al. 2006

Sébastien Barberan, et al., « Un dispositif de cuisson original en Languedoc dans l'antiquité. Les fours à pain à cloche mobile en céramique ", dans Sfecag - Actes du Congrès de Pézenas, Marseille, SFECAG, 2006, p. 257-271.

Borgard, Puybaret 2003

Philippe Borgard, Marie-Pierre Puybaret, « Approche archéologique du travail de la laine au $\mathrm{I}^{\mathrm{er}}$ siècle après J.-C. ", in Margherita Tirelli, Giovannella Cresci Marrone (éd.), Produzioni, mercie 
commerci in Altino preromana e romana, Rome, Ed. Quasar, Studi e ricerche sulla Gallia Cisalpina 17, 2003, p. 299-318.

Borgard, Puybaret 2004

Philippe Borgard, Marie-Pierre Puybaret, « Le travail de la laine au début de l'Empire : l'apport du modèle pompéien. Quels artisans ? Quels équipements ? Quelles techniques ? ", in Carmen Alfaro Giner, John Peter Wild, Benjamí Costa (éd.), Purpureae vestes: actas del I Symposium internacional sobre textiles y tintes del Mediterráneo en época romana, Valence, Consell insular d'Eivissa i Formentera, Universitat de València, 2004, p. 47-59.

BRUNEAU et al. 1970

Philippe Bruneau et al., L'îlot de la maison des Comédiens, Athènes, École française d'Athènes, EAD 25,1970 .

Brunet 1997

Michèle Brunet, « Le moulin délien », dans Dimitri Meeks, Dominique Garcia (éd.), Techniques et économie antiques et médiévales : le temps de l'innovation, Paris, Errance, 1997, p. 29-38.

de Castro Martínez 2001

Teresa de Castro Martínez, « De nuevo sobre el Tannur en Al-Andalus: un ejemplo etnohistórico en el estudio de la alimentación andalusí », Fundamentos de antropología 10-11, 2001, p. 285-296.

CHAMONARD 1906

Joseph Chamonard, « Fouilles de Délos. Fouilles dans le Quartier du Théâtre », BCH 30, 1906, p. 486-609.

CHAMONARD 1922

Joseph Chamonard, Le quartier du théâtre : étude sur l'habitation délienne à l'époque hellénistique, Athènes, École française d'Athènes, EAD 8.1, 1922.

de Ruyt 2001

Claire de Ruyt, « Les foulons, artisans des textiles et blanchisseurs ", in Jean-

Paul Descoeudres (éd.), Ostia : port et porte de la Rome antique, Genève, Georg, 2001, p. 186-191.

Flohr 2013

Miko Flohr, The world of the Fullo, Oxford, OUP, Oxford studies on the Roman economy, 2013.

Fraisse, Moretti 2007

Philippe Fraisse, Jean-Charles Moretti, Le Théâtre, Athènes, École française d'Athènes, EAD 42, 2007.

Frankel 2003

Rafael Frankel, « The Olynthus Mill, Its Origin, and Diffusion: Typology and

Distribution ", American Journal of Archaeology 107, 1, 2003, p. 1-21.

FRANKEL, Syon 2016

Rafael Frankel, Danny Syon, "Chapter 11: Mills and Querns », in Danny Syon (éd.), Gamla III. The Shmarya Gutmann Excavations 1976-1989. Finds and Studies. Part 2, Jérusalem, IAA Reports 59, 2016.

GD

Philippe Bruneau, Jean Ducat, Guide de Délos, Athènes, École française d'Athènes, SitMon $1,4^{\mathrm{e}}$ éd. refondue et mise à jour, 2005.

HOLLEAUX 1904

Maurice Holleaux, « Rapport sur les travaux exécutés dans l'île de Délos par l'École française d'Athènes pendant l'année 1904 », CRAI 48, 6, 1904, p. 732. 
JOCKEY 1993

Philippe Jockey, «Techniques et ateliers de sculpture à Délos à l'époque hellénistique », Thèse de doctorat inédite, Université Paris X - Nanterre, 1993.

JOCKEY 1995

Philippe Jockey, «Unfinished Sculpture and its workshops on Delos in the Hellenistic Period », in Yanis Maniatis, Norman Herz, Yannis Basiakos (éd.), The Study of Marble and other Stones used in Antiquity, Londres, Archetype, 1995, p. 87-94.

KARVONIS 2008

Pavlos Karvonis, « Les installations commerciales dans la ville de Délos à l'époque

hellénistique », BCH 132, 2008, p. 153-219.

KARVONIS, MALMARY 2012

Pavlos Karvonis, Jean-Jacques Malmary, « Du quartier à l'agora : étude de cas dans le Quartier du théâtre à Délos », dans Véronique Chankowski, Pavlos Karvonis (éd.), Tout vendre, tout acheter. Structures et équipements des marchés antiques, Bordeaux, Ausonius, Scripta antiqua 42, 2012, p. 263-275.

Karvonis, Malmary 2018

Pavlos Karvonis, Jean-Jacques Malmary, « Délos, entrepôt méditerranéen. Le stockage dans les installations commerciales », dans Véronique Chankowski, Xavier Lafon, Catherine Virlouvet (éd.), Entrepôts et circuits de distribution en Méditerranée antique, Athènes, École française d'Athènes, BCH Suppl. 58, 2018, p. 169-194.

Lapalus 1939

Étienne Lapalus, L'Agora des Italiens, Athènes, École française d'Athènes, EAD 19, 1939.

LE QUÉRÉ 2018

Enora LE QUÉRÉ, « Un lot de céramique d'époque impériale romaine, provenant du puits du Prytanée de Délos », BCH 142, 2018, p. 317-402.

LEROI-GOURHAN 1973

André Leroi-Gourhan, Évolution et techniques, 2. Milieu et techniques ${ }^{2}$, Sciences d'aujourd'hui, Paris, Albin Michel, 1973.

MARCADÉ 1957

Jean Marcadé, « Les trouvailles de la maison dite de l'Hermès, à Délos », BCH 77, 1953, p. 497-615.

Monteix 2010

Nicolas Monteix, Les lieux de métier. Boutiques et ateliers d'Herculanum, Rome, École française de Rome, BEFAR 344, 2010.

Moritz 1958

Ludwig Alfred Moritz, Grain Mills and Flour in Classical Antiquity, Oxford, The Clarendon Press, 1958.

Mulder-Heymans 2002

Noor Mulder-Heymans, « Archaeology, experimental archaeology and ethnoarchaeology on bread ovens in Syria ", Civilisations. Revue internationale d'anthropologie et de sciences humaines 49, 2002, p. 197-221.

Peacock 2013

David Peacock, The Stone of Life: Querns, Mills and Flour Production in Europe Up to c. AD 500, Southampton, Highfield, Monographs in Archaeology ns 1, 2013. 
Pietrogrande 1976

Antonio Luigi Pietrogrande (éd.), Scavi di Ostia. 8, Le fulloniche, Rome, Soprintendenza agli scavi di Ostia antica, Libreria dello Stato, 1976.

Rostovtzeff 1937

Michael Rostovtzeff, « Two Homeric bowls in the Louvre », AJA 41, 1, 1937, p. 86-96.

Rotroff 2006

Susan I. Rotroff, Hellenistic pottery: the plain wares, Athènes, ACSA, Athenian Agora 33, 2006.

Trümper 1998

Monika Trümper, Wohnen in Delos. Eine baugeschichtliche Untersuchung zum Wandel der Wohnkultur in hellenistischer Zeit, Rahden, M. Leidorf Verlag, Internationale Archäologie 46, 1998.

Trümper 2008

Monika Trümper, Die « Agora des Italiens » in Delos: Baugeschichte, Architektur, Ausstattung und Funktion einer späthellenistischen Porticus-Anlage, Rahden/Westf., M. Leidorf Verlag, 2008.

Zapheiropoulou, Chatzidakis 1994

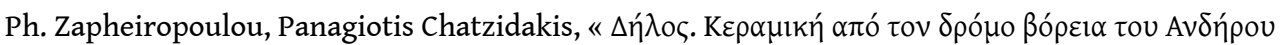

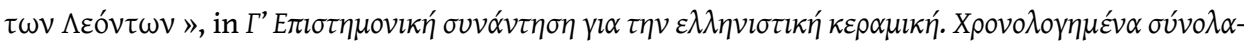

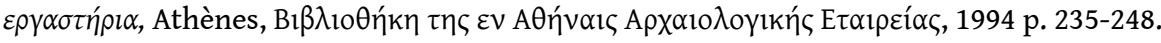

\section{NOTES}

1. Le fond de la cavité est composé d'un grand bloc de gneiss taillé en cercle et entouré de petits moellons de la même roche. En l'état, il est difficile de déterminer si cette construction correspond à une vasque maçonnée ou bien si le bloc de gneiss servait de support à un récipient disparu.

2. Creusées dans les murs est $(4 \times 9 \times$ prof. $6 \mathrm{~cm})$ et sud $(5 \times 9 \times$ prof. $5,5 \mathrm{~cm})$, ces deux empreintes sont situées à $4 \mathrm{~cm}$ (mur est) et $9 \mathrm{~cm}$ (mur sud) au-dessus du niveau de la dernière assise des murets (altitude locale absolue : 16,95 m).

3. CHAMONARD 1906, p. 486-609, en particulier p. 565.

4. Sur Ostie, voir PIETROGRANDE 1976; DE RUYT 2001, p. 186-191, en particulier p. 187, fig. 2-3; sur Pompéi et Herculanum, voir MONTEIX 2010, p.192-205. D’une manière générale, sur les fouleries en Italie, voir FLOHR 2013.

5. Un tel volume apparaît peu opportun pour le stockage de liquide : soit celui-ci était seulement situé dans les vasques de fond - et l'on se demanderait alors l'intérêt d'enfermer celles-ci dans un «bassin » de plan rectangulaire creusé dans le sol -, soit il était stocké dans l'ensemble formé par la vasque et le bassin - et l'intérêt de la vasque échappe. Les mêmes remarques pourraient être faites pour des denrées alimentaires solides (grain et légumineuses). Dans les deux propositions faites par J. Chamonard, la vidange de l'ensemble reste problématique.

6. La fresque provenant de la foulerie de L. Veranius Hypsaeus (VI 8, 2.21-22) à Pompéi, conservée au Museo archeologico nazionale di Napoli (inv. $\mathrm{n}^{\circ}$ 9974), reste une des meilleures illustrations de cette posture.

7. CHAMONARD 1922, p. 27 et p. 29-31.

8. FRAISSE, MORETTI 2007, p. 244-248; voir aussi infra. 
9. KARVONIS, MALMARY 2012, p. 270-271; KARVONIS, MALMARY 2018, p. 182-184.

10. Calcul des capacités réalisé par KARVONIS, MALMARY 2012, p. 270.

11. CHAMONARD 1922, fig. 92.

12. Cf. supra n. 10.

13. CHAMONARD 1922, fig. 92.

14. e.g. MARCADÉ 1953 , p. 599-600 et fig. $95, \mathrm{n}^{\text {os }}$ B 7343 et B 7344 ; BRUNEAU et al. 1970, p. 257 et pl. $47, \mathrm{n}^{\text {os }} \mathrm{D} 198-\mathrm{D} 200$.

15. Voir sur ce point LE QUÉRÉ 2018, p. 317-402, en particulier p. 337 et p. 350.

16. CHAMONARD 1922, p. 212 ; KARVONIS 2008, p. 153-219, en particulier p. 180-181; KARVONIS, MALMARY 2012, p. 270-271; KARVONIS, MALMARY 2018, p. 182.

17. FLOHR 2013, p. 127-128.

18. MONTEIX 2010, p. 199.

19. Pline, Histoire Naturelle, XXXV, 196-198 ; MONTEIX 2010, p. 203 et fig. 101.

20. FRAISSE, MORETTI 2007, p. 246-248.

21. ROTROFF 2006, p. 81 ; LE QUÉRÉ 2018, p. 337.

22. KARVONIS, MALMARY 2012, p. 269-271 et fig. 5-6.

23. CHAMONARD 1906, p. 486-609.

24. Calcul des capacités réalisé par KARVONIS, MALMARY 2012, p. 270-271.

25. CHAMONARD 1906, p. 577 : «salle irrégulière, dont le niveau semble avoir été plus bas que celui de la rue d'environ $0,60 \mathrm{~m}$. Le sol est recouvert d'une couche de ciment, où sont enfouis trois pithoi »; KARVONIS, MALMARY 2012, p. 271.

26. Entendu comme celui de l'époque du fonctionnement de la foulerie, sans doute largement détruit et surcreusé lors des fouilles de la fin du XIX ${ }^{\mathrm{e}}$ siècle.

27. Cf. supra, n. 1.

28. TRÜMPER 1998, p. 285-286 et fig. 48.

29. CHAMONARD 1906, fig. 26 et 31.

30. HOLLEAUX 1904, p. 732.

31. LAPALUS 1939, p. 62-63. Voir aussi JOCKEY1995, p. 87-94.

32. JOCKEY1995, p. 63.

33. KARVONIS 2008, p. 174 ; voir aussi JOCKEY 1993, p. 469-470.

34. HOLLEAUX 1904, p. 732.

35. LAPALUS 1939 , p. 62.

36. D'autres traces appartenant à des constructions antérieures à ces boutiques ont également été trouvées au niveau d'autres boutiques : cf. LAPALUs 1939, p. 63, n. 11.

37. LAPALUS $1939, \mathrm{pl}$. V et photographie inédite $n^{\circ} 426$ conservée à la photothèque de l'EFA.

38. Sur la chronologie relative des exèdres et des boutiques, voir LAPALUS 1939, p. 61 ; TRÜMPER 2008, p. 43-44 et fig. 21-22.

39. LAPALUS 1939, p.63: "Dans l'angle sud-ouest subsiste encore un pithos en terrecuite, enfoncé dans le sol. Son orifice forme le centre d'une dépression conique 
recouverte d'un enduit dans lequel sont noyés de gros éclats de poterie; cet enduit se continue sur le mur ".

40. La numérotation de ces pièces est une numérotation qui nous est propre, pour faciliter notre étude et les renvois pour le lecteur. Ces édifices n'étant pas répertoriés dans le Guide de Délos, ni publiés ailleurs, ils ne possèdent pas, pour l'instant, de nomenclature architecturale et topographique établie.

41. Nous devons à la bienveillance de ce dernier l'autorisation d'en entreprendre l'étude, alors même que ses travaux sont encore à ce jour largement inédits. Sur la fouille de la rue au sud de ces pièces, voir ZAPHEIROPOULOU, CHATZIDAKIS 1994, p. 235-248.

42. BORGARD, PUYBARET 2003, p. 299-318, en particulier p. 300-303, 306-314; BORGARD, PUYBARET 2004, p. 47-59, en particulier p. 52-57.

43. Ces observations, limitées par le cadre du nettoyage, seraient à approfondir.

44. Là encore, nous devons à la confiance et à la bienveillance de P. Chatzidakis et d'I. Svana, chargée de la publication de cet édifice, l'autorisation de travailler sur ce secteur fouillé par eux dans les années 2000 et resté encore en grande partie inédit.

45. Voir, par exemple, DE CASTRO MARTíNEZ 2001, p. 285-296; MULDER-HEYMANS 2002, p. 197-221.

46. Sur ce point, voir AMOURETTI 1986, p. 150.

47. «Hormis [nos fours à pains], le plus intéressant est celui qu'on trouve en Afrique orientale, en Syrie, en Asie centrale et aux Indes pour rôtir les galettes. C'est une cloche en terre cuite très épaisse, au fond de laquelle on brûle du bois ou des bouses de bovidés. Lorsque la flamme est tombée, on plaque sur la paroi les galettes de pâte fraîche qui cuisent et qu'on enlève au moment où elles sont sur le point de se détacher " (LEROI-GOURHAN 1973, p. 157). Pour des exemples antiques, légèrement différents des exemples déliens parce que mobiles, voir BARBERAN, et al. 2006, p. 257-271.

48. CHAMONARD 1906, p. 565 ; BRUNET 1997, p. 29-38, en particulier p. 31-32.

49. FRANKEL 2003, p. 1-21, en particulier p. 6-8 et fig. 5-6 ; FRANKEL, SYON 2016, p. 85-95, en particulier p. 88-90 et fig. 11.6 et 11.11 .

50. Sur cette question voir ROSTOVTZEFF 1937, p. 86-96 ; MORITZ 1958, fig. 1 ; AMOURETTI 1986, p. 140-144 ; AMOURETTI 1995, p. 33-47 ; PEACOCK 2013.

51. Voir sur ce point BRUNET 1997.

52. Cet espace a également été étudié par $\mathrm{Cl}$. Hasenohr dans le cadre de ses travaux sur l'Agora des Compétaliastes et ses abords, actuellement en cours de publication.

53. Sur ce moulin, voir le rapport de la mission 2018 de L. Jaccottey, déposé à l'EFA, dans le cadre du programme qu'il mène sur les outils de mouture de Délos. Nous le remercions chaleureusement pour nous avoir donné accès à ses données.

54. Cinq autres fragments de même type se trouvent également en remploi dans l'espace de l'atelier: un dans la paroi orientale de la pièce $\mathrm{n}^{0} 1$, un autre dans la canalisation de la pièce $\mathrm{n}^{\circ} 4$, trois autres dans le muret situé à l'est du puits de la pièce $\mathrm{n}^{\circ} 4$. 
INDEX

Thèmes : EFA

Année de l'opération : 2019

chronologie https://ark.frantiq.fr/ark:/26678/pcrtaFkrKZEXbs

lieux https://ark.frantiq.fr/ark:/26678/pcrtXvsaqTQa4J

sujets https://ark.frantiq.fr/ark:/26678/pcrttrEq4Rcpkr, https://ark.frantiq.fr/ark:/26678/

pcrtRxLPuVsO8f, https://ark.frantiq.fr/ark:/26678/pcrtIq8AvOPlPV, https://ark.frantiq.fr/ark:/ 26678/pcrtbptj4SOA1W, 26678/pcrtIMsuG0RWTs

\section{AUTEURS}

ENORA LE QUÉRÉ

Université de Rouen, GRHis EA 3831

NICOLAS MONTEIX

Institut Universitaire de France, GRHis EA 3831

SANDRA ZANELLA

BIBRACTE EPCC 